\title{
Wellsite Verification Testing Of An Advanced Geothermal Primary Heat Exchanger (APEX)
}

Final Report 2146:02-F

Contract EY-76-C-03-1125

25 September 1936 - 13 November 1977

REC

C $\quad$ OV $5^{1979}$

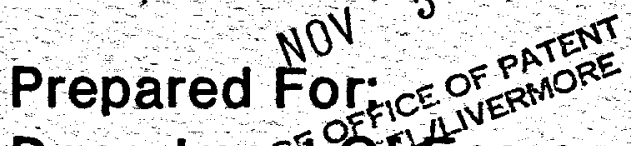

DepartmeEg

Division Of Geothermal Energy

By:

J.F. Addoms

C.M. Gracey

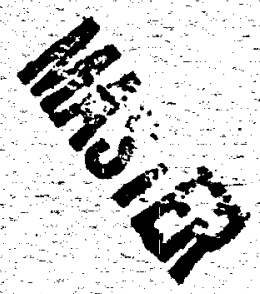




\section{DISCLAIMER}

This report was prepared as an account of work sponsored by an agency of the United States Government. Neither the United States Government nor any agency Thereof, nor any of their employees, makes any warranty, express or implied, or assumes any legal liability or responsibility for the accuracy, completeness, or usefulness of any information, apparatus, product, or process disclosed, or represents that its use would not infringe privately owned rights. Reference herein to any specific commercial product, process, or service by trade name, trademark, manufacturer, or otherwise does not necessarily constitute or imply its endorsement, recommendation, or favoring by the United States Government or any agency thereof. The views and opinions of authors expressed herein do not necessarily state or reflect those of the United States Government or any agency thereof. 


\section{DISCLAIMER}

Portions of this document may be illegible in electronic image products. Images are produced from the best available original document. 
WELLSITE VERIFICATION TESTING OF AN ADVANCED GEOTHERMAL PRIMARY HEAT EXCHANGER (APEX)

Contract EY-76-C-03-1125

Prepared for:

Department of Energy

Division of Geothermal Energy

By

J. F. Addoms

C. M. Gracey

This book was prepared as an account of work sponsored by m agency of the United States Government. Neither the United States Government nor any mency thereof, nor any of their employoes, makes any completeness, or usefulness of any intormation, appabritus, or responsibility for the occurbcy. represents that its use would not infringe privately ouned rights. Reference heresin olisclosed, of

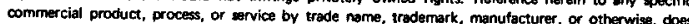

not necesserily constitute or imply lizs endorsement, recommendation, or fowaring by the United

States Governintent or any agency therobl. The views and opinions of authors expressed herein to not

necesserily state or reflect those of the United States Government or any asency thereof.

\section{AEROJET LIQUID ROCKET COMPANY Sacramento, California}




\section{ABSTRACT}

This report describes the well-site test phase of a research program conducted by Aerojet Liquid Rocket Company to establish the feasibility of using a recirculating solid bed material to el iminate heat exchanger fouling in geothermal service. The concept was directed towards application as the primary heat exchanger in a geothermal power plant which utilizes a binary cycle. The APEX approach was shown to be effective for condenser operation with fouling cooling water. Similarly, APEX could be applied for geothermal direct heat utilization, for example, the vapor generator in an absorption refrigeration system.

Phase I of this program culminated in a laboratory demonstration of APEX concept feasibility with brine simulants. Testing under the current project phase of the research effort was conducted at the Geothermal Component Test Facility located at East Mesa, California. Technical feasibility was established by testing the effectiveness of the bed material in preventing the fouling of a heat exchanger test section. The elimination of fouling was demonstrated using both geothermal well water and facility cooling water as the fouling fluids. 


\section{TABLE OF CONTENTS}

Page

1.0 Introduction

2.0 Summary 5

3.0 Conclusions and Recommendations $\quad 8$

3.1 Conclusions 8

3.1.1 Well 6-1 (Brine) 8

3.1 .2 Wel1 6-2 (Brine) 8

3.1.3 East Mesa Facility Cooling Water 9

3.1.4 APEX Concept 9

3.1.5 Portable Test Trailer 10

3.2 Recommendations 10

$\begin{array}{ll}4.0 & \text { Technical Discussion } \\ & 12\end{array}$

4.1 Experimental Design 12

4.1.1 Design Requirements and Criteria 12

4.1.2 Process Flow 12

4.1.3 Process and Instrumentation Design 16

4.1.4 Process Equipment 23

4.2 Fabrication 25

4.3 Testing 31

4.3.1 Laboratory Verification 31

4.3.2 Well Site 33

4.4 Test Resuits 44

4.4.1 Laboratory Tests $\quad 44$

4.4.2 Wel1 Site Tests 47

4.5 Data Interpretation 68

4.5.1 Brine Test Results 68

4.5.2 Facility Cooling Water Test Results 71

4.5.3 APEX Concept 73

4.5.4 Economic Implications 77

Appendix A. Chemical Analysis of East Mesa Geothermal We11 A-1

6-1 and 6-2 Brines

Appendix B. Tabulation of Reduced Data from Group 1 Tests B-1 


\section{LIST OF TABLES}

Table No.

Page

I Test Summary 40

II APEX-100 Tube Scale Analysis 57

III APEX-200 Bed Analysis 67

\section{LIST OF FIGURES}

Figure №.

Page

$\begin{array}{rlr}1 & \text { APEX Process Flow Schematic } & 2 \\ 2 & \text { APEX Phase II Process Flow Diagram } & 13 \\ 3 & \text { APEX Process and Instrumentation Design Diagram } & 17 \\ 4 & \text { Standard Piping Symbols, Single Line Piping } & 18 \\ 5 & \text { Standard Electrical Schematic Symbols and Notes } & 19 \\ 6 & \text { Standard P\&ID Equipment and Instrumentation } & 20 \\ & \text { Symbols } & 26 \\ 7 & \text { Travel Trailer Floor Plan Modification } & 27 \\ 8 & \text { APEX Instrumentation and Equipment Trailers } & 28 \\ 9 & \text { APEX Equipment Trailer - Right Side } & 29 \\ 10 & \text { APEX Equipment Trailer - Left Side } & 30 \\ 11 & \text { APEX Equipment Trailer - Rear View } & 32 \\ 12 & \text { APEX Instrumentation Console } & 34 \\ 13 & \text { STurry Pump Test Setup } & 36 \\ 14 & \text { Vapor Disengaging Tank } & 37 \\ 15 & \text { Facility Piping to ALRC Equipment Trailer } & 45 \\ 16 & \text { Slurry Pump Seal After } 60 \text { Hours Operation } & 46 \\ 17 & \text { Pump Casing and Impeller After First 100 Hour Test } & 50 \\ 18 & \text { Tube Fouling with Brine from East Mesa Well } 6-1 & 50 \\ 19 & \text { El imination of Foul ing Using APEX, East Mesa } 6-1 & 53 \\ 20 & \text { Tube Sections Showing Scaling After Testing with Brine } & 55 \\ 21 . & \text { APEX 300 Bottom Tube Outlet Specimens } & 56 \\ 22 & \text { 100X Enlargement of Tube Wall and Scale Showing } & \end{array}$
Corrosion of Tube Surface By Scale 


\section{LIST OF FIGURES (cont.)}

Figure No.

Page

23 APEX-200 Tubeside Fouling from Facility Cooling

59

Tower Water (Horizontal Operation)

24. APEX 300V Tubeside Fouling with Facility Cooling

60 Tower Water (Vertical Operation)

25 Baseline Exchange Tubeside Fouling from Well 6-2 62 Brine

26 Fouling with Facility Water with Continuous and

63

27 APEX 200 Tube Sections Showing Scaling After Testing 65 with Facility Cooling Water

$28 \quad$ Fouling Rates for East Mesa Brines, Unflashed 74

29 Fouling Rates for East Mesa Cooling Water 75 


\section{$1.0 \quad$ INTRODUCTION}

The development of the Advanced Geothermal Primary Heat Exchanger (APEX), will provide a self-cleaning heat exchanger for utilization with geothermal brines which form scale. During the Phase I Contract (E(04-3)1125) period, the Aerojet Liquid Rocket Company (ALRC) conducted laboratory research experiments which verified the technical feasibility of the APEX concept, Ref. 1. In Phase II, covered by this report, APEX evaluation was continued with field testing at the Department of Energy (DOE) East Mesa Geothermal Component Test Facility.

One of the problems encountered in energy conversion from geothermal brines has been the deposition of solids on process equipment. Fouling of heat exchanger tube walls as the brine cools can greatly reduce the effectiveness of the heat exchanger. The reduction in heat transfer coefficient, and the resulting need for frequent cleaning, replacement, or oversizing of the heat exchanger, makes the use of some geothermal resources economically unattractive. The APEX approach is intended to minimize or el iminate heat exchanger fouling from geothermal brines, and thereby increase the economic usefulness of hydrothermal resources.

The APEX fluidized bed concept functions by recirculating solids (such as sand) through the heat exchanger with the geothermal brine, as shown in Figure 1. The action of the bed material in mechanically scouring the tube wall and/or providing nucleation sites for solids formation is intended to keep the tube walls clean.

The APEX approach was evaluated at the Aerojet Research Physics Laboratory during Phase I. Solids flow, injection, and separation tests

Ref. T. Laboratory Investigation of an Advanced Geothermal Primary Heat Exchanger Final Report 2146:08 dated 9-24-76. 
1.0, Introduction (cont.)

were initially performed to characterize test equipment operation. A series of tests was conducted with a heat exchanger flow section using both clean water and a simulated geothermal brine. Baseline heat transfer data with clean water, baseline fouling data with the simulated brine, and data with the brine and the recirculating bed material, were obtained. It was found that the presence of the recirculating solids could completely eliminate or greatly reduce fouling, depending upon test conditions.

The objectives of Phase II of the program were to extend the successful Phase I feasibility demonstration of the concept, conducted under laboratory conditions, to field testing at an actual geothermal wellsite, as well as to preliminarily quantify the effects of bed operating parameters such as duty-cycle, velocity, bed makeup, and bed density.

The Phase II program was divided into three major technical tasks. Task 1, Well-Site Experiment Design, included all the efforts required to complete the design of the experimental test rig operated at the DOE East Mesa Geothermal Component Test Facility. The heart of this design was three double pipe (tube within a pipe) heat exchanger sections in which a fouling fluid, typically geothermal brine, was circulated on the tubeside and a clean working fluid (deoxygenated water) in the annulus between the tube and pipe. One exchanger section was used as a baseline for scaling. No bed material was circulated through this unit. The other exchangers were equipped for bed addition, recirculation, and removal. All exchangers were provided with temperature instrumentation to permit continuous monitoring of heat transfer coefficients and hence fouling resistance buildup.

Task 2, System Fabrication, included procurement of commercially available components, refurbishing Phase I equipment, and fabrication of special components, as well as assembly and checkout of the APEX test system at Aerojet. 
1.0 , Introduction (cont.)

The third major technical task was well site testing. The Task 3 effort included transportation, setup, and checkout of the test rig at East Mesa, followed by verification testing, and data analysis.

The conclusions reached as a result of APEX geothermal well-site testing are discussed as well as the recommendations for further needed development. It was concluded that the APEX approach was effective in preventing fouling in the fouling fluids tested. The main recommendation is that continued APEX testing include provisions for multi-tube heat exchanger evaluation.

This report covers the work performed under Contract EY-76-C-031125 from 25 September 1976 to 13 November 1977. The work described was conducted for the Utilization Technology Branch of the Division of Geothermal Energy, Department of Energy (initiated under the Energy Research and Development Administration). Clifton B. McFarland is the DOE Program Manager. The program was conducted at the Aerojet Liquid Rocket Company facility at Sacramento, California and the DOE Geothermal Component Test Facility at East Mesa, California.

The project activity at Aerojet included contributions from the following personnel:

B. Breindel

Dr. A. L. Blubaugh

J. F. Addoms

C. Gracey

C. Farlee

D. Cahil1

R. Pruett

Dr. E. M. Vander Wa11

M. E. Bell
Program Manager

Operations Project Manager

Project Engineer

Lead Test Engineer

Field Test Engineer

Field Instrumentation Engineer

Test Apparatus Design Assembly

Manager of Chemical Processes

Data Manager 


\subsection{SUMMARY}

The Phase II program was divided into three major technical tasks; well-site experiment design, experiment fabrication, and well-site testing.

The experiment was planned to permit simultaneous testing of three identical heat exchanger designs in parallel, under identical operating conditions. The heat exchangers were single tube within pipe units with the fouling fluid on the tubeside and clean deoxygenated water recirculating in the annulus. Two of the three exchangers were equipped with solid bed injection and removal equipment. The third exchanger was designed to operate as a baseline unit and had no provision for solid recirculation. Each exchanger was provided with instrumentation to measure flowrates and inlet and outlet temperatures of both process streams.

Two trajlers were used to assemble the experiment. The process equipment was mounted on a flat bed trailer. The remote instrumentation was mounted in a control panel located within a conventional travel trailer. This travel trailer also served as a work station for the operating crew. The two trailers were transported to the site independently and interconnected there at the same time that process and utility lines were being installed from the facility to the experiment.

A11 testing was performed at the East Mesa Geothermal Component test facilities operated for the government by Lawrence Berkeley Laboratory. Three groups of tests were conducted. The first test group was performed to evaluate the relative fouling rate between exchangers using the brine from Well 6-1 with no bed as compared with an exchanger using a fluidized bed (APEX). The brine had a total dissolved solid content of $25,000 \mathrm{ppm}$. It was pretreated by venting the noncondensible gases, predominately $\mathrm{CO}_{2}$, and subcooling slightly before entering the experimental exchangers. The bed, 5 wt \% of 100 mesh garnet, was introduced and recirculated on a duty 


\section{0, Summary (cont.)}

cycle mode for two hours each 24 hours of operation. The brine and coolant velocities were controlled at $10-\mathrm{ft} /$ second. Brine inlet and outlet temperatures averaged $320^{\circ} \mathrm{F}$ and $270^{\circ} \mathrm{F}$ respectively. The nominal exchanger mean temperature difference (MTD) was $80^{\circ} \mathrm{F}$. The MTD and brine $\triangle T$ were allowed to vary as fouling progressed. Flowrates were held constant. The test sections were horizontal.

Testing was continued at the above operating conditions until plugging of Wel1 6-1 forced a shutdown with 410 hours cumulative operating time at this point. Analysis of thermal data clearly demonstrated that (1) fouling of the tubes did occur when operating with brine from Well 6-1 and (2) that the APEX concept was effective in preventing this fouling. Sectioning of the tubes showed no evidence of tube wall erosion due to the bed material. Scouring was more effective on the bottom half of the tube indicating some stratification of the bed. Spectrographic analysis of the scale formed in the baseline exchanger showed large quantities of iron and significant amounts of sulfur.

The second test group was conducted with facility cooling tower water used to test the APEX concept in place of Well 6-1. The facility water originates in local wells and contains a high concentration of calcium carbonate. The reverse solubility of calcium carbonate results in deposition on the tubewalls when the facility water is used as a coolant. Facility cooling water was substituted for the brine in two of the test heat exchangers. One of these exchangers was oriented vertically. Velocities through the exchangers were controlled at $10 \mathrm{ft} / \mathrm{second}$. The coolant water nominal temperatures were $70^{\circ} \mathrm{F}$ inlet and $120^{\circ} \mathrm{F}$ outlet. The MTD was $75^{\circ} \mathrm{F}$. Test durations were 58 hours on the horizontal unit and 116 hours on the vertical unit. Analys is of the thermal data indicated the APEX concept was effective in preventing scale formation provided the bed material was recirculated continuously. 


\section{0, Summary (cont.)}

The final test group was also performed using facility cooling water for the fouling fluid. Flow velocities were reduced to $6-1 / 2 \mathrm{ft}$ per second in the tubes; 90 mesh $\mathrm{SiO}_{2}$ sand was used as the bed material in the horizontal unit; 100 mesh garnet sand was retained in the vertical unit. Test duration was 86 hours on the vertical unit and 64 hours on the horizontal unit. Thermal analysis showed both units to be effective in preventing fouling during the period of recirculation. Analys is of the $\mathrm{SiO}_{2}$ bed material showed no change in particle size as the test progressed. Significant quantities of iron and calcium accumulated on the bed material. The garnet bed material was not analysed. 


\subsection{CONCLUSIONS AND RECOMMENDATIONS}

\subsection{CONCLUSIONS}

The conclusions have been grouped into sections relating to the fouling fluids used during the APEX field tests. General conclusions related to the APEX approach follow.

\subsubsection{Well 6-1 (Brine)}

The brine from Well 6-1 does cause fouling when operated in an unflashed mode; the extrapolated annual fouling factor is $.007 \mathrm{hr}-\mathrm{ft}^{2}{ }^{\circ} \mathrm{F} /$ Btu.

The APEX concept is effective in preventing fouling when operated on an intermittent basis with bed recirculation two hours per day (the shortest time tested), using 100 mesh garnet bed material.

The APEX concept can clean this brine scale by a

scouring action.

Garnet bed density as low as 1.6 weight percent were tested and were adequate to prevent fouling. $\mathrm{SiO}_{2}$ bed material was effective in preventing fouling.

The fouling film is predominately iron compounds including iron sulfide.

\subsubsection{Well 6-2 (Brine)}

The brine from Well 6-2 does cause fouling when operated in an unflashed condition using conventional exchangers. The 


\section{1, Conclusions (cont.)}

extraplated annual fouling factor is $.012 \mathrm{hr}-\mathrm{ft}^{2} \mathrm{o} / \mathrm{Btu}$. The APEX set-up was operated indirectly with 6-2 brine; the fluid was used to heat the facility cooling water (see Section 3.1.3).

\subsubsection{East Mesa Facility Cooling Water}

The facility cooling water deposits a tenacious scale which is predominately $\mathrm{CaCO}_{3}$.

The APEX concept is totally effective in preventing this scale when operated on a continuous basis. Intermittent operation, at $10 \mathrm{ft} / \mathrm{sec}$ and a bed density of $5 \mathrm{wt} \%$, did not prevent scale buildup.

The cleaning mechanism may involve the bed material serving as nucleation sites for deposition of the scale.

Both $\mathrm{SiO}_{2}$ and garnet bed materials are effective in preventing fouling.

A velocity as low as $6-1 / 2 \mathrm{ft} / \mathrm{second}$ is completely effective in preventing scale.

\subsubsection{APEX Concept}

APEX concept feasibility was demonstrated both with geothermal brine and with facility cooling water which formed a $\mathrm{CaCO}_{3}$ scale.

The operating conditions (solids recirculation time, velocity, solids weight percent, solids density and vertical vs horizontal orientation) required to prevent fouling depends on the tenacity of the scale.

Some bed stratification occurs at $10 \mathrm{ft} / \mathrm{sec}$ with 100 mesh garnet in the horizontal orientation. 
3.1, Conclusions (cont.)

Vertical orientation is an effective method of overcoming bed stratification.

Low velocities and low bed particle densities are feasible in horizontal or vertical units if continuous recirculation is employed.

\subsubsection{Portable Test Trailer}

The portable test trailer concept was an effective method of meeting the program needs for instrumentation protection, working space for the crew, spares and tool storage, and experiment operation.

\subsection{RECOMMENDATIONS}

Long duration (1000 to $2000 \mathrm{hr}$ ) tests are needed in subscale multi-tube exchangers to establish the APEX concept capabilities for application in full scale plants.

Experiments are required to determine the manifolding requirements to assure adequate bed distribution in a multi-tube exchanger.

Research, design, and experimentation work is necessary to develop a reliable solids handling system using components which are applicable for use in a full scale binary cycle power plant.

Analytical development of heat exchanger design model would be extended based on the following experiments: 


\section{2, Recommendations (cont.)}

- Single tube tests to develop parametric data on minimum acceptable design conditions for:

(a) long duration nucleation effects

(b) bed particle size

(c) bed particle density

(d) carrier fluid velocity

(e) bed weight \%

- The single tube experiments should be expanded to a limited number of other brines and fields to develop a broader base of APEX capabilities and operating requirements.

- Long duration scaling tests are required in brines contemplated for power plant use to establish the scaling characteristics and the need for an anti-scaling exchanger.

- Basic experimentation is required to relate tube material, velocity, and bed makeup to erosion and corrosion rates for fouling fluids of interest and to further investigate the test evidence that the APEX bed action reduces tube wall corrosion. 
4.0 TECHNICAL DISCUSSION

\subsection{EXPERIMENT DESIGN}

\subsubsection{Design Requirements and Criteria}

The goals of the experiment design were to provide a system which would verify the APEX concept feasibility and capabilities for fouling control and durability at a geothermal well site. The chemical composition of the dissolved solids in the geothermal wells tested are shown in Appendix A. The design used existing Phase I equipment where possible. other design requirements and criteria were applied to adapt to the capabilities and limitations of the East Mesa test site facilities, to achieve flexibility and simplicity of operation, and to permit extended test duration capability.

\subsubsection{Process Flow}

Figure 2 is the process flow schematic developed for the experimental setup. This schematic contains alternate circuits to permit testing with either brine or facility cooling water as the fouling fluid in the APEX units. The primary testing effort is with brine as the fouling fluid. The design temperatures, pressures, and flowrates have been indicated for this operating mode and the following description is for that case.

Three parallel experiments were designed, two experiments employing the APEX concept, and one baseline experiment for comparison purposes. The three test exchangers operate under essentially identical brine flow conditions. The baseline exchanger has no recirculating bed. One of the two APEX units was designed to be operated with a continuous recirculating bed density of 3-5 weight \% of 100 mesh garnet sand. This was the most successfur of the Phase I bed combinations tested. The second APEX unit 


\section{1, Experiment Design (cont.)}

was planned to operate on a duty cycle where the bed circulates under the same conditions as the first APEX unit but for only a fraction of the time. The duty cycle operation results in a savings in recirculation pump net power, reduced potential erosion damage, and minimized MTD reduction experienced due to recirculation.

The experimental exchangers are double pipe units with the fouling fluid flowing through a center $3 / 4-i n c h, 16$ gauge tube with the clean working fluid flowing through the annulus formed by a 1 -inch schedule 40 pipe which jackets the 3/4-inch tube. A 3/4-inch diameter tube was selected as being representative of the tube size which would be selected in a final heat exchanger design. ASTM A-179 carbon steel heat exchanger tubing was picked for the exchanger brine tubes and ASTM A-106 Grade $B$ seamless pipe and tubing for all other piping because (1) it is the brine piping material in use at the East Mesa facilities, (2) successful application of carbon steel results in a more economic design, (3) fouling caused by corrosive action can be expected to be more severe in carbon steel than more exotic materials thus providing a better test of the concept.

Inlet pressure and temperature conditions were chosen based on the brine conditions established for Well 6-1 in the East Mesa field. This well was selected because it has the highest dissolved solids content of any of the wells in that field. It was therefore expected to result in the most rapid fouling under the normal operating conditions of a primary exchanger in a binary cycle plant operation.

Brine flowrates through the test exchanger were estab1ished at $10 \mathrm{ft} / \mathrm{second}$ based on Phase I test data. It was observed that flowrates in excess of $5 \mathrm{ft} / \mathrm{sec}$ were generally required to prevent stratification of the bed material. This depends on the bed particle density and diameter. The bulk of the Phase I tests establishing the concept 


\section{1, Experiment Design (cont.)}

feasibility were therefore performed at a nominal $10 \mathrm{ft} / \mathrm{second}$. The same velocity was selected for Phase II to avoid introducing a new variable.

The brine circuit consists of a noncondensable separator at the brine supply to remove entrained gas and to insure 100\% liquid to the experiment, a supply manifold feeding the three experimental exchangers, and a brine return manifold equipped with a backpressure control valve to prevent flashing within the experiment.

The APEX 200 exchanger is provided with alternate piping such that it can be diverted from its primary experimental function and used to condition the brine to a lower inlet temperature. This provided capability for subcooling the delivered brine.

The selected bed recirculation approach for the APEX exchangers makes use of sand slurry pumps. The slurry pump, located at the discharge from the experimental exchanger, increases the pressure of the solids discharge from the separator to a higher pressure than the brine stream into the exchanger, thereby permitting bed recirculation. The pressure can be set by an orifice which bypasses flow from the liquid leg discharge of the separator to the pump suction.

The APEX 300 unit is actually two identical exchanger designs. One is oriented horizontally and one vertically. Either exchanger may be selected for use in a given test group but not simultaneousiy.

The circuit for removing the heat from the brine is a closed loop system employing clean deoxygenated water as the working fluid. The working fluid temperature into the experimental exchangers is controlled 


\section{1, Experiment Design (cont.)}

by a valve which regulates the flow of the facility cooling water to the working fluid cooler. A working fluid inlet temperature of $190^{\circ} \mathrm{F}$ was selected for two reasons. The resulting MTD is considerably higher in the experimental exchanger than would be experienced in a prototype unit. This tends to promote more rapid fouling from dissolved solids which have a normal solubility curve. More importantly, it results in more heat removal from the brine and hence a greater temperature difference between the recirculating bed and the inlet brine from the well. The brine flowrate through the experimental exchanger is calculated from a heat balance around the bed injector; therefore the highertemperature difference results in greater accuracy.

The working fluid (shellside) flowrate to the experimental exchangers is regulated by a flow control valve in the inlet leg of each exchanger. The controlling signal to the valve comes from an orifice flow element. The shellside flowrate was established at $10 \mathrm{GPM}$, the same flowrate as on the tubeside. This results in the temperature difference across the exchanger remaining almost constant from inlet to outlet. By maintaining a nearly constant temperature difference, the log mean temperature difference and the average temperature difference are kept essentially the same. Since the heat transfer coefficient visual meter operates on an average difference, this improves the meter accuracy.

\subsubsection{Process and Instrumentation Design}

Figure 3 is the process and instrumentation design diagram as developed for the experimental setup. This diagram does not show the modifications incorporated for utilizing cooling water as the fouling fluid which were described in the previous section. Figures 4 , 5 , and 6 provide the symbol identification used on the diagram. 


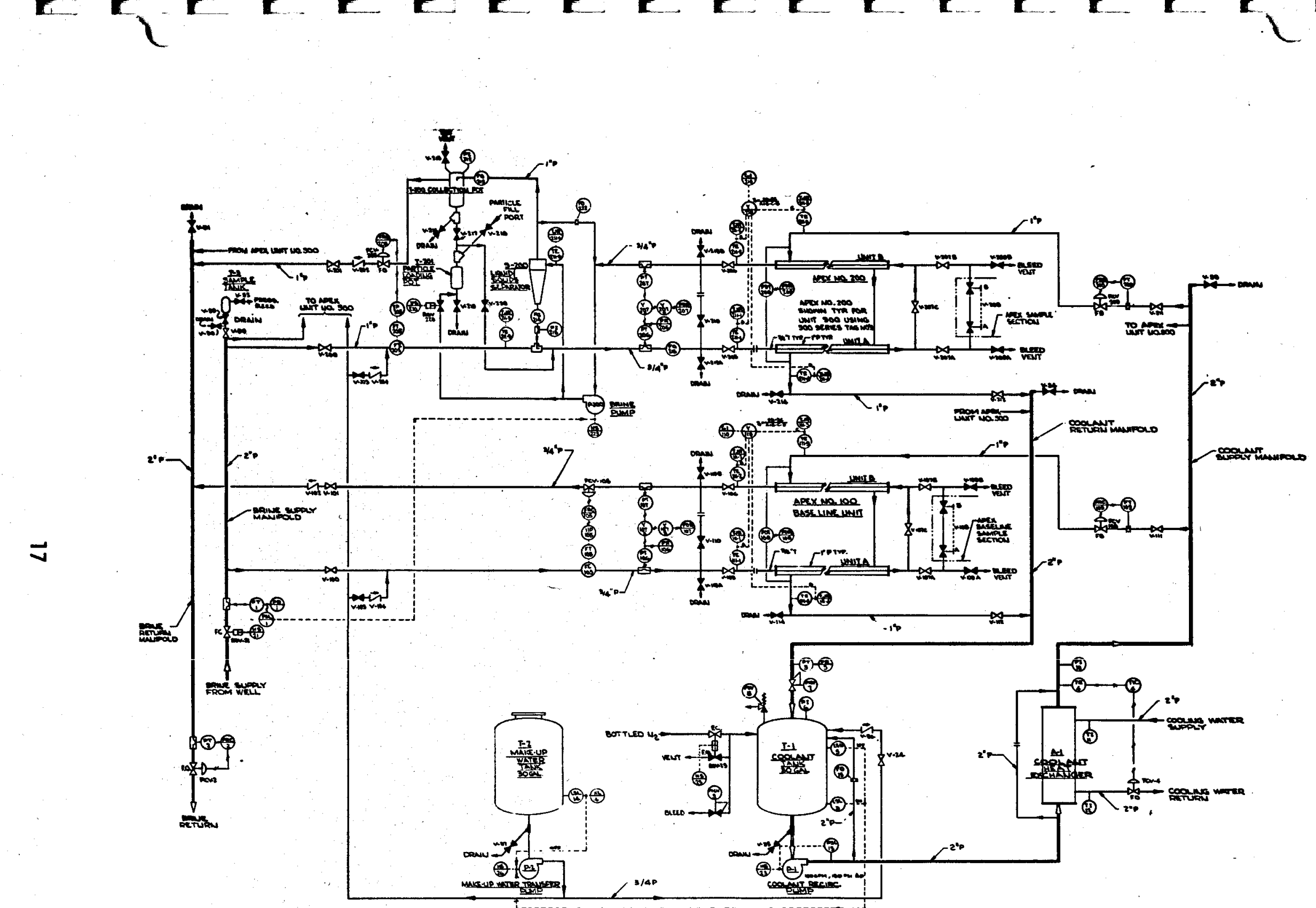

Figure 3. APEX Process and Instrumentation Design Diagram 


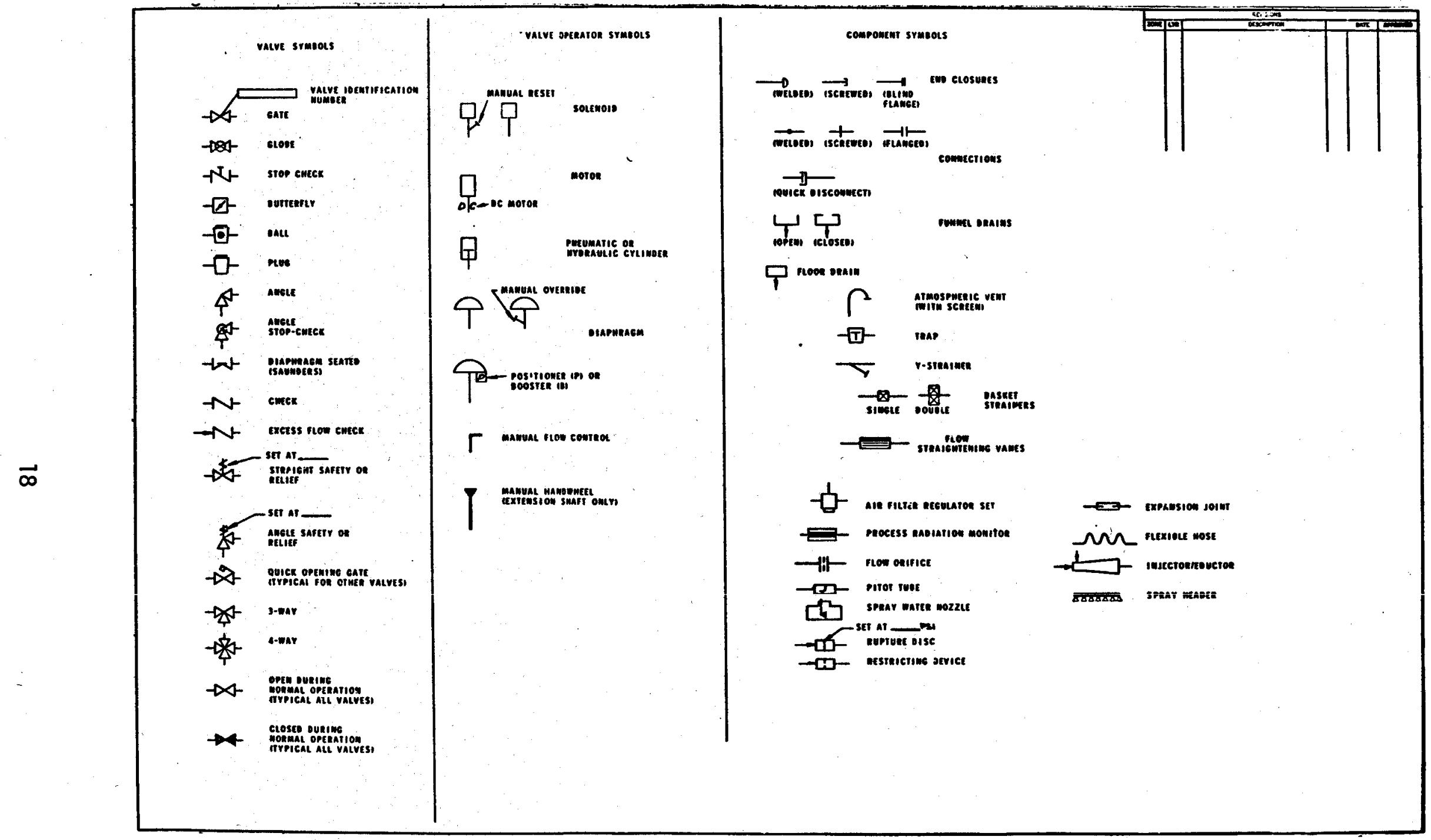

Figure 4. Standard Piping Symbols, Single Line Piping 


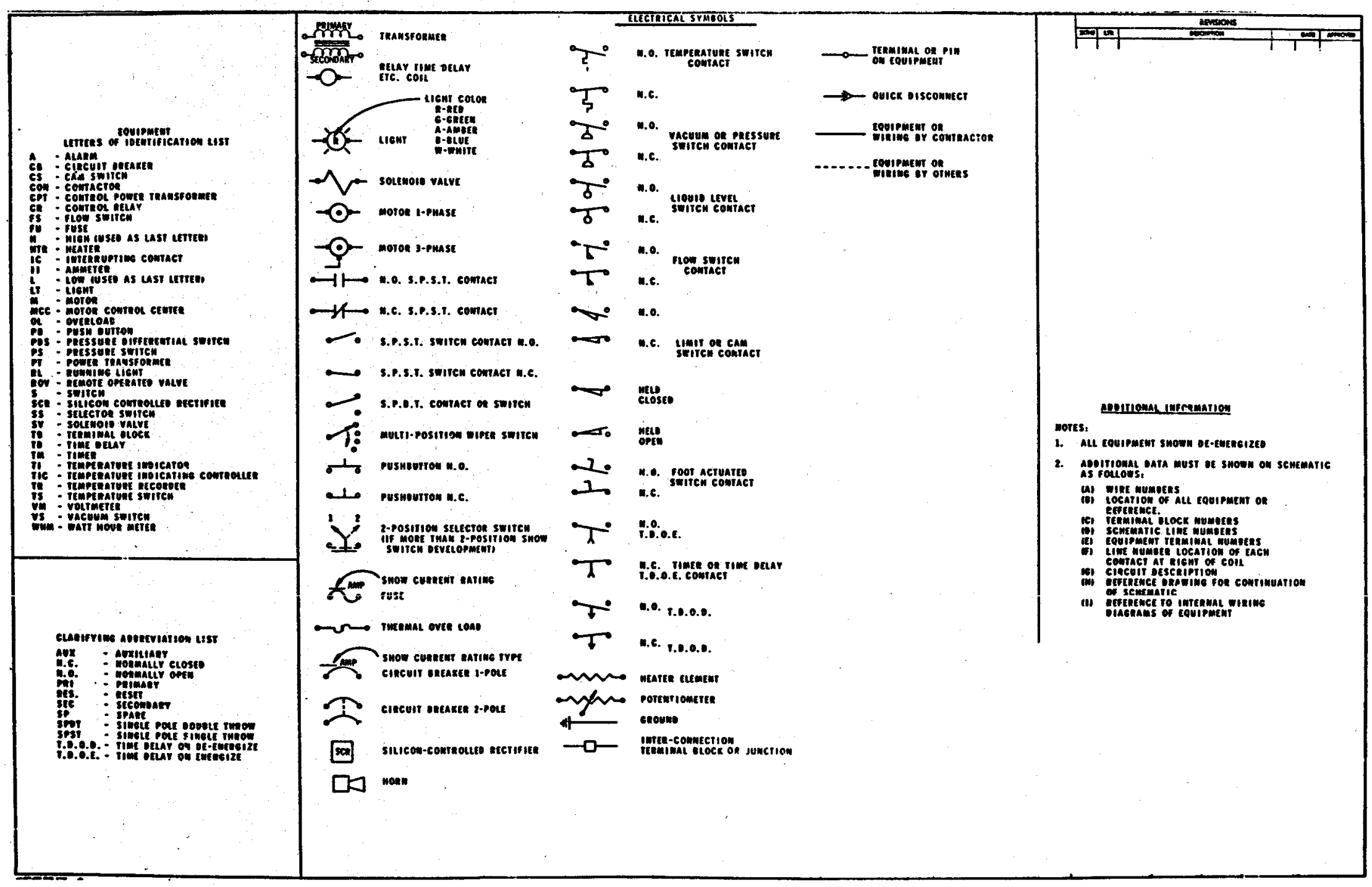

Figure 5. Standard Electrical Schematic Symbols and Notes 


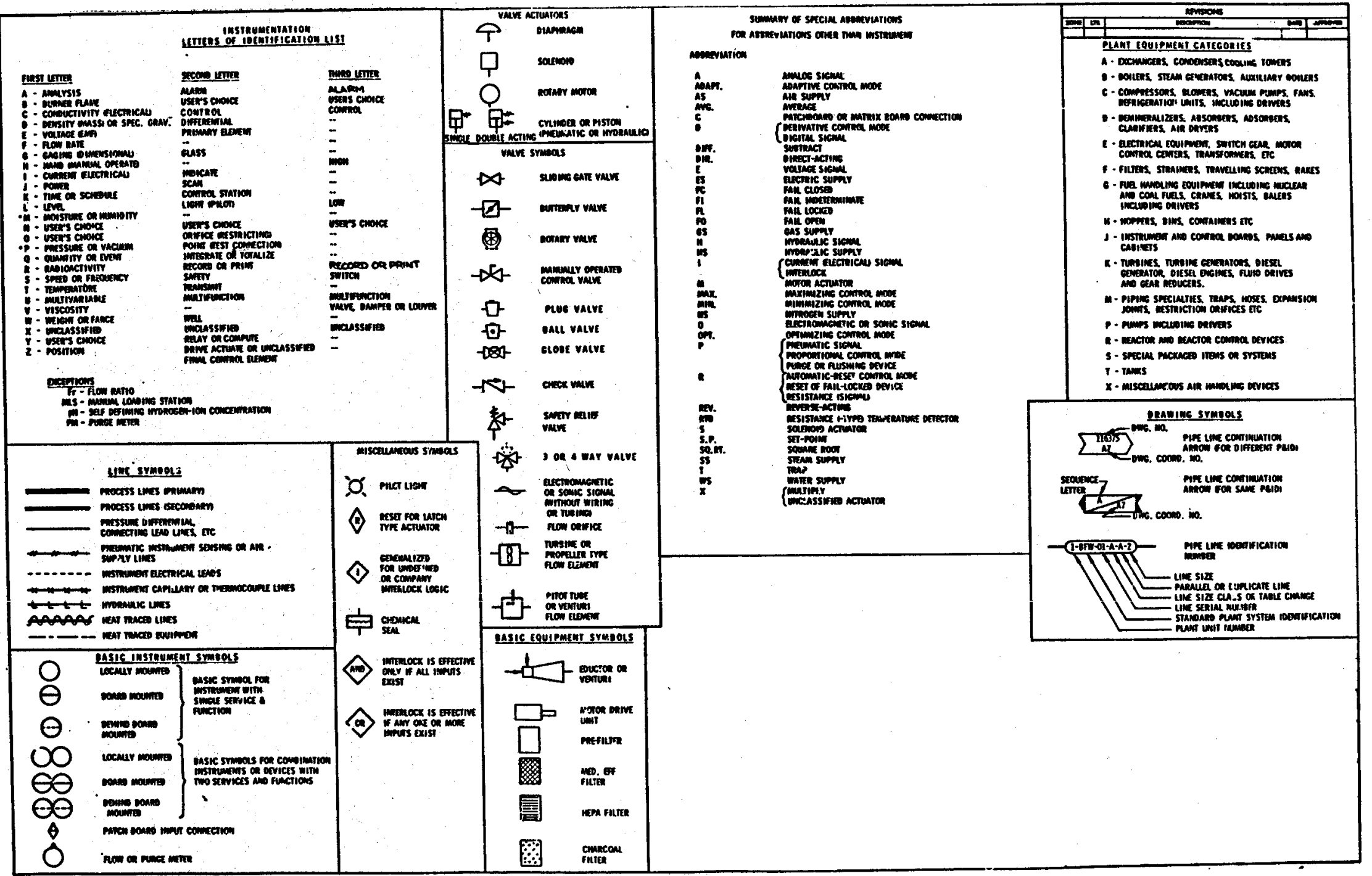

Figure 6. Standard P\&ID Equipment and Instrumentation Symbols 


\section{7, Experiment Design (cont.)}

The instrumentation plan, in general, was to continuously record all measurements critical to the analysis of the experimental exchangers. Measurements required for the operation of the equipment were presented on local indicators.

The following description of the design shown on Figure 3 for APEX No. 200 is applicable for all experimental exchangers.

Referring to Figure 3, the brine feed for each experiment is tapped from a main two-inch diameter pipe manifold. The flow is measured and controlled using a magnetic flow element. Other flow measurement systems were considered but rejected because of the concern that progressive error would be introduced due to corrosion of the sensing elements. The flowrate is remotely recorded. The brine temperature is measured and recorded using platinum resistance probes for accuracy. Downstream of the bed material injection point the flow passes through a sight glass for visually observing the bed material flowing and estimating the density. The brine coolant temperatures are measured and recorded at the entrance and exit of the test exchanger using the same type of platinum resistance probes. These temperatures are used for MTD, heat load, and flowrate calculations and for input to the heat transfer coefficient meter. The pressure drop across the exchanger is measured and recorded using a differential pressure transducer. The $\triangle P$ was intended as a check on the reaction within the exchanger since the $\triangle P$ tends to increase with fouling and with corrosion.

After leaving the test heat exchanger, the brine enters the separator where the solid bed material is separated from the brine. The solids are reinjected into the fresh brine upstream of the exchanger, and the spent liquid brine returned to the site facilities via a collection pot. Both the liquid and solid discharge from the separator is monitored with sight glasses to observe the bed flow characteristics. 


\section{7, Experiment Design (cont.)}

Each experimental exchanger module is provided with block valves at the inlet and return manifolds of both the brine and coolant sides to permit isolation of the experiment for repair or maintenance. Each exchanger is also equipped with a bypass so that the entire system can be started and flows adjusted and stabilized before the exchangers are brought on stream.

Loading and unloading of the bed material is accomplished in the same manner as on the Phase I effort. The bed material in the particle loader is fluidized and injected using the slurry pump. Valve V-220 is opened and ROV 220 is cycled until the desired loading, as determined by the sightglass or sampling is achieved. Unloading is accomplished by cycling the pump until the bed material is removed.

Samples of the brine and bed are obtained at the midpoint of the exchanger where the two exchanger sections are joined. The flow is directed to the collector by opening the sample bomb valves, $V-208$ and closing $V-207 C$. A sample is trapped by reversing this sequence. The bomb is removed by closing V-207A\&B, and unscrewing the bomb from the circuit.

The coolant supply system consists of an accumulator, a recirculation pump, a heat rejection cooler, a make-up water tank and a transfer pump. The accumulator is pressurized to insure adequate NPSH for the recirculation pump. Bottled regulated nitrogen gas is provided to accomplish this pressurization. The accumulator is equipped with a level switch which activates the transfer pump to transfer make-up water to the accumulator as needed. The make-up water tank is open to atmosphere and filled periodically as required. A coolant line has been provided to each experimental module brine circuit to provide flushing capability if required. 
4.1, Experiment Design (cont.)

\subsubsection{Process Equipment}

The process equipment is made up of a combination of standard commercial equipment, commercial equipment modified for this application, ALRC designed and fabricated equipment, and components recovered and refurbished from Phase I or ALRC surplus stores.

\subsubsection{Pumps}

The pumps are all standard commercial units. The coolant recirculation pump, P-1, is designed to supply $100 \mathrm{GPM}$ at 150 psid. This is considerably oversized for the present experiment size, however, the next smaller size did not provide any significant flow margin and the cost differential was minor.

The make-up water transfer pump, $P-2$, is the same pump used for coolant recirculation in program Phase I. This pump supplies $5 \mathrm{gpm}$ against a 150 psi head.

The slurry pumps supply $20 \mathrm{gpm}$ at $40 \mathrm{psid}$. This is considerably more head than required which presented a control problem. A variable speed drive was considered but ruled out because of cost. A direct pump bypass to permit operation at a different point in the pump curve was not practical because the pump curve is virtually flat. The bypass system selected makes use of the pressure drop in the separator to reduce the pressure to the desired level. A supplemental benefit derived by recirculating clear brine is that the weight \% of solids pumped is decreased, thus reducing the wear on the pump. 


\section{1, Experiment Design (cont.)}

\subsubsection{Heat Exchangers}

The coolant heat exchanger, $A-1$, is a standard 4 tubepass commercial unit containing 37 square feet of heat exchange surface. The coolant is tubeside and the facility water shellside.

The experiment exchangers, APEX 100, 200, and 300, are identical. These units were fabricated at ALRC and are patterned after the Phase I units. Each exchanger consists of two $10 \mathrm{ft}$ long sections. The sections are constructed of a 3/4-inch tube within a 1-inch pipe. The 3/4-inch tube is held concentric within the pipe by a 1/8-inch round wire wrapped around the OD of the 3/4-inch tube in a spiral with 1 turn every 2 feet. One end of the exchanger is sealed with a teflon ferrule to permit differential expansion between the pipe and tube. The tube and the annulus flow areas are approximately the same. This permits utilization of similar flowrates and similar velocities for both brine and coolant which has advantages in terms of operating the experiment in the desired range of MTD and heat transfer coefficients.

\subsubsection{Tanks}

The coolant water tanks, T-1 and T-2, are the ALRC 30-gallon stainless steel tanks which were used in Phase I of the program for the brine and the water tanks. The connections on the tanks have been modified to meet the needs of the current program.

The collection pots, T-200 and T-300, and the particle loading pots, T-201 and T-301 were built up at ALRC from pipe and pipe fittings in accordance with the design requirements. 


\section{1, Experiment Design (cont.)}

\subsubsection{Separator}

The separators, S-200 and S-300, are standard commercial cyclone units identical to the separators used in Phase I except for the size.

\subsubsection{Trailers}

The equipment trailer is a 16 -foot flatbed unit capable of transporting a 6,000 ib load. The trailer is equipped with jacks at each corner for anchoring and leveling. All the process equipment and piping are mounted on this trailer.

The instrumentation trailer is a modified 28-foot travel trailer. This trailer has been modified by replacing the beds with instrument racks. The travel trailer houses all the remote instrumentation and controls, spare parts, tools, as well as providing work space for the ALRC operating crew. Figure 7 illustrates the trailer modifications made.

\subsection{FABRICATION}

Figure 8 shows an overall view of the office trailer and the flat bed equipped trailer containing the test setup.

Figures 9, 10, and 11 are views of the test setup from the right and left side and from the rear. Figure 9 shows the contactors which provide power to operate the pumps, the local flow and pressure indicators, and the pressurizing gas bottles for the coolant tank pressurization system. Figure 10, taken from the opposite side, shows the sand loaders and collection pots on the near side of the bulkhead. The holes through the bulkhead allow viewing of the various sightglasses. The separators are behind the 


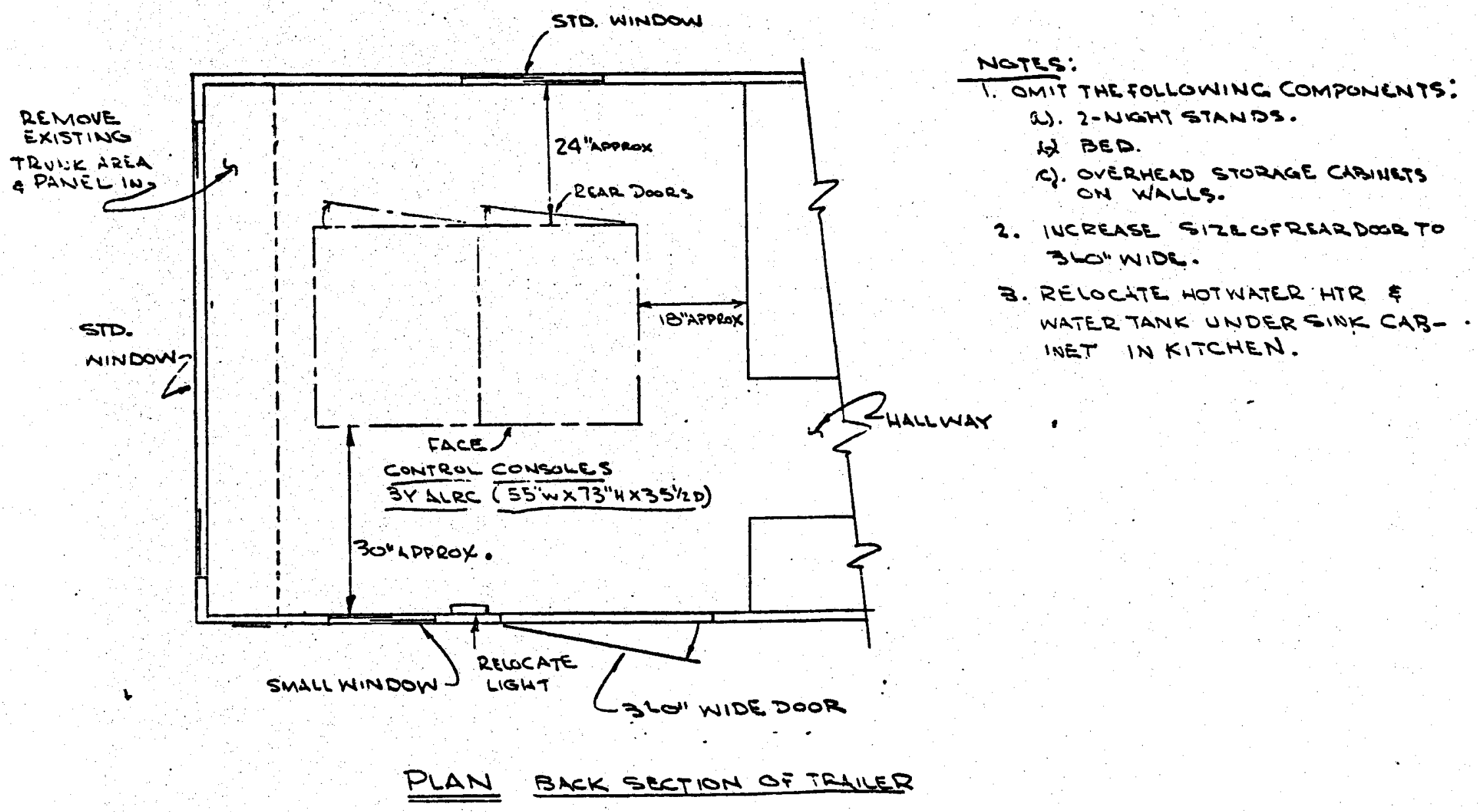

Figure 7. Travel Trailer Floor Plan Modification 


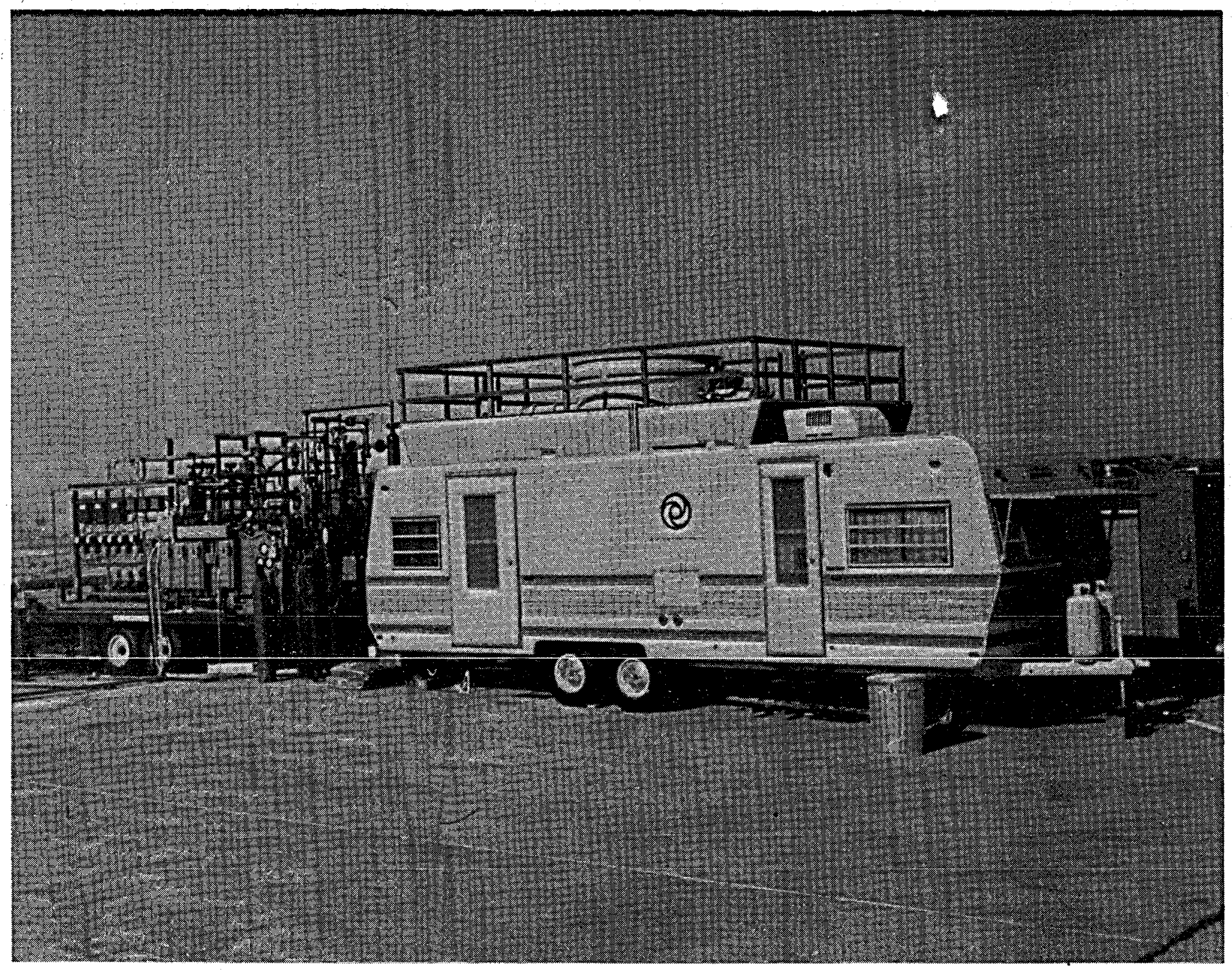

Figure 8. APEX Instrumentation and Equipment Trailers 


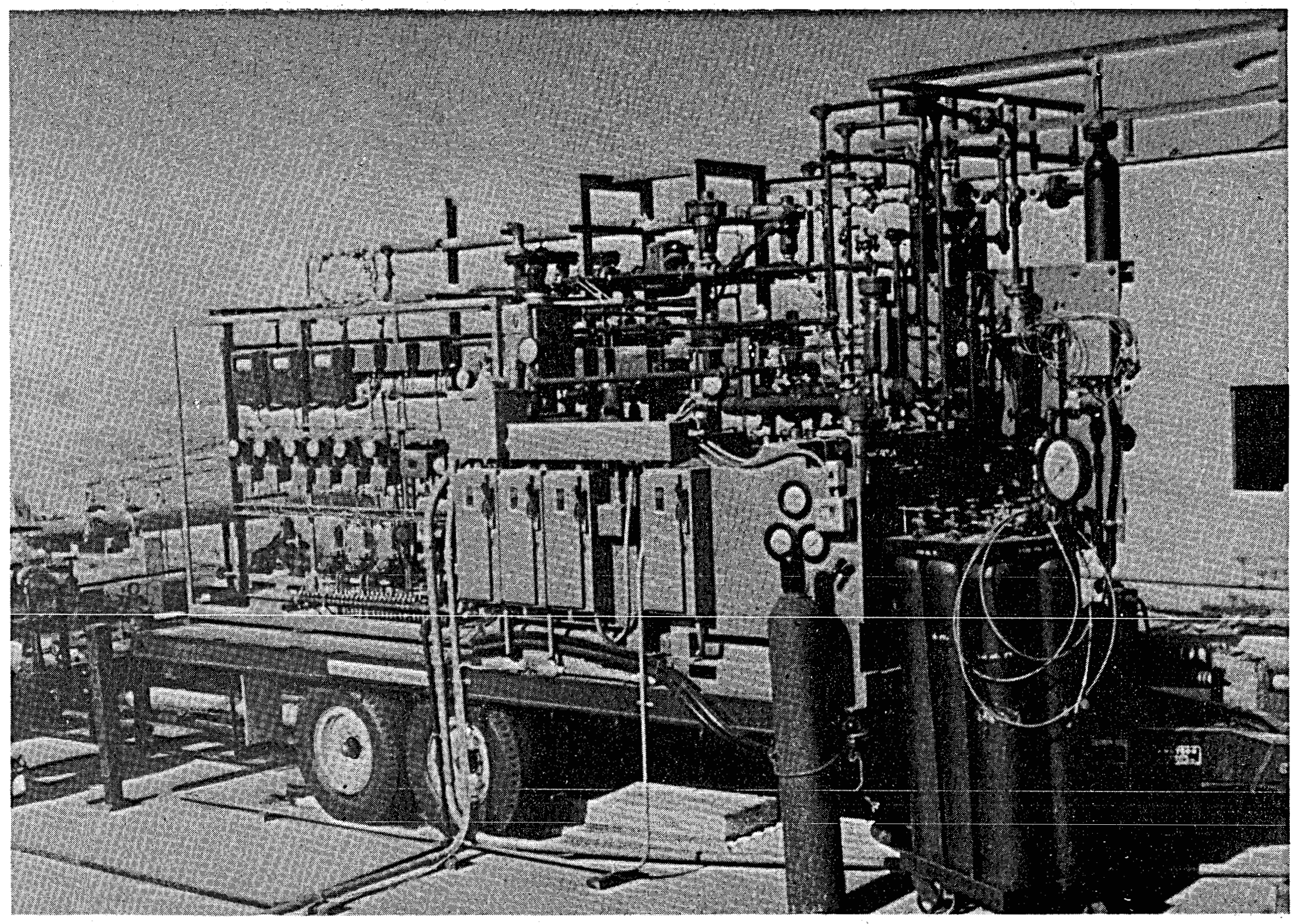

Figure 9. APEX Equipment Trailer - Right Side 


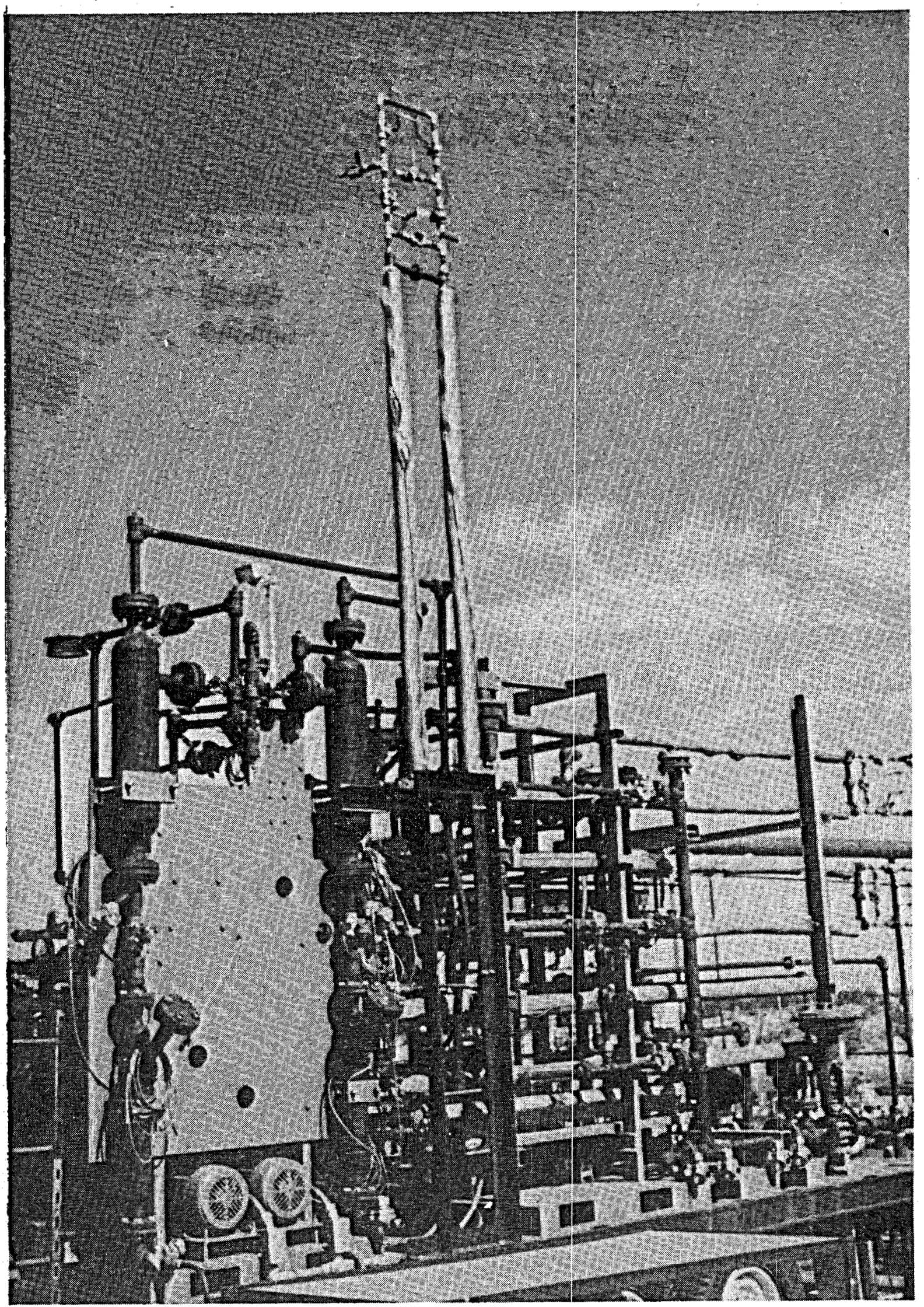

Figure 10. APEX Equiipment Trailer - Left Side 


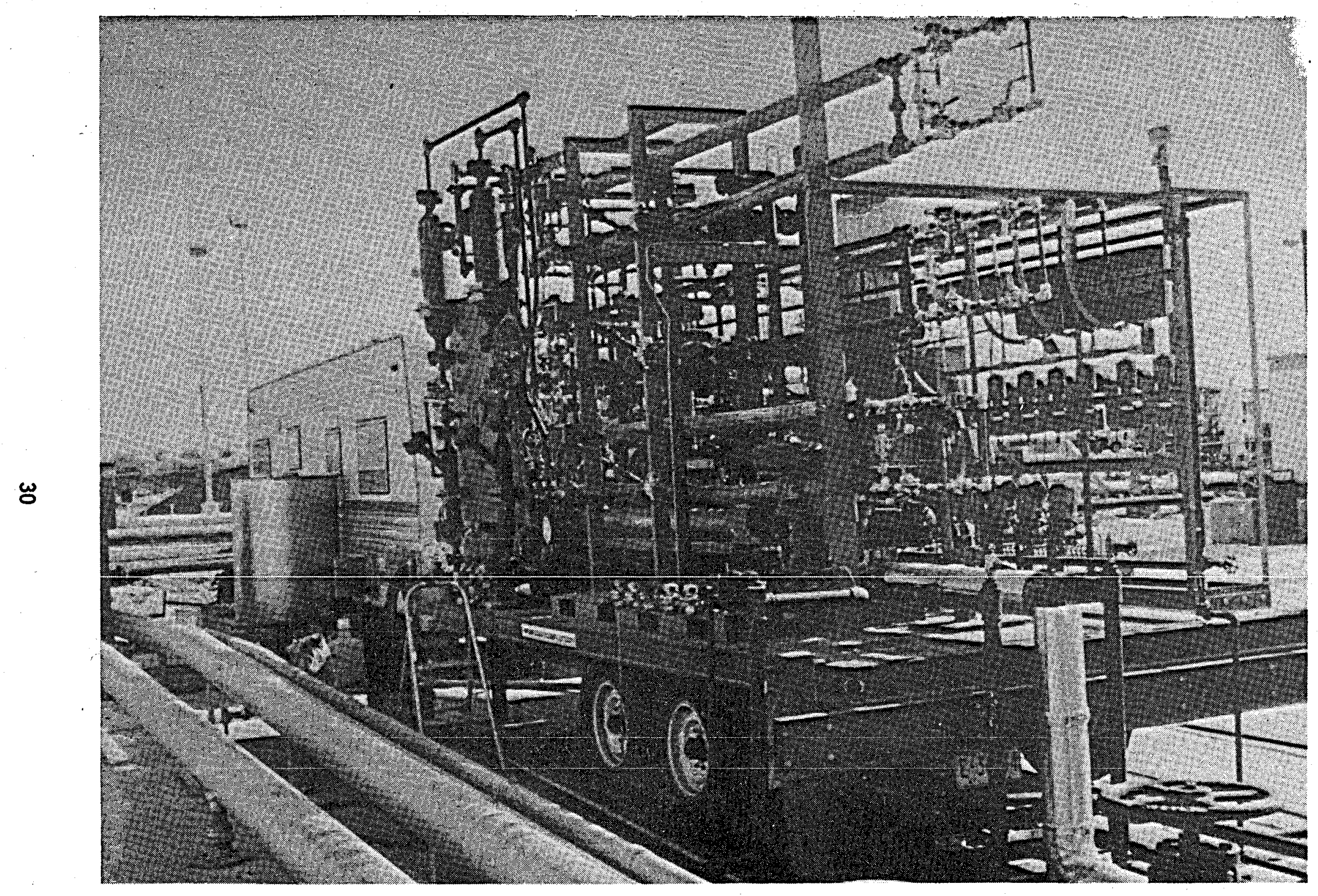

Figure 11. APEX Equipment Trailer - Rear View 


\section{2, Fabrication (cont.)}

bulkhead and the brine pumps below the bulkhead. The three APEX test exchangers can be seen in the right. They are stacked with APEX 100 on top and 300 on the bottom. The sample collection devices for each unit can be seen on the far right. The coolant cooler is below APEX-300.

Figure 11 taken from the rear, shows the APEX exchangers and the connection between the facility plumbing and the test rig. The coolant holding tank can be seen next to the office trailer.

Figure 12 is a photograph of the instrumentation console which is located in the office trailer. The heat transfer coefficient meters are located on the top right of the console, from left to right are APEX-100, 200 , and 300. The flow recorder-controllers are located in vertical sequence below the heat transfer coefficient meters with APEX-100 on top. The coolant flow controllers are on the right hand side and the brine controllers on the left. The brine inlet pressure and $\triangle P$ recorders for APEX-100, 200, and 300 are located to the right of the flow controllers.

The left half of the console contains a digital clock at the top. The three recorders in the center right are temperature recorders for, from left to right, APEX-100, 200, and 300. The pressure recorder for the coolant return manifold and the brine inlet and return manifolds is located on the left between the clock and the temperature recorders. The bottom section of the console contains the switches for operating the pumps, the brine inlet valve, and the sand loader valves.

\subsection{TESTING}

\subsubsection{Laboratory Verification}

The Phase II process schematic, Figure 3 , is similar to that used in Phase I with the major exception that a slurry pump is 


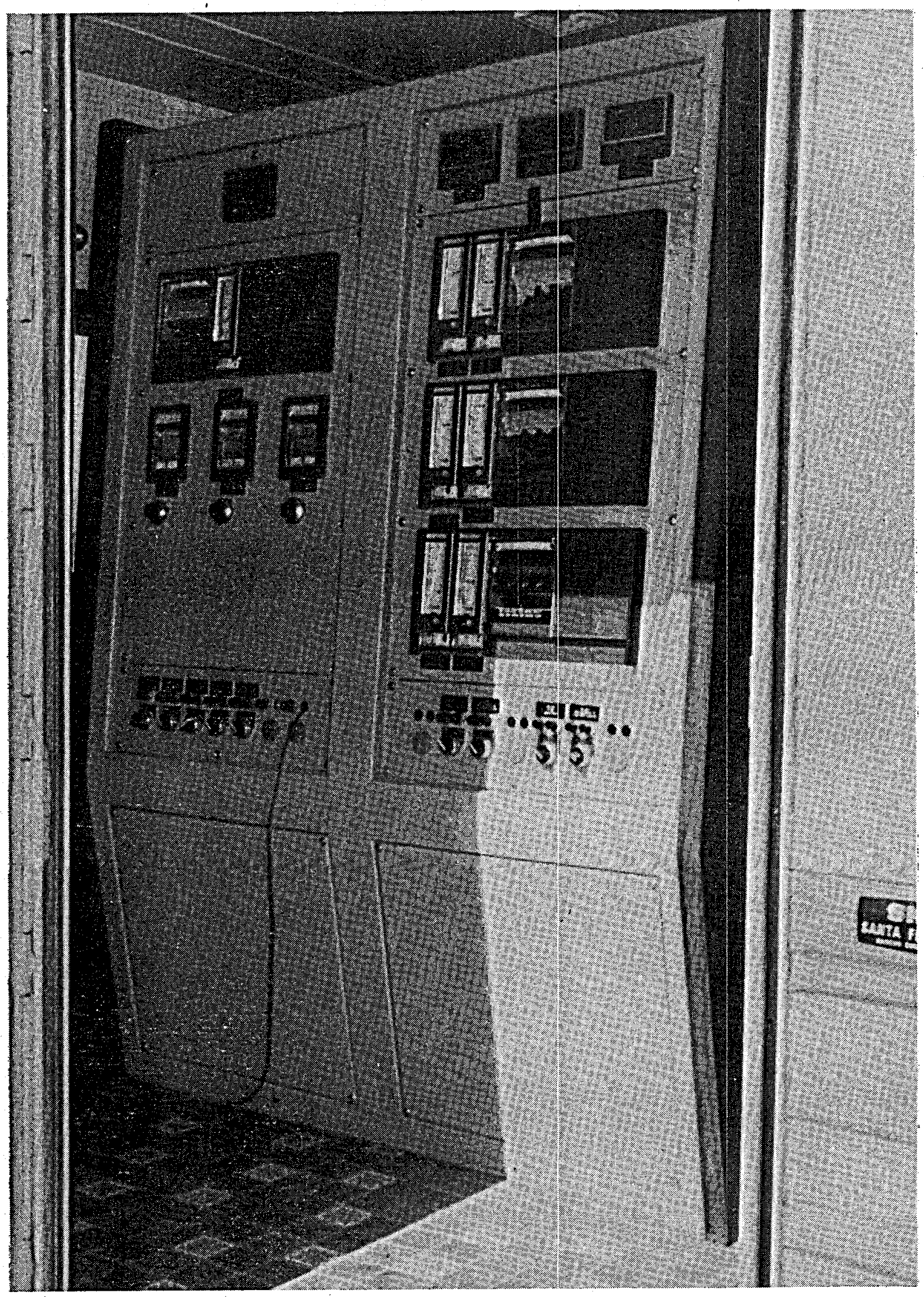

Figure 12. APEX Instrumentation Console 


\section{3, Testing (cont.)}

used to reinject the recirculating bed material into the brine rather than the eductor used in Phase I. This is considered to be representative of the approach which would be initially considered for a full scale unit.

Duration testing of the slurry pump was required before it could be selected as a viable component for the Phase II field testing effort. The test goals were to (1) establish that the pump will circulate bed material of the particle density, size, and weight $\%$ planned, (2) to establish the rate of decay of pressure head developed, and (3) to establish the wear patterns of the pump so that adequate and proper spare parts were on hand at the test site.

The duration testing of the pump was performed using ambient temperature deionized water to which garriet sand bed material was added.

Figure 13 is a photograph of the test setup with the pump disconnected from the suction and discharge pipe. The bed loader and the sampling system from the Phase I program were incorporated into the setup for loading the bed material and to sample the recirculating slurry for determination of weight \% solids and particle size degradation. The pump head developed was taken out across an orifice plate.

\subsubsection{Well Site \\ 4.3.2.1 Test Setup and Checkout}

The tasks required to setup and checkout the test rig included the instrumentation connection between the console and the test rig, plumbing of cooling water and brine from the facilities to the trailer, electrical hookup, instrumentation calibration, insulation of the test 


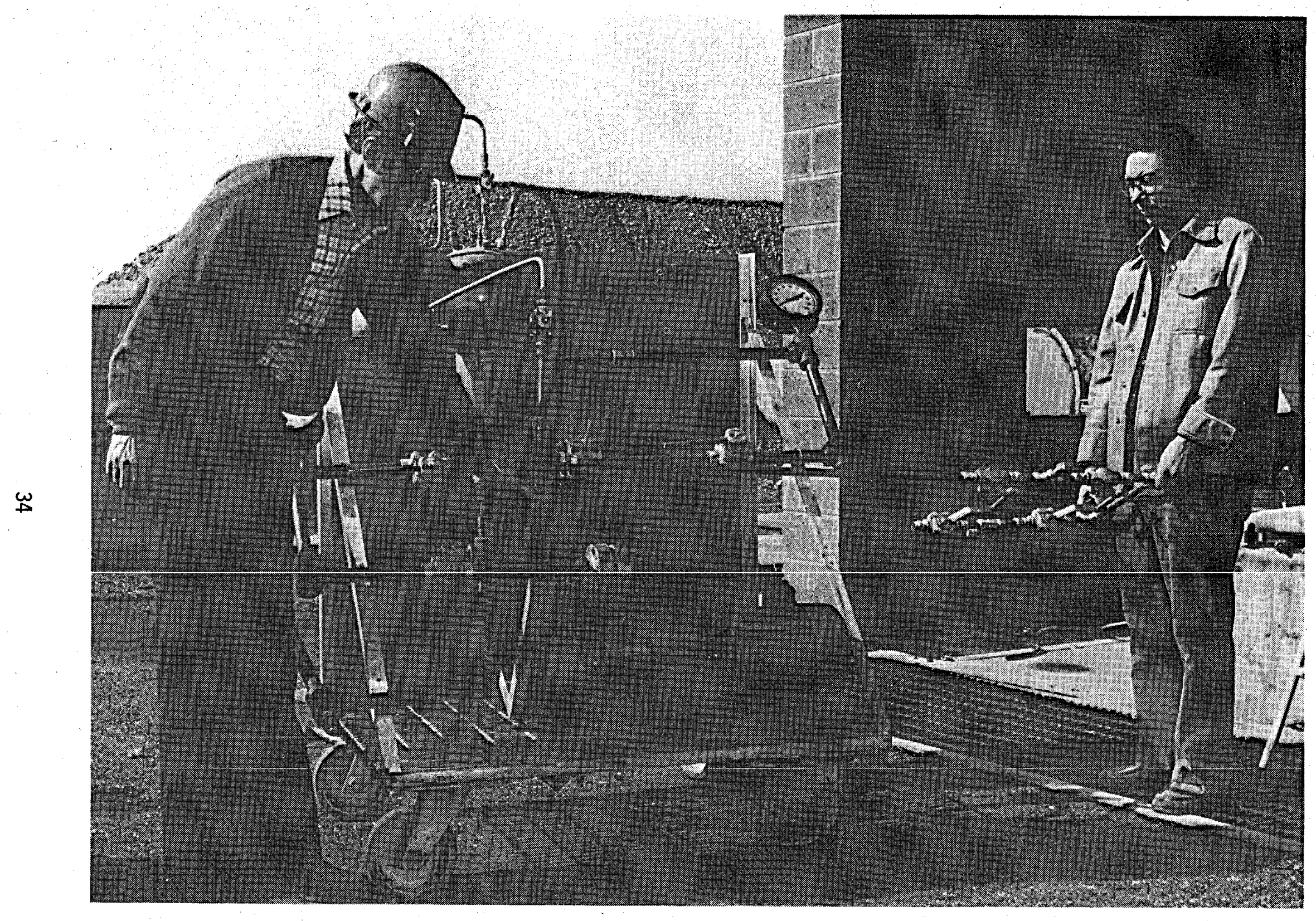

Figure 13. Slurry Pump Test Setup 


\section{3, Testing (cont.)}

exchangers, and setup of the coolant supply and pressurization system. No significant problems were encountered except with the brine supply system. Several modifications were required to the brine supply system before $100 \%$ liquid could be delivered to the experiment.

It was necessary to provide both a noncondensible disengaging tank and a subcooling circuit to achieve satisfactory operation. Figures 14 and 15 illustrate the final brine supply system utilized during the experiments. Figure 14 shows the disengaging tank. This tank was patterned after the tank, design developed by Battelle to handle noncondensables from well 6-1. It was constructed from 12-inch pipe and designed to provide the same residence time as the Battelle unit. The inlet to the tank from the well is the insulated line on the left side. A bypass stream from the well to the flasher tanks was provided and used when the experiment was shut down temporarily. A small 3/4-inch line can be seen joining the brine supply at the tank inlet. This is the cool brine being recirculated from APEX-200 heat exchanger to provide subcooling. The noncondensables are vented from the top of the tank through the control valve to the brine return line from the equipmenttrailer. The brine supply is fed from the bottom of the tank to the ALRC traijer.

Figure 15 shows the connections at the trailer end. The insulated line is the brine inlet. The two lines on each side are cooling water supply and return. The small line is the cool brine for brine supply subcooling. The tank closest to the trailer is the flasher used by the ALRC experiment. The other flasher is for the bypass brine stream.

\subsubsection{Operating Procedures}

The ALRC experiment was designed to operate on a continuous basis for four weeks except for periodic shutdowns, as necessary, 


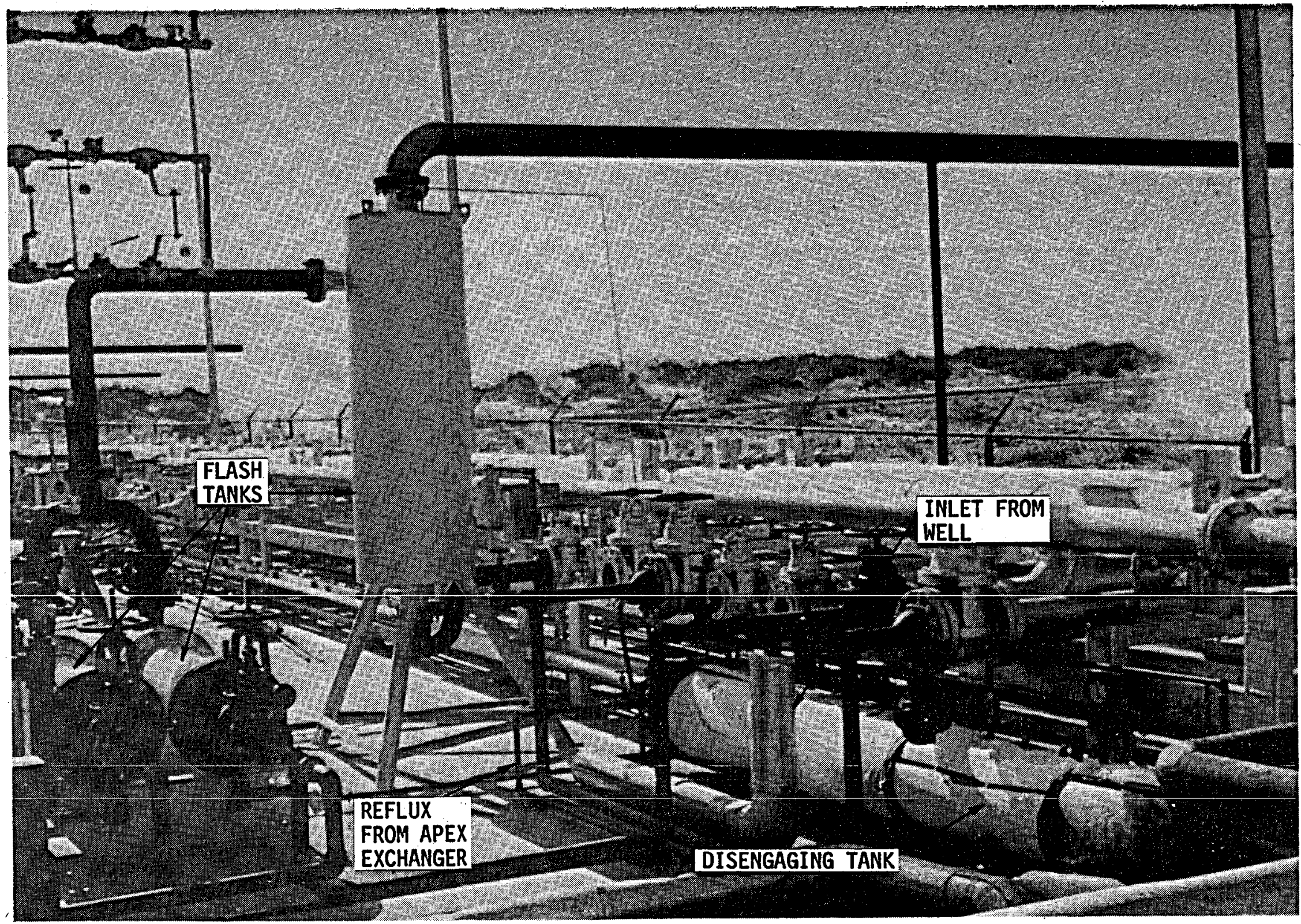

Figure 14. Vapor Disengaging Tank 


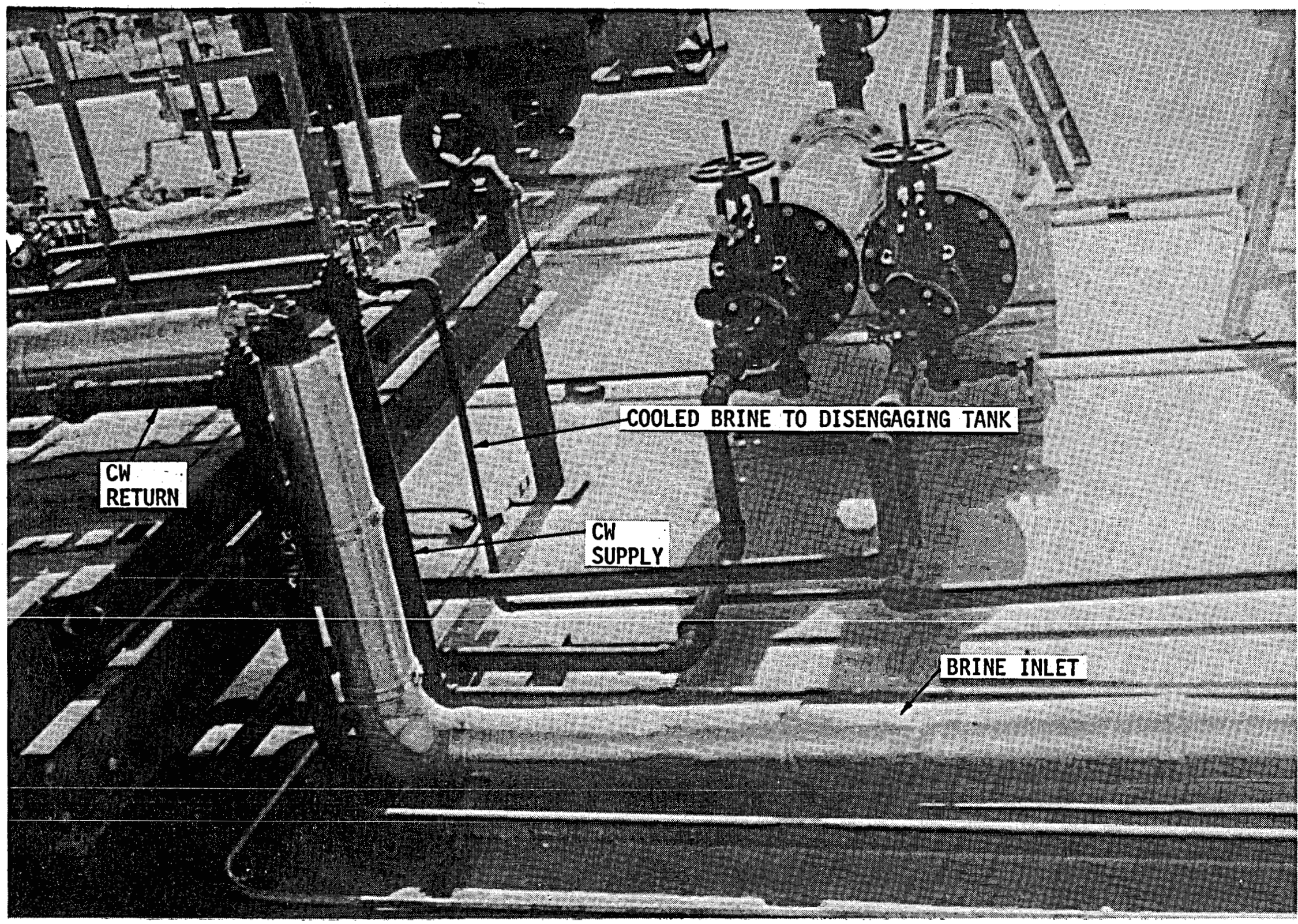

Figure 15. Facility Piping to ALRC Equipment Trailer 


\section{3, Testing (cont.)}

for maintenance. In order to accomplish this without the expense of constant attendance, an automatic alarm device was incorporated into the system such that any critical component failure would close the brine supply valve and the closing of the supply valve would activate a red warning light.

A number of shutdowns occurred during the course of the experiments both scheduled and unscheduled. The unscheduled shutdowns were generally a result of both facility and test equipment blown circuit breakers. This problem was corrected by bypassing redundant breakers and balancing the electrical load between phases. On one occasion, pressure was lost in the coolant tank, shutting down the system. This was due to a stuck check valve. A single unscheduled interruption occurred when facility instrument air pressure was lost.

Most equipment failures could be anticipated by closely monitoring the system performance during operation. In these cases, shutdowns were scheduled at convenient times and components were repaired during a single shutdown. Shutdowns were ncessary for the following items:

1. Temperature probe replacement.

2. Pump mechanical seal replacement (2 pumps).

3. Pump shaft replacement (1 pump).

4. Coolant exchanger cleaning (twice).

Frequently, the shutdowns did not require both units to be shut down. The total time lost for shutdowns during the Group 1 testing period prior to well failure was 46 hours on APEX-100 and 73 hours on APEX-300. 


\section{3, Testing (cont.)}

\subsubsection{Test Conditions}

Three groups of tests were performed at the geothermal test site. The nominal operating points for each test group are presented in Table I. The first group of tests were performed using brine from Well 6-1 as the fouling medium. The second and third test group utilized the facility cooling water for the fouling medium. Well 6-2 was used to provide the heat for the working fluid during group 2 and 3 testing via the baseline heat exchanger.

\subsection{Group 1 Testing}

Two experimental heat exchangers were employed during group 1 testing. The baseline APEX 100 unit provided fouling data on the brine from Well 6-1 under conventional operation and the APEX-300 unit demonstrated the relative performance of the APEX concept. The APEX-200 unit was diverted from its original experimental purpose to provide subcooling for the brine during group 1 testing.

The operating flowrates were unchanged from the design values shown in Figure 2. The brine temperatures were adjusted from the original design values slightly because of the necessity for subcooling the brine. The working fluid inlet set temperature was increased from $175^{\circ} \mathrm{F}$ to $190^{\circ} \mathrm{F}$. This change was made to reduce the heat load and increase the MTD in the working fluid cooler. The rapid fouling experienced from the facility water would require inconveniently frequent cleaning shutdowns without this change.

Raw data was measured on both the baseline exchanger, APEX-100, and the recirculating bed exchanger, APEX-300, at least twice a day. 


\section{TABLE I}

TEST SUMMARY

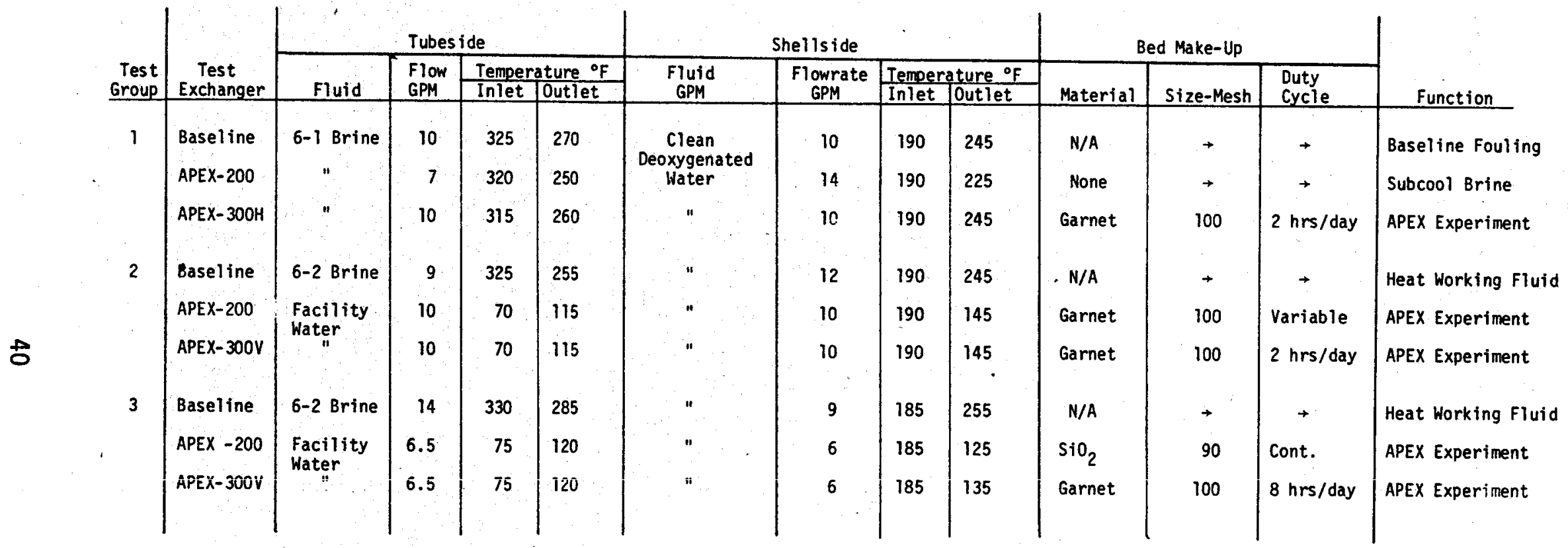




\section{3, Testing (cont.)}

The APEX-300 data was taken just before bed addition and just after bed removal, to best observe the effects of the bed. The data for APEX-100 was taken as close to 12 hour intervals as could conveniently be accomplished, to provide the most uniform time spread between data points.

The temperatures at each critical station in the heat exchanger loop, both coolant and brine, were recorded, as were the flowrates to the exchanger and the U-meter reading. The U-meter was wired to integrate a simultaneous reading of all the critical temperatures used to calculate the heat transfer coefficient. The coolant temperatures were used in this temperature integration for the heat load calculation. The $\mathrm{U}$-meter thus has the advantage of simultaneous temperature readings while the individual temperature data were read as they were recorded on a sixpoint recorder, which has about a one-minute cycle. The U-meter has the technical objection that the average temperature difference is used in the presentation rather than the log mean temperature difference. This objection is academic in the case of the experiments conducted because, in a 11 cases, the inlet and outlet temperature differences were maintained very nearly equal, i.e., within $10 \%$ of each other. Thus, the variations between the average temperature difference and $\log$ mean temperature difference is on the order of $0.1 \%$.

The heat transfer coefficients were computed using both the U-meter reading and the individual temperature readings in the early stages of testing, however, the individual temperature readings were found to result in a greater data spread than when the U-meter readings were used. This spread was attributed to the fact that the individual temperatures could not be read simultaneously or as accurately. The U-meter 


\section{3, Testing (cont.)}

was therefore used exclusively for the major portion of the heat transfer coefficient calculations and the use of individual temperature readings were limited to heat load calculations for comparative purposes, to provide a check on the validity of the data point and for recirculation flowrate calculations.

Appendix B sumarizes the reduced data from test group 1 and describes the techniques, formulas, and assumption made in reducing these data and determining a tubeside fouting resistance.

\subsection{Group 2 Testing}

Group 2 tests were conducted following the failure of Well 6-1 using the facility water, which had been used for cooling, as the fouling fluid. The facility water had exhibited strong fouling characteristics when used to cool the working fluid during previous testing.

The test rig was modified to permit facility water to be used in place of brine in either the APEX-200 or APEX-300 experimental exchanger. The baseline APEX-100 exchanger was set up to operate in the conventional fashion, i.e., brine on the tubeside and working fluid (clean treated water) on the shellside. This unit thus provides the dual function of providing the required heat to the working fluid and providing fouling data on Well 6-2.

The initial testing sequence for the supplemental test series was verification testing of the new system. These tests were performed using the baseline exchanger and the APEX-200 unit. The APEX-300 experiment was blocked while being modified for vertical operation capabilities 


\section{3, Testing (cont.)}

during this initial test series. Only a single APEX experiment can be conducted using the modified system under normal operating conditions. This is limited by the capacity of the baseline exchanger to heat the working fluid.

The APEX-200 was tested for three days under the same flow rate conditions as used in the previous test series to: (1) verify that the system would scale, and (2) verify that the APEX concept would remove the scale. At the conclusion of the verification testing, the APEX-200 was shut down and the vertical APEX-300 was brought on stream under identical operating conditions so that the relative merits of vertical and horizontal operation could be analyzed.

The same basic procedures for measuring and collecting raw data were followed in group 2 testing as described previously for group 1 testing. Some simplifying procedures were followed in data reduction and analysis procedures. The uniformity of the flowrates measured made the procedures previously used of computing separate shellside and tubeside heat transfer coefficient unnecessary. The fouling was computed directly from the overall heat transfer coefficient calculated from the $U$-meter readings.

\subsection{Group 3 Testing}

Group 3 tests were performed using facility water as the fouling medium to study the APEX concept effectiveness at lower operating velocities. The test conditions and procedures for group 3 tests were identical to group 2 with the following exceptions. (1) the flowrates in the APEX exchangers were reduced, (2) the reduced flowrates permitted simul taneous operation of APEX-200 and APEX-300V. The basel ine exchanger was able to provide sufficient heat to the working fluid to handle 


\section{3, Testing (cont.)}

both exchangers at this reduced heat load condition, (3) $\mathrm{SiO}_{2}$ bed material was substituted for garnet bed material in the horizontal unit, (4) a continuous recirculation mode was used in the horizontal APEX unit and the bed material was recirculated for eight hours each day in the vertical unit.

The basic data analysis procedures used for the group 2 tests were utilized for analys is of the group 3 tests. However, the temperature fluctuations of the process streams during group 3 tests were of a greater magnitude than encountered in previous testing. It was considered necessary to correct the measured heat transfer coefficient to a baseline temperature condition. The data were corrected to an average cooling water temperature of $93^{\circ} \mathrm{F}$ and an average working fluid temperature of $150^{\circ} \mathrm{F}$. The formula used to compute $h_{t}$ in group 1 testing was used to adjust the tubeside, and shellside heat transfer coefficients.

\subsection{TEST RESULTS}

Test results are presented in this section. Interpretation of the results are discussed in the next section (4.5).

\subsubsection{Laboratory Tests}

Two 100-hour laboratory tests on the slurry pump, conducted to qualify the pump, disclosed no degradation of the developed pump head. Both tests were terminated because of excessive leakage of the mechanical seal. Figure 16 is a photograph of the mechanical seal after the test. The ceramic face is undamaged; however, the carbon face is badly worn. Figure 17 is a photograph of the pump casting and impeller after the first 100-hour test. Some minor erosion of the impeller vanes was experienced. 


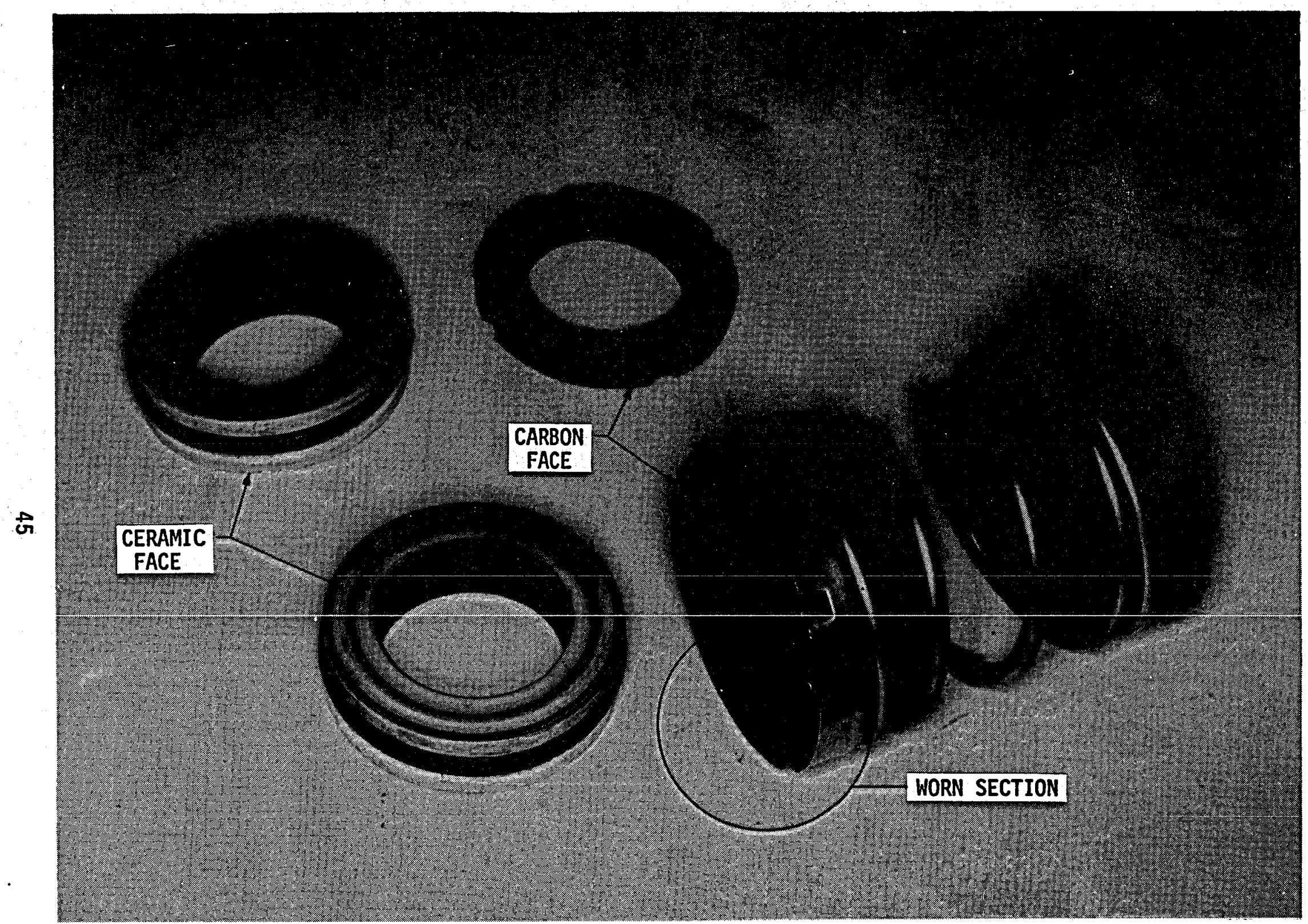

Figure 16. Slurry Pump Seal After 60 Hours Operation 


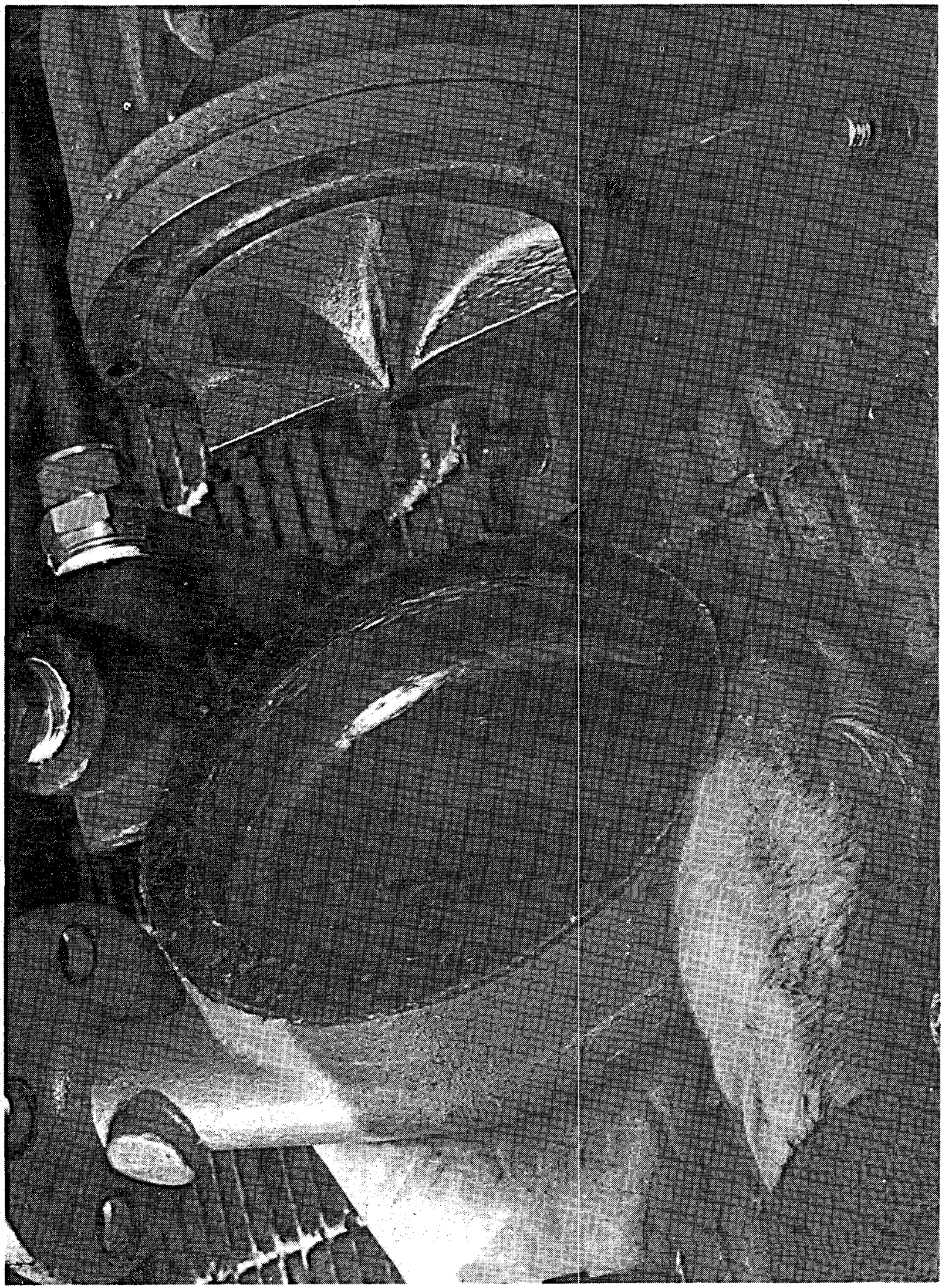

Figure 17. Pump Casing and Impeller After First 100 Hour Test 


\section{4, Test Results (cont.)}

The slurry pump qualified for use in the Phase II field testing. It was anticipated from these tests that frequent replacement of the mechanical seals could be required when continuously recirculating bed materials. Therefore, spare seals were purchased for backup during the field testing.

The durability results of these tests have little direct relationship to the applicability of slurry pumping for the full scale application. The pump was selected primarily based on availability and was qualified as adequate for experimental test duration only. Slurry pump manufacturers do not anticipate excessive wear fn larger sizes.

\subsubsection{Well-Site Tests}

The fouling test results are presented for all three groups of tests by plotting the calculated tubeside fouling as a function of test duration. the fouling is determined by measuring the decay in overall heat transfer coefficient, which is a subtraction process. This means that the absolute accuracy of the temperature instrumentation is not of great significance in determining the accuracy of the raw data, but rather the repeatability is significant. The repeatability of the platinum resistance probes used can be considered to be perfect for practical purposes. The manufacturer specifies $\pm 0.05^{\circ} \mathrm{C}$ at $0^{\circ} \mathrm{C}$.

The accuracy to which the raw data can be read can have a large influence on the overall accuracy. The U-meter, which integrates all the critical temperature readings into one voltage output displayed digitally can be read without error. Flowrates can be read to \pm 0.1 GPM which could introduce an error of $1 \%$ in Group 1 and 2 testing flowrates and a $1.5 \%$ error in Group 3 flowrates. 
4.4, Test Results (cont.)

Minor fluctuations in operating temperatures occur due to supply water temperature variations. This has a minor influence on heat transfer coefficients because of changes in fluid properties with temperature. These variations were not considered to impact the data reduction for Group 1 and 2 testing. A maximum error of $\pm 1 \%$ in $h_{t}$ is possible due to brine temperature fluctuation. The temperature fluctuations experienced in Group 3 testing were more extreme and corrections were made to allow for these fluctuations in the data reduction of APEX-200.

The Group 3 testing of the APEX-200 has an additional error not encountered on other tests. This is that heat transfer data was measured while the bed material was being recirculated. The weight $\%$ bed material being circulated at a specific time has some influence on the recirculation flowrate and possibly some influence on heat transfer coefficient if sufficient sand is in the system. The heat transfer data taken simultaneously with a bed sample in which the weight $\%$ of bed material is determined to fall within a narrow range, so 5 to $10 \%$, would not be subject to error due to the recirculation flowrate uncertainty. Data falling outside this range could be less accurate.

The effect of the maximum errors in flowrate and temperatures on tubeside and shellside resistances were computed assuming each parameter was in error in the direction to cause the greatest deviation. A potential error of $\pm 5.4 \times 10^{-6} \mathrm{hr}-{ }^{\circ} \mathrm{F}-\mathrm{ft}^{2} /$ Btu was calculated for Group 1 and 2 test data. The potential error for Group 3 tests was $\pm 13.5 \times 10^{-6}$ hr- ${ }^{\circ} \mathrm{F}-\mathrm{ft}^{2} / \mathrm{Btu}$ for the APEX-200 unit. The APEX-300 unit, which was not corrected for process stream temperature fluctuations has a considerably greater potential error. This potential error was not calculated because the data was so conclusive that any temperature stream correction would be insignificant. 
4.4, Test Results (cont.)

The potential errors calculated when compared to the data generated were not of a sufficient magnitude to influence the validity of any of the conclusions reached or any of the trends displayed on the data plots.

The test results are presented in this section and they are discussed and interpreted in the next section.

\subsubsection{Group 1 Test Results}

A plot of the fouling resistance as a function of time for the baseline exchanger, is shown in Figure 18. The early data, points 2 through 6 , have been discarded because the temperature probe which measures the brine inlet temperature was found to be bad when checked between the time of data points 6 and 7 , and it appeared to have been progressively failing from examination of the data.

The fouling characteristics of the baseline exchanger are subject to some speculation. The first 230 hours of operation are straightforward and the data are well behaved. The data can be well represented by a smooth curve. At the 230 hour point a radial change in the data occurs. Several interpretations of this phenomenom are possible.

Figure 18 shows the interpretation of the data which ALRC believes to represent the true condition. The fouling proceeds on approximately a straight 1 ine basis with discontinuities occurring in the last 170 hours of testing in which the fouling buildup is reduced significantly. A review of the data shows a power failure occurred between two of the three discontinuities and the equipment was shut down with the brine locked up in the exchanger for an extended period. This could permit some 


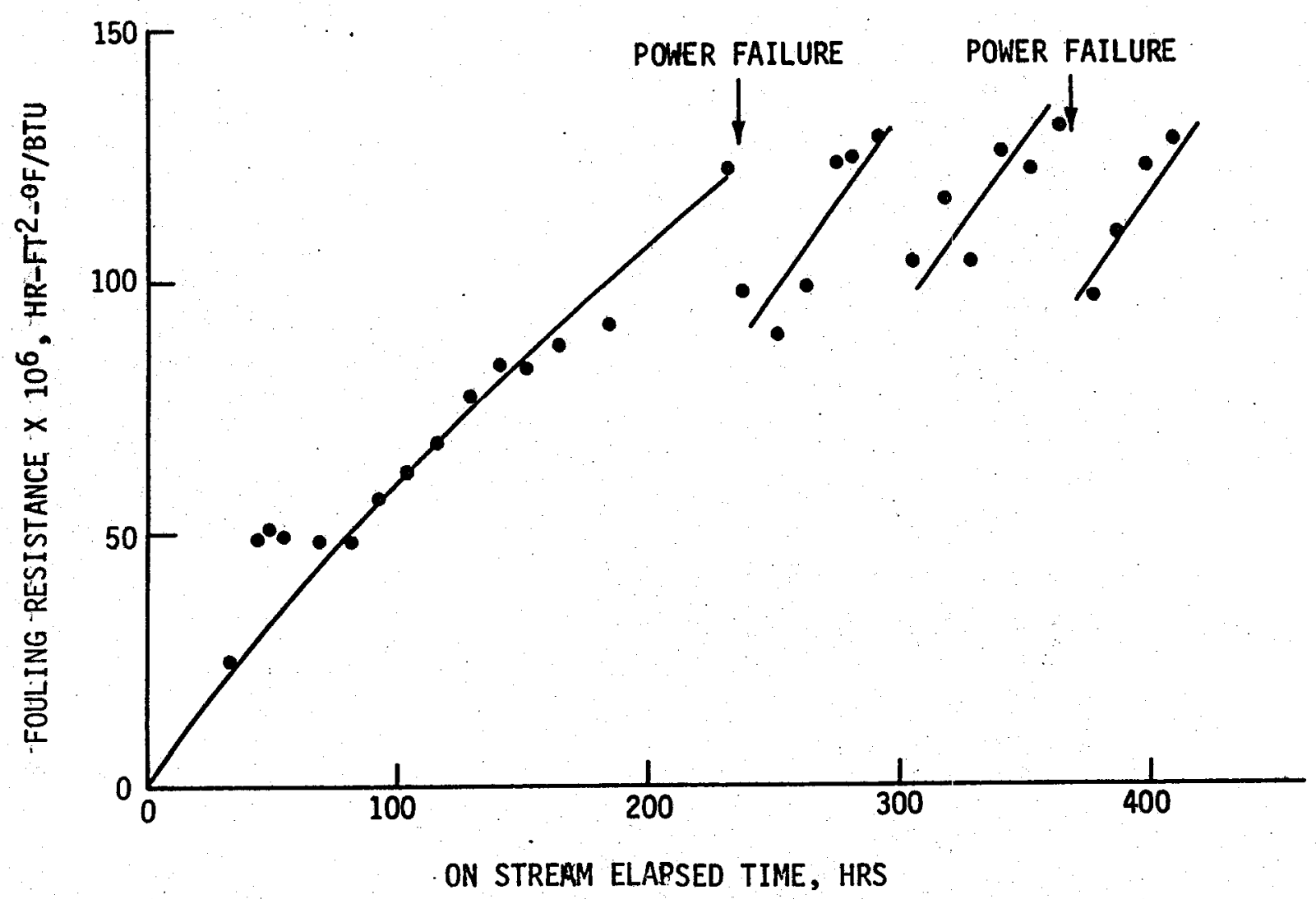

Figure 18. Tube Fouling with Brine from East MESA Well 6-1

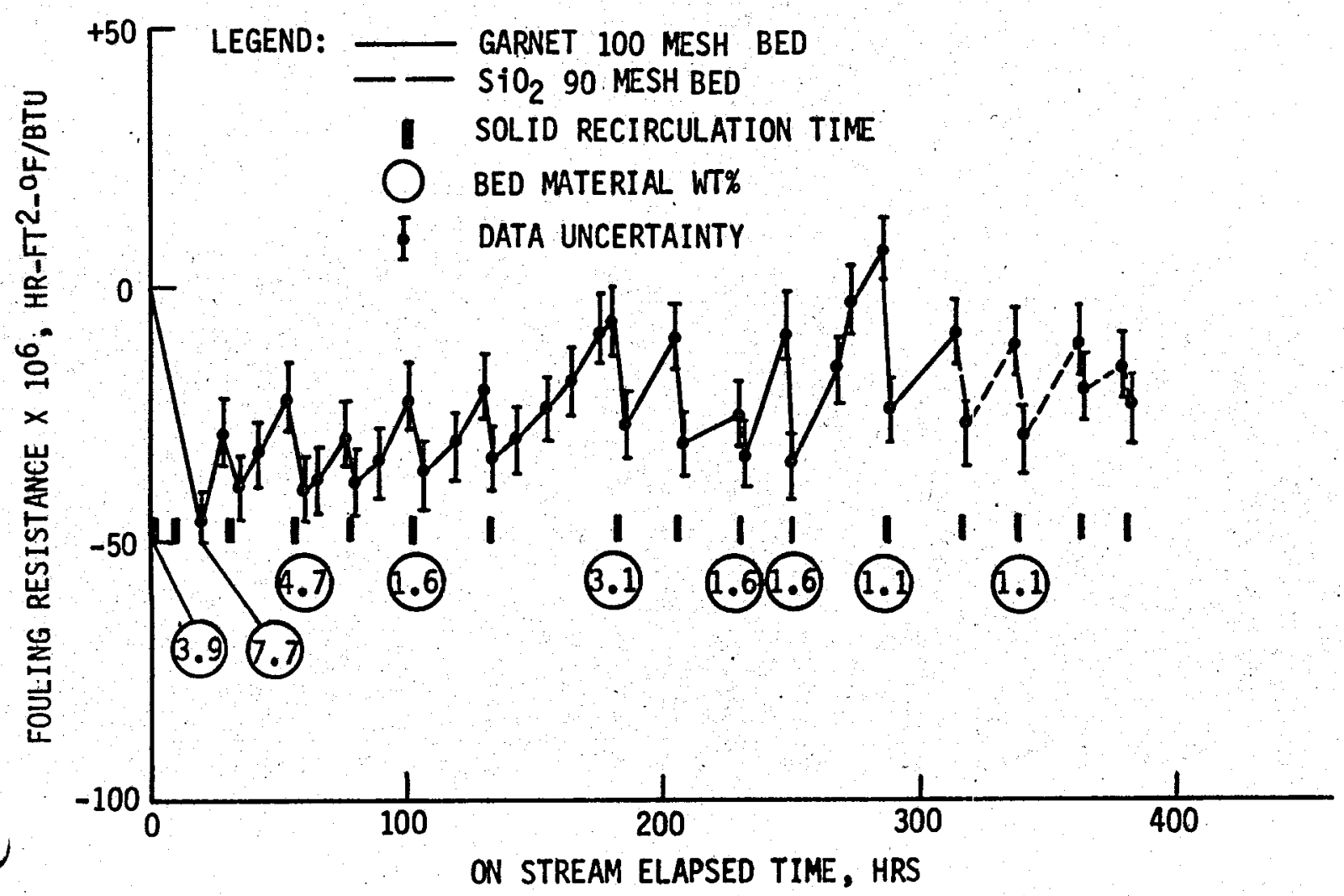

Figure 19. Elimination of Fouling Using APEX East MESA Well 6-1 


\section{4, Test Results (cont.)}

of the scale to return to solution as the brine cooled, assuming $\mathrm{CaCO}_{3}$ as a scale constituent or possibly thermal contraction and subsequent expansion of the tube dislodged a portion of the scale. No anomaly of this sort can be observed in the data which would account for the third discontinuity. other shutdowns occurred which did not influence the fouling buildup.

The actual shape of the fouling rate curve of the baseline exchanger has no significance regarding the functioning of the APEX concept, although it may be significant in determining if the APEX concept is required in the primary heat exchanger design for use in a binary cycle geothermal power plant. The significant point is that the baseline exchanger did fout.

The fouling film accumulated in the equivalent of 10 days operation was on the order of $0.0001 \mathrm{hr}-{ }^{\circ} \mathrm{F}-\mathrm{ft}^{2} / \mathrm{Btu}$. This is the equivalent of a fouling film thickness of about 3 mils, assuming a scale thermal conductivity of $1 / 10$ that of steel. This compares closely with the 2 mil average thickness actualily measured during subsequent heat exchanger tube sectioning and inspection.

The fouling results obtained on APEX-300 are shown plotted in Figure 19. Data points 2 through 6 have been rejected as invalid because of temperature probe damage, as was experienced on APEX-100. The time of injection of the bed material is indicated by the solid bars along the abscissa of the plot along with the weight \% bed material, when available. The solid lines indicate test points in which 100 mesh garnet was being used as the bed material. The dotted lines at the end of the testing effort indicate the switch to 90 mesh $\mathrm{SiO}_{2}$ for the bed material. The APEX-300 fouling film thickness, in contrast to the APEX-100 unit, is consistently negative, indicating that the exchanger throughout testing is cleaner than the initial start point, which was assumed to be the clean condition. In all 


\section{4, Test Results (cont.)}

cases where garnet bed material was used, it will be observed that the exchanger tends to foul until the bed material is added and that immediately after the bed is removed, the exchanger is in a cleaner state than just before the bed was added. This clearly demonstrates that the concept works. The data spread is insufficient to estabiish clearly whether the fouling film is totally removed each time the bed is added. In one case, beginning at the 135 hour point, two days elapsed between bed inspection instead of the normal one day. In this case, a larger fouling film built up. Examining the data subsequent to this, it appears that several days operation were required to return the exchanger to the level of cleanliness existing before the two-day build-up, but it did return to that condition.

The results obtained with the $\mathrm{SiO}_{2}$ bed material are not conclusive. The $\mathrm{SiO}_{2}$ material appeared to perform similar to the garnet for the first two days of operation. No improvement was noted after bed addition the last two days of testing. Further, the $\mathrm{SiO}_{2}$, being considerably lighter than the garnet, exhibited a tendency to be carried out the overflow of the separator rather than reinjected and it was difficult to maintain a significant weight percent of bed material flowing. This could have been corrected by an adjustment to the bypass orifice diameter. The 6-1 well plugged before this adjustment could be made.

The heat exchanger tubes were removed at the end of the test phase and sectioned at various positions for photographic examination and measurement of the tube condition after testing with well 6-1 brine.

Figure 20 shows all of the APEX heat exchanger tubes sectioned at various positions between the fluid entrance and exit. All the tubes showed some degree of scaling. 


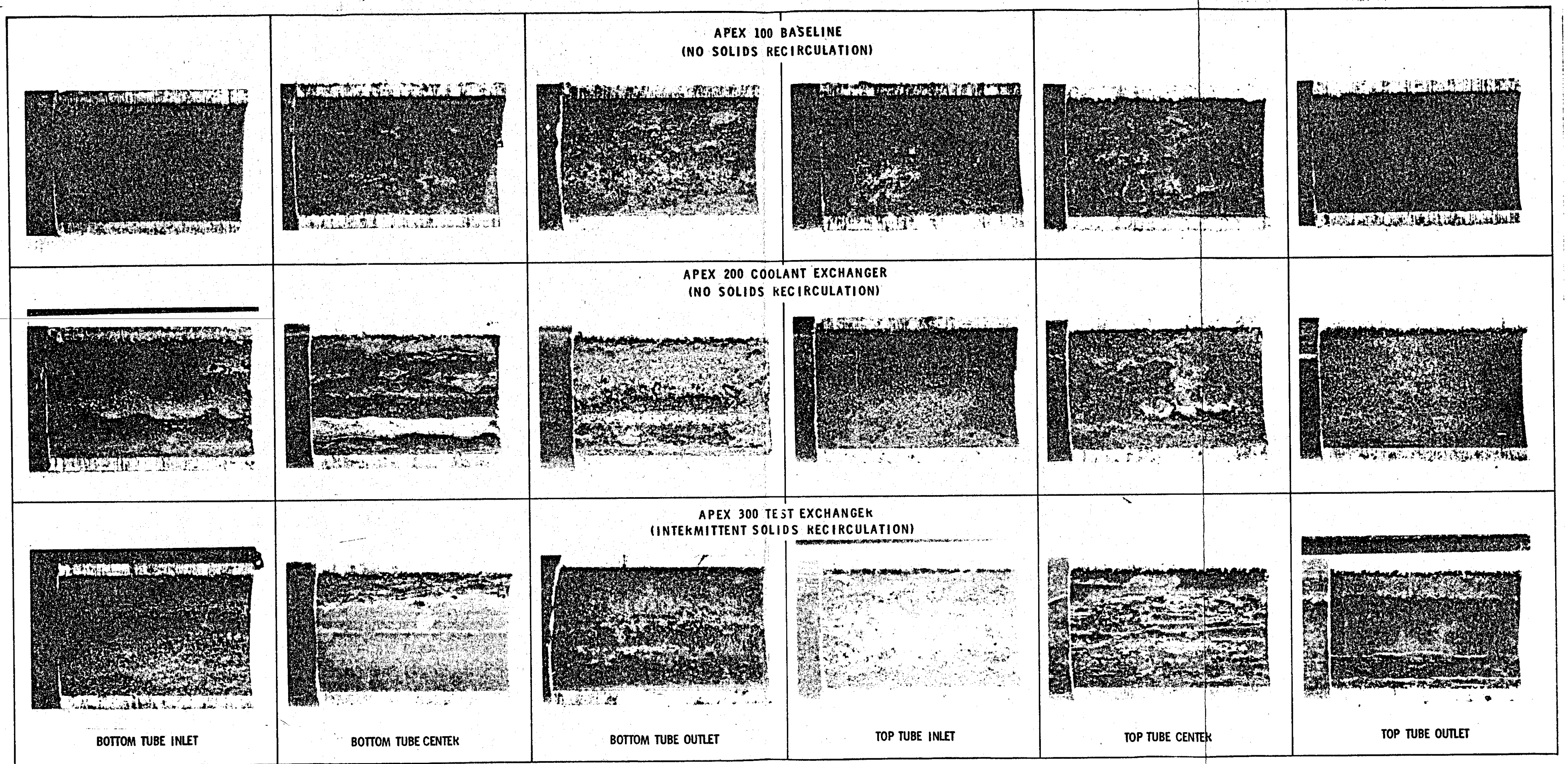

Figure 20. Tube Sections Showing Scaling after Testing with Brine 


\section{4, Test Results (cont.)}

Tubes with no solids circulation were visibly fouled.

The baseline heat exchanger tube, APEX-100, was circumferentially covered with scale the entire length. Similarly, the brine coolant exchanger tube, APEX-200, had the same appearance.

The tube with solids recirculation, APEX-300, was streaked with a clean surface along the entire bottom side in its horizontally mounted position. The clean surface covered an angular profile between $120^{\circ}$ and $180^{\circ}$. Figure 21 shows a section of the APEX-300 tube separated to $i 17$ ustrate bottom and top surface conditions. Figure 22 shows a 100X magnification of the edge of an APEX-300 tube at the location where the scale interfaces with the clean surface. It is interesting to notice in Figure 22 that where scale formation occurs, more reaction with the carbon steel tubing is observed. This would tend to suggest that a tube maintained clean would be better in preventing chemical attack of the tube. A chemical analys is of APEX-100 tube scale seems to indicate a scale/tube reaction due to large concentration of iron found. Table II contains a chemical analysis of the APEX-100 tube scale. Iron, silicon, zinc, arsenic, and sulfur were most noticeable among the elements analyzed. The scale elemental consistency was nearly the same in the two tube units that made up the entire APEX-100 heat exchanger.

\subsubsection{Group 2 Test Results}

Group 2 tests were performed using facility water as the fouling fluid. Both APEX units were operated during this series, first the APEX-200 horizontal unit and next the APEX-300 vertical unit. The baseline exchanger was operated to provide heat to the system using the brine from well 6-2. 


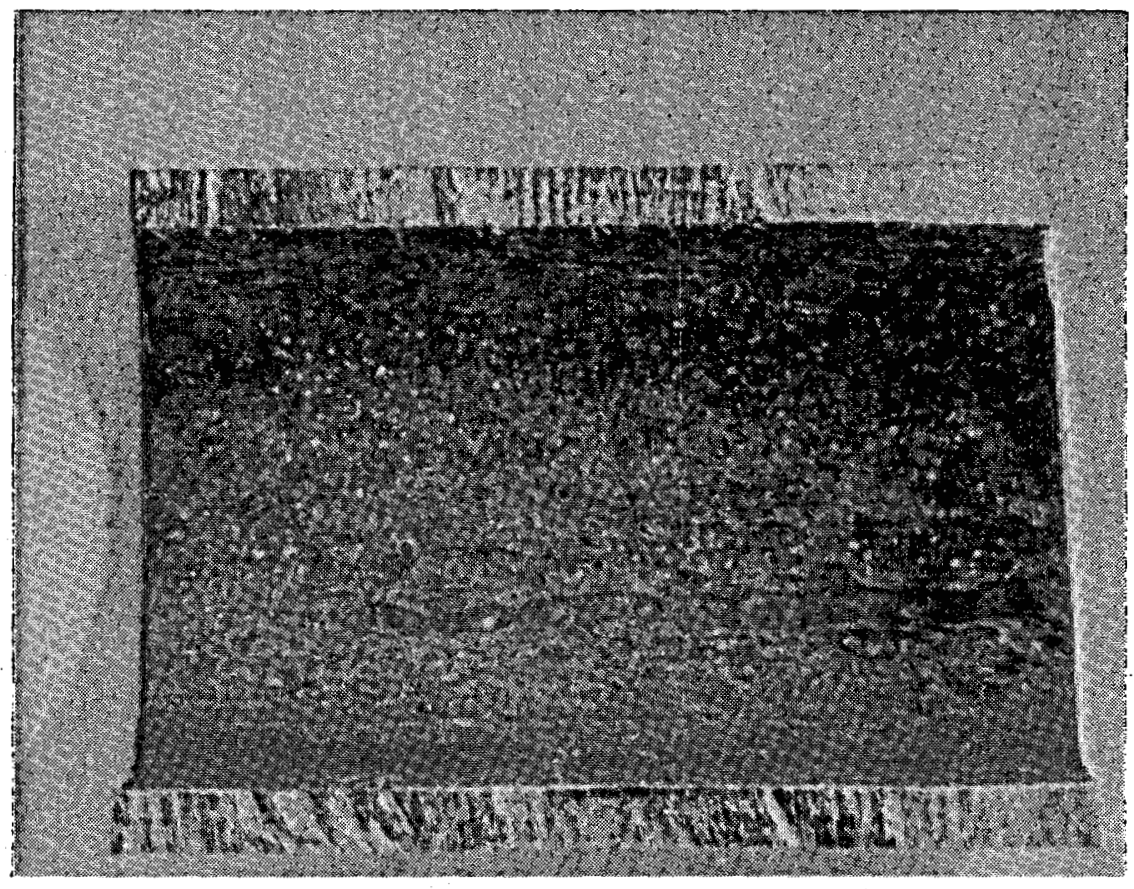

TOP HALF OF TUBE

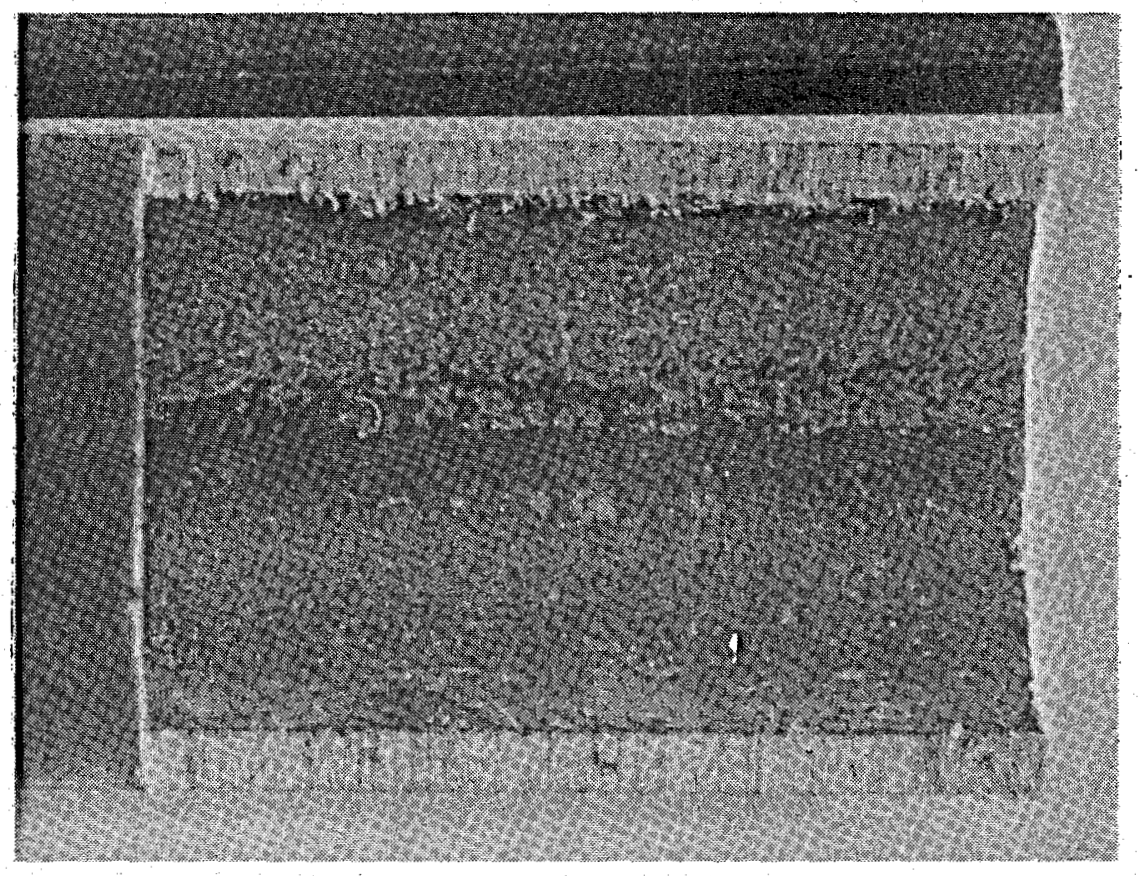

BOTTOM HALF OF TUBE

Figure 21. APEX 300 Bottom Tube Outlet Specimens 


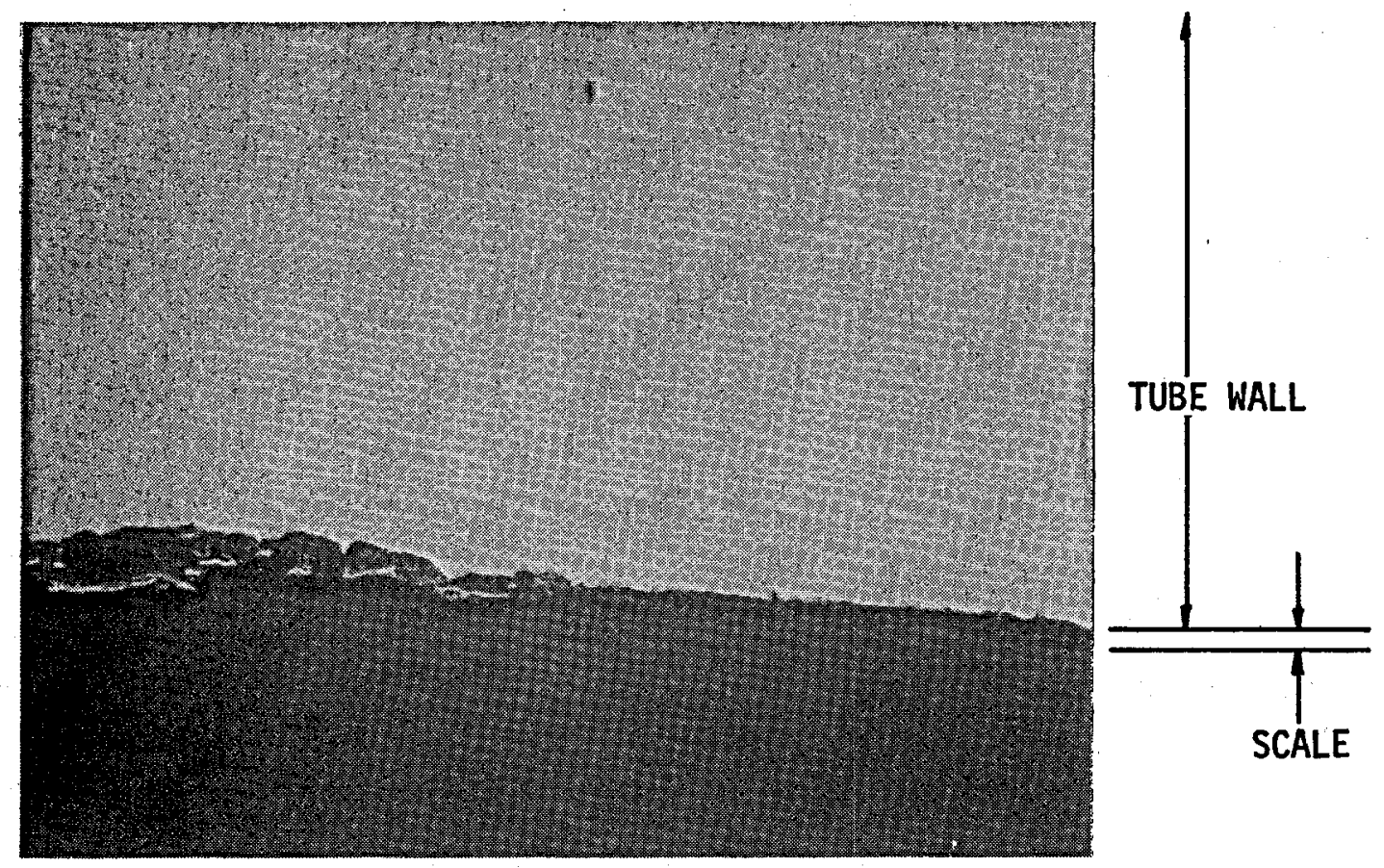

Figure 22. 100X Enlargement of Tube Wall and Scale Showing Corrosion of Tube Surface by Scale 


\section{TABLE II}

APEX-100 TUBE SCALE ANALYSIS

Average Elemental Composition, \% by Weight

Top Tube* Bottom Tube*

$\begin{array}{lll}\text { Iron } & 55 . \% & 54 . \% \\ \text { Zinc } & 2.3 & 4.0 \\ \text { Aluminum } & 1.5 & 1.6 \\ \text { Silicon } & 2.9 & 3.7 \\ \text { Antimony } & 1.0 & 0.71 \\ \text { Copper } & 0.98 & 0.48 \\ \text { Chromium } & 0.21 & 0.090 \\ \text { Arsenic } & 2.4 & 1.6 \\ \text { Boron } & 0.029 & 0.011 \\ \text { Manganese } & 0.40 & 0.47 \\ \text { Magnesium } & 0.0059 & 0.022 \\ \text { Lead } & 0.20 & 0.12 \\ \text { Nickel } & 0.073 & 0.054 \\ \text { Molybdenum } & 0.26 & 0.28 \\ \text { Calcium } & 0.78 & 0.74 \\ \text { Tin } & 0.045 & 0.055 \\ \text { Silver } & 0.037 & 0.012 \\ \text { Cobalt } & 0.024 & 0.021 \\ \text { Titanium } & 0.012 & 0.013 \\ \text { Strontium } & 0.20 & 0.16 \\ \text { Sulphur } & 2.50 & 2.50 \\ \text { Oxygen et al } & 0 \\ \text { Sinder }\end{array}$

*The heat exchanger assembly was fabricated in a " $U$ " shape having bottom and top tubes. Flow entered the bottom tube and discharged from the top tube. 
4.4, Test Results (cont.)

Figure 23 illustrates the fouling characteristics observed with the horizontal APEX-200 exchanger. The exchanger was allowed to foul overnight to verify the rapid fouling anticipated when heating the facility water. The overall heat transfer coefficient decayed by $5 \%$ overnight which was the order of magnitude desired.

The 100 mesh garnet bed material used for the earlier tests was added for $1-1 / 2$ hours and then removed. The action of the bed material increased the heat transfer coefficient but did not return it to the original clean level. The exchanger was allowed to foul for another five hours, at which point bed material was added for 45 minutes. Again, the heat transfer coefficient went up but did not return to the previous level. The exchanger was allowed to foul overnight after which bed material was added and allowed to remain in the system for a full day before removal. The heat transfer coefficient returned to its previous level rapidly and remained substantially unchanged at this value for the remaining test duration. No fouling occurred while the bed was circulating, but the exchanger never returned to its original level of cleanliness.

The APEX-300 vertical unit which was operated under the same conditions as the APEX-200 horizontal unit shows similar results as shown in Figure 24. In general, the same fouling rates and the same partial cleaning with bed recirculation was observed, A brief period occurred in which the recirculation of the bed material completely restored the exchanger to the level of cleanliness achieved during the previous cycle. However, the trend toward only partial recovery was reestablished during the final two days of testing. The duration of bed recirculation and the elapsed time between recirculation periods was varied during the six-day test cycle without any apparent influence. 


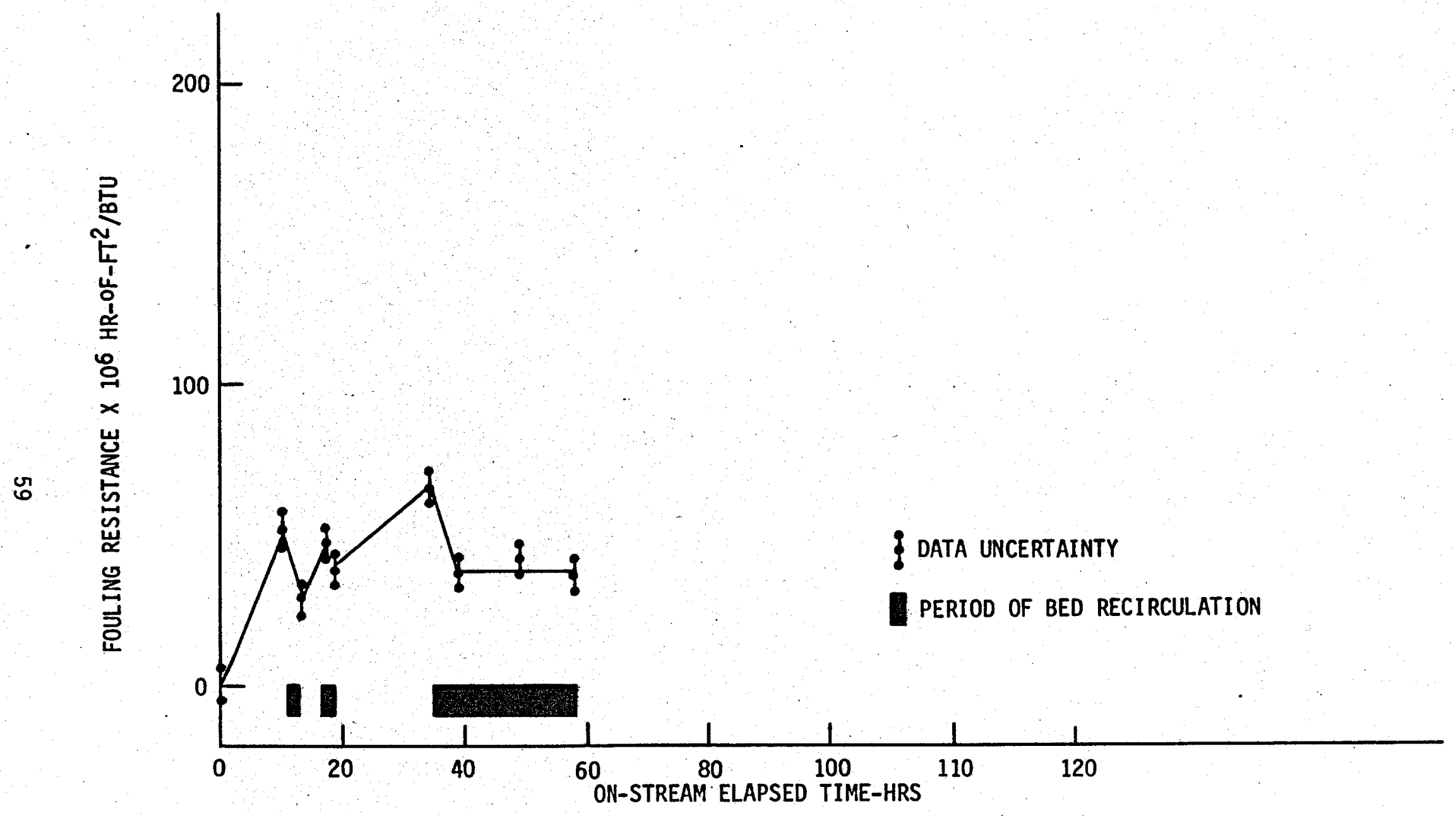

Figure 23. APEX-200 Tubeside Fouling from Facility Cooling Tower Water (Horizontal Operation) 


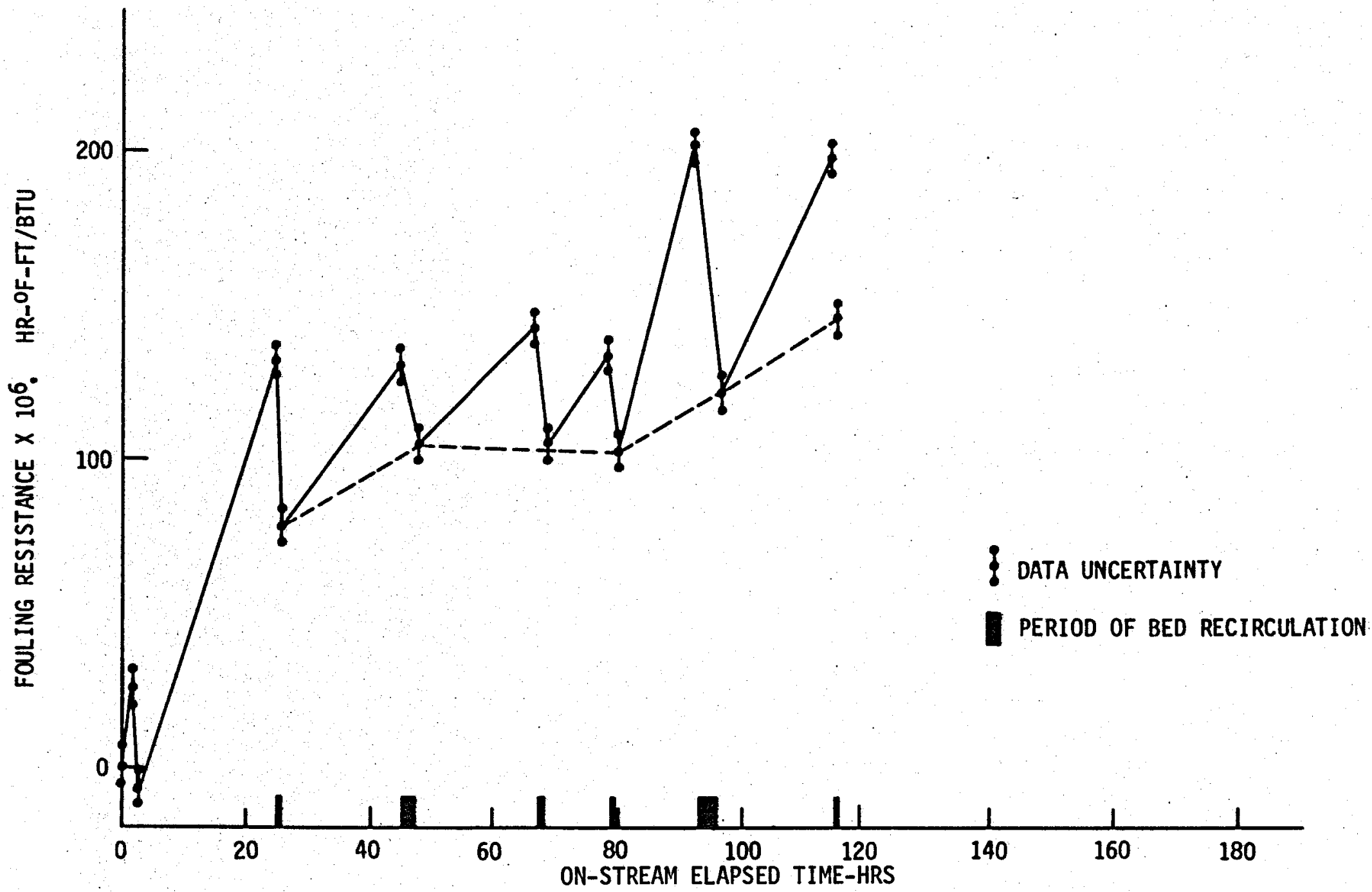

Figure 24. APEX-300V Tubeside Fouling with Facility Cooling Tower Water (Vertical Operation) 


\section{4, Test Results (cont.)}

The fouling characteristics of Well 6-2 were monitored on the baseline exchanger during the APEX-200 and 300 tests. These data are shown in Figure 25. The fouling progressed at a fairly uniform and unexpectedly high rate during the initial testing. The experiment was shut down when the switch from APEX-200 to APEX-300 was made. An anomaly in the data was observed when the experiment was reactivated. The heat transfer coefficient was about $3 \%$ lower than when the experiment was shut down. The fouling of the baseline exchanger during the succeeding six days proceeded at a much reduced rate.

The duration of the Group 2 tests were not long enough to define whether intermittent solid recirculation would limit the degree of fouling.

\subsubsection{Group 3 Test Results}

The Group 3 tests were performed using facility water as the fouling fluid. Both the horizontal and vertical APEX exchangers were operated in parallel using lower operating velocities, 6-1/2 ft/second, on the tubeside. $\mathrm{SiO}_{2}$ bed material which is lower in density than garnet, was used in the horizontal unit to avoid bed stratification. Continuous recirculation was used in the horizontal unit based on the Group 2 test results. The vertical APEX was operated with garnet bed material and a greatly increased duty cycle.

The test results are plotted in Figure 26. Both APEX-200 and APEX-300V fouling results are shown on the same figure for comparative purposes. As shown in the plot of the data, the APEX-200 unit was brought on stream 22 hours after the APEX-300V unit. 


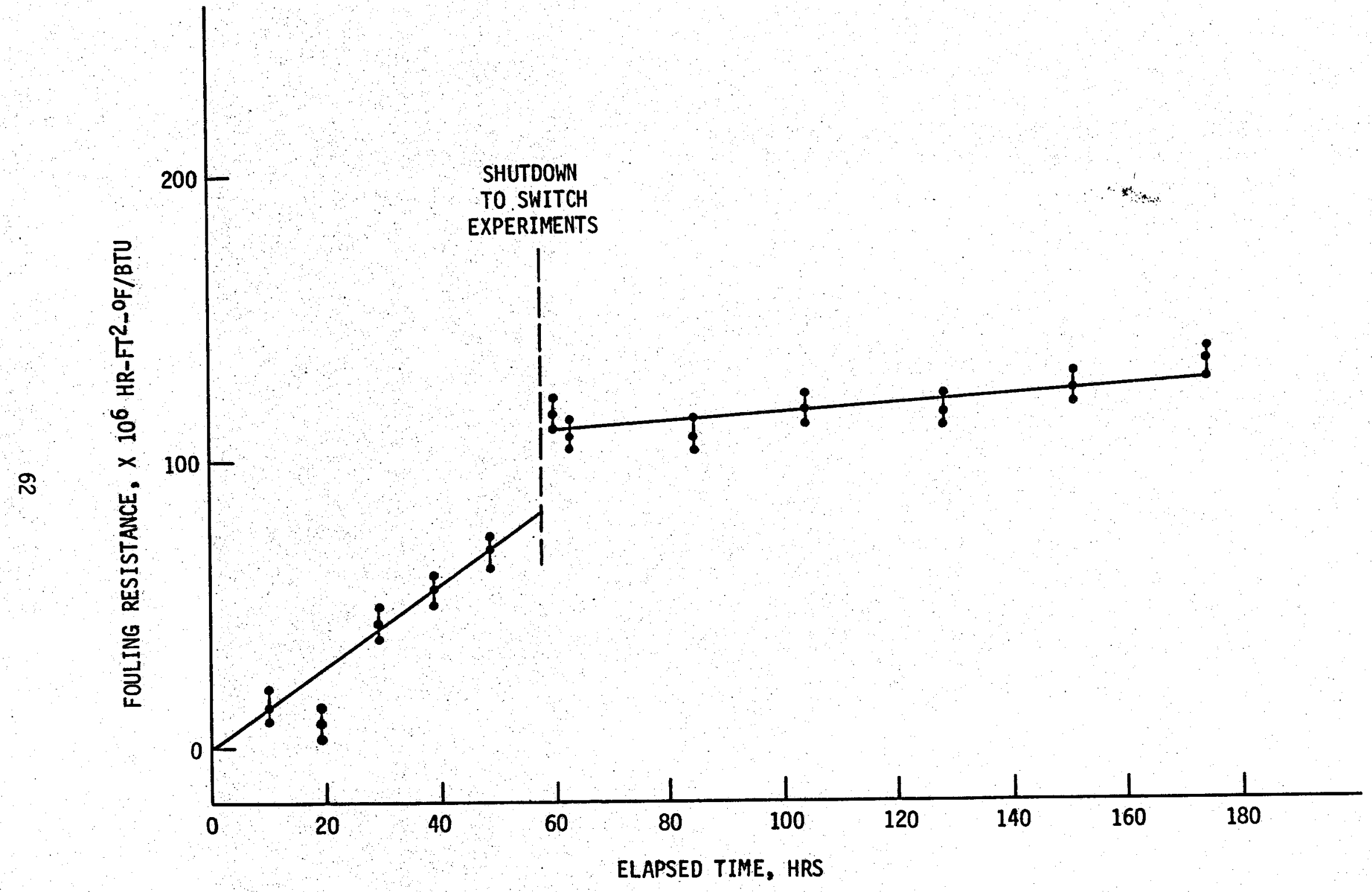

Figure 25. Basel ine Exchanger Tubeside Fouling from Well 6-2 Brine 


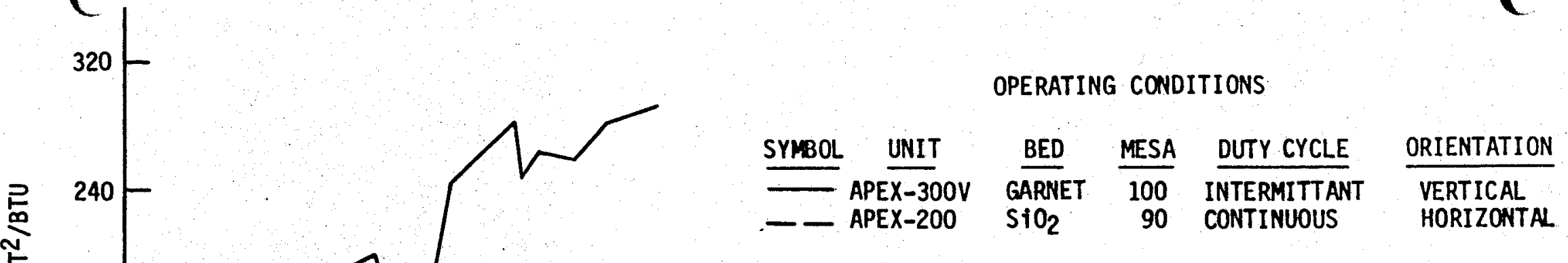

ZIA QD APEX-300V BED RECIRCULATION PERIODS
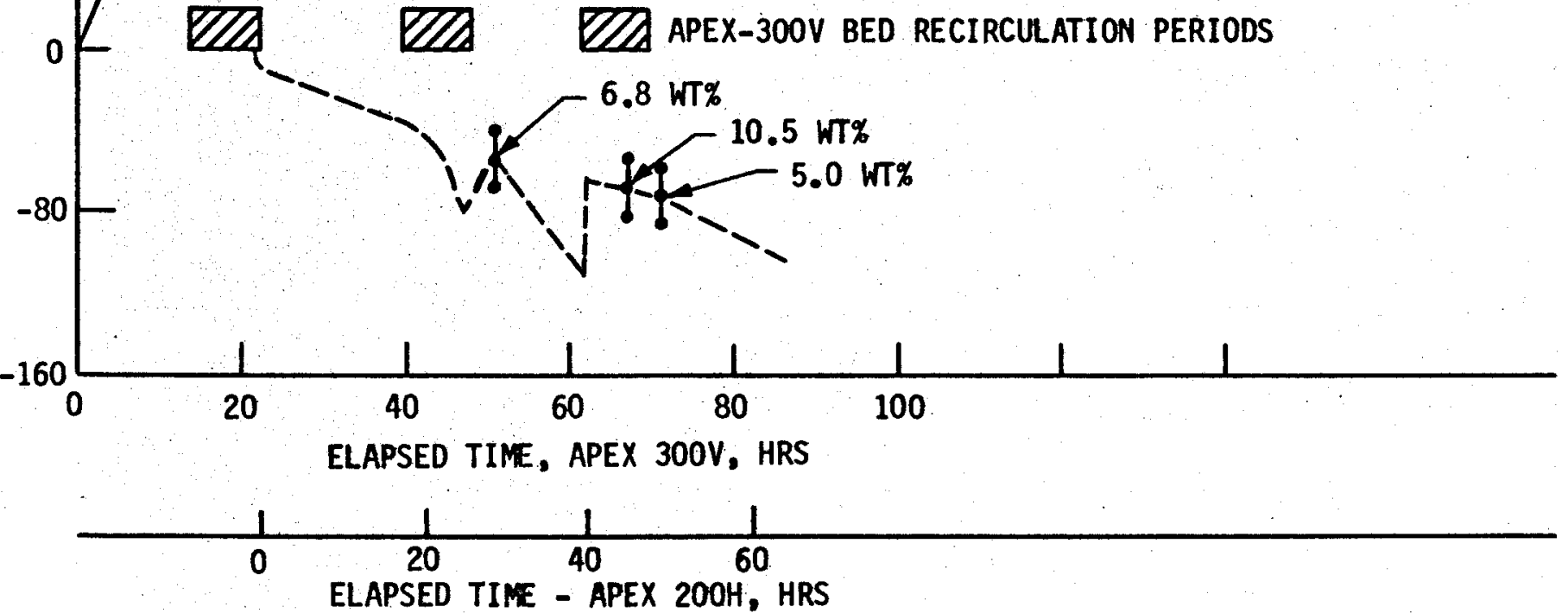

Figure 26. Fouling with Factlity Water with Continuous and Intermittent Solids Recirculation 
4.4, Test Results (cont.)

The periods of bed recirculation on the APEX-300V unit are shown by the solid horizontal bars. The bed was continuously recirculated on APEX-200. A11 the APEX-200 data taken is shown on the plot. Three points are considered to be accurate within $\pm 13.5 \times 10^{-6}$ $\mathrm{hr}-{ }^{\circ} \mathrm{F}-\mathrm{ft}^{2} / \mathrm{BTU}$ because the bed material was sampled and did fall within a reasonably narrow band of concentration. This range has been indicated on the plot for these three points. The other data were taken either without benefit of a sample, or the concentration deviated significantly from the selected band. Therefore, the confidence in the accuracy of these points is somewhat lower.

The significant observations to be made from these data are that fouling occurs at a relatively rapid rate in the APEX-300V unit until the bed material is injected. The bed material essentially prevents further fouling but does not clean the exchanger which is substantially what would be expected based on Group 2 testing. When the bed material is removed, fouling resumes. This establishes the capability of using lower velocities with garnet if the unit is vertical.

The APEX-200 shows a continuous trend toward reduced fouling as the test progresses. This indicates that not only does continuous recirculation prevent the formation of scale from the cooling water, but a scouring action is taking place to gradually remove the residual scale existant in the tubes at the start or clean condition. The effectiveness of the $\mathrm{SiO}_{2}$ bed material in a horizontal orientation is particularly significant in that it suggests that high velocity within the tubes will not be a design criteria which will limit the versatility of the APEX concept.

The exchanger tubes were sectioned and examined at the conclusion of Group 3 tests. Figure 27 shows the post test appearance 


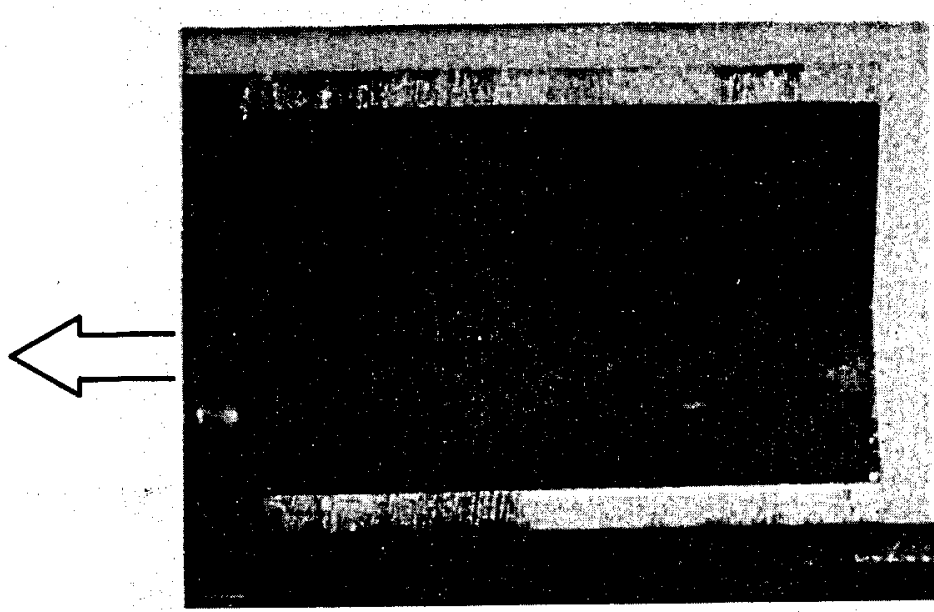

OUTLET, TOP TUBE

요

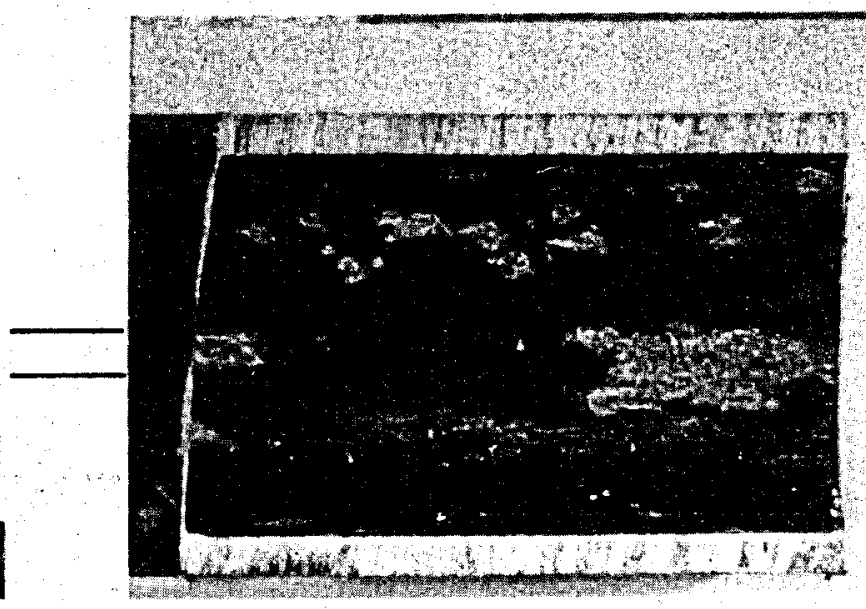

INLET, TOP TUBE

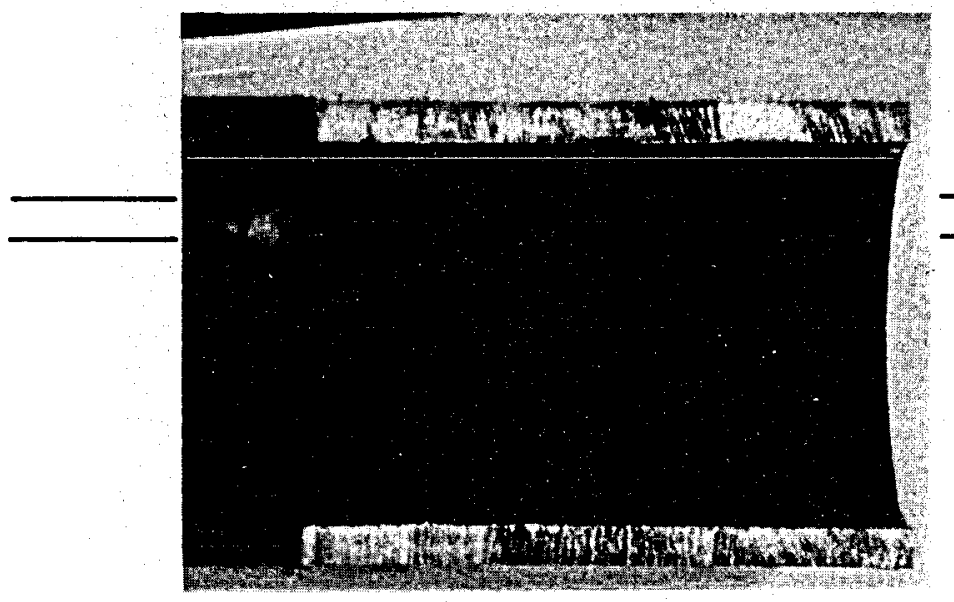

INLET, BOTTOM TUBE

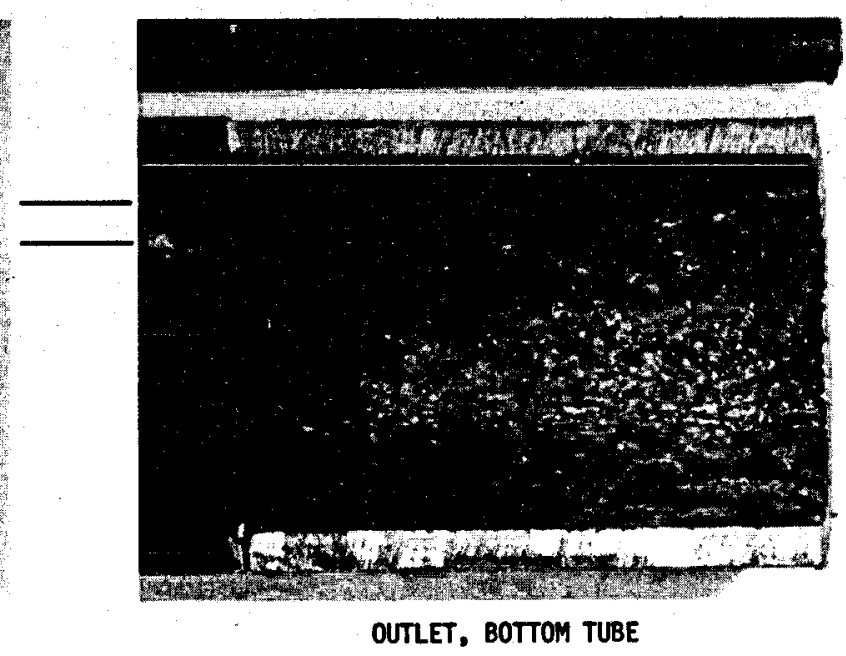

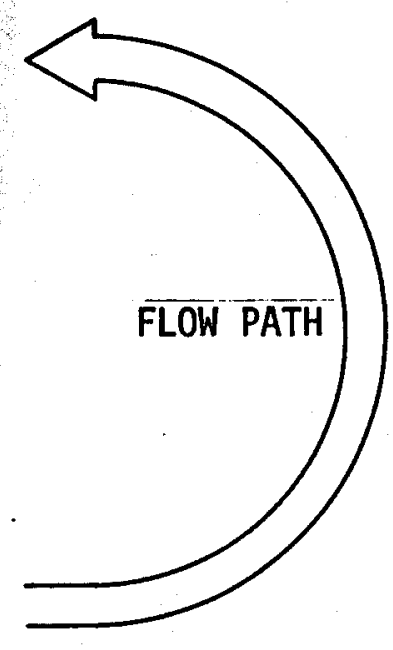

Figure 27. APEX 200 Tube Sections Showing Scaling After Testing with Facility Cooling Water 
4.4, Test Results (cont.)

of the APEX-200 heat exchanger tubes. The APEX-200 heat exchanger tubes were irregularly streaked with scale alternating with clean surfaces around the entire circumference of the tube wall. The scale that was formed between the clean areas of the tube surfaces had a polished, dense appearance. No severe scale depositions were observed on the APEX-200 heat exchanger tubes.

The bed samples from the APEX-200 heat exchanger were analyzed. The results of these chemical and physical analyses are presented in Table III. Sample No. 0 reflects the 90 mesh silica bed unexposed to coolant flow. Samples No. $9,2,3$ and 5 were flow samples collected during three days of continuous testing. These flow samples were collected before bed recharging was performed. After each sample collection, the bed was recharged enough to saturate the system. After two charges, the bed loader was refilled with overflow bed collected in the discharge collection pot. This procedure would tend to dilute the bed and probably, at best, give relative representation of bed history during the test. Iron, aluminum, and calcium were most noticeable among the elements analyzed. A brownish colored coating was visualily observed on the bed particles. Each succeeding test specimen was a darker brown which suggests a buildup in the bed material with time although no evidence of this buildup could be deduced from the particle size analyses. The chemical analysis shows the presence of foreign material suggesting that the operating was sufficient only to fill in surface irregularities. The particle size distribution was found to be nearly the same for all specimens. An average particle size of $144 \mu$ with a deviation of $\pm 4 \mu$ between specimens was deter-. mined. This indicates the bed particles were not being reduced nor becoming larger in size as the test progressed. 
Elemental Composition, \% by Weight

\begin{tabular}{|c|c|c|c|c|c|c|}
\hline Sample No. & $0(0 \mathrm{Hrs})^{*}$ & $\mathrm{I}(2.5 \mathrm{Hrs} .)^{*}$ & $\underline{2(22.5 \mathrm{Hrs} .)^{*}}$ & $3(31.5 \mathrm{Hrs} .)^{*}$ & $4(49.5 \mathrm{Hrs})$ & $5(56.0 \mathrm{Hrs})$. \\
\hline Silicon & 47. \% & 45. \% & 43. $\%$ & $44 . \%$ & 45. \% & 44. \\
\hline Iron & 0.029 & 1.6 & 3.1 & 2.7 & 1.5 & 1.5 \\
\hline Aluminum & 0.0097 & 0.36 & 0.67 & 0.36 & 0.34 & 0.37 \\
\hline Magnes ium & 0.0050 & 0.086 & 0.12 & 0.081 & 0.053 & 0.062 \\
\hline Zirconium & 0.0084 & 0.12 & 0.082 & 0.029 & 0.0085 & 0.0077 \\
\hline Boron & $N D<0.01$ & 0.016 & 0.021 & $T R<0.01$ & $N D<0.01$ & $T R<0.01$ \\
\hline Manganese & $N D<0.003$ & 0.22 & 0.26 & 0.24 & 0.11 & 0.12 \\
\hline Copper & 0.000084 & 0.00013 & 0.00019 & 0.00020 & 0.00021 & 0.00023 \\
\hline Silver & $N D<0.0001$ & 0.00042 & $N D<0.0001$ & $N D<0.0001$ & $N D<0.0001$ & $N D<0.0001$ \\
\hline Titanium & 0.0051 & 0.021 & 0.018 & 0.017 & 0.0092 & 0.0085 \\
\hline Calcium & 0.0012 & 0.062 & 1.0 & 0.34 & 0.64 & 1.1 \\
\hline Yttrium & $N D<0.009$ & 0.050 & 0.037 & $T R<0.009$ & $N D<0.009$ & $N D<0.009$ \\
\hline Chromium & $T R<0.0004$ & 0.0011 & 0.0011 & 0.00064 & $N D<0.0004$ & $N D<0.0004$ \\
\hline Sulphur & 0.010 & 0.010 & 0.007 & 0.012 & 0.009 & 0.009 \\
\hline
\end{tabular}

\section{Partical Mesh Size Distribution, \% by Weight}

\begin{tabular}{|c|c|c|c|c|c|c|}
\hline Sample No. & $\geq 50$ & $\begin{array}{l}50 \text { to } \\
100 \\
\end{array}$ & $\begin{array}{r}100 \text { to } \\
140 \\
\end{array}$ & $\begin{array}{r}140 \text { to } \\
325^{\prime} \\
\end{array}$ & $\begin{array}{r}325 \text { to } \\
400^{\circ} \\
\end{array}$ & $\leq 400$ \\
\hline 0 & 1.4 & 41.6 & 40.2 & 14.3 & 0.2 & 0.1 \\
\hline 1 & 1.4 & 45.9 & 38.3 & 14.2 & 0.2 & 0.05 \\
\hline 2 & 1.1 & 41.5 & 41.6 & 13.4 & 0.1 & 0.05 \\
\hline 3 & 1.2 & 37.9 & 40.7 & 16.2 & 0.4 & 0.1 \\
\hline 4 & 1.3 & 45.7 & 36.6 & 13.4 & 0.2 & 0.1 \\
\hline 5 & 1.4 & 44.6 & 40.6 & 14.1 & 0.6 & 0.3 \\
\hline
\end{tabular}

*Sample collection time indicated is from start of test. 
4.0, Technicat Discussion (cont.)

\subsection{DATA; INTERPRETATION}

\subsubsection{Brine Test Results}

The build up of scale as a result of using well 6-1 brine tubeside of a heat exchanger is 11lustrated by figure 18 . Interruptions of the process apparently caused some of the scale to be redissolved causing the reduction in fouling evidenced in the data as shown in Figure 18. It is significant that after each interruption the baseline exchanger (APEX 100) fouled at approximately the same rate as before. The interruption of the process does not affect the APEX 300 tube that was operated with solids recirculation since it had little or no scale to be removed (Figure 20). Since the basel ine fouling rate was not changed by the interruptions, the APEX 300 data continue to be valid after the interruptions.

Comparison of the data in Figure 18 (no solids recirculation) with the data in Figure 19 (solids recirculated) shows that the APEX approach prevented fouling by removing scale deposed tubeside from Well 6-1 brine. These results were effected with intermittent solids recirculation ( 2 hours per day) using 100 mesh garnet material. Bed densities as low as 1.6 weight percent were effective in scale removal. The less dense and less abrasive $\mathrm{SiO}_{2}$ was also effective in preventing fouling.

The data shown in Figure 19 require some interpretation. The APEX 300 tube exhibited less resistance (negative fouling factor) after the solids were recirculated. The test set up was pressure tested at Sacramento before shipment to East Mesa and was checked out in the field. Apparently this left some residuals in the tubes that was removed along with the brine scale by recirculation of the solids. Thus negative 


\section{5, Data Interpretation (cont.)}

fouling factors would result since the initial overall heat transfer coefficient (which was then used to get the fouling resistance by differencing with subsequently measured overall coefficients) was based on measurements that were made with these residuals apparently present.

There is also a slight increase in the fouling resistance toward the end of the test as shown in Figure 19. The examination of the APEX 300 tubes subsequent to the testing (Figure 21) shows some scaling over the surface of the top half of the horizontal tube and clean surfaces on the bottom half. There is obviously some saltation occurring even at the $10 \mathrm{ft} / \mathrm{sec}$ velocities. The failure to remove the scale fully over all $360^{\circ}$ of the tube perimeter could explain the slight increase in fouling with time.

The assumption that some residuals were present in the tube before testing with the brine raises a question about the scale analysis (TableIII). Some of the elements found in the scale may have been the pretest residuals in the tube. The quantity of residuals, however, should be small compared to the brine scale quantities since the reduction in the APEX 300 tube resistance was small compared to the increase in the APEX 100 tube resistance.

Another possible contribution to the slightly increasing APEX 300 resistance with time could be shell side resistance. The outside of the APEX 300 tube had a thin deposit of carbon on it. The carbon apparently came from the carbon face of the brine pump mechanical seal which was reduced by wear during the test.

There are several observations that impact tube erosion. The weight percent of the bed varied from $7.7 \%$ to $1.6 \%$ solids with the 100 mesh garnet. No significant difference in the effectiveness was observed 


\section{5, Data Interpretation (cont.)}

with bed material weight percent. Also $\mathrm{SiO}_{2}$ was effective in removing scale. The nominal bed recirculation duty cycle was two hours on per day. On two occasions the exchanger was operated 2 days without bed recirculation. In both cases a 2 hour solids recirculation did not reduce the fouling resistance to that which was measured before the two day period. This higher resistance was gradually reduced during subsequent cleaning cycles. This would indicate that the once a day frequency is close to optimum. Low solids weight percent, use of the less abrasive $\mathrm{SiO}_{2}$, and intermittent operation all result in less potential for tube erosion.

Operating times were short compared to the life of a heat exchanger and no obvious signs of mechanical erosion were detected in the sections of the APEX 300 tubes that were examined after the testing. Corrosion caused by scale formation may be much more destructive than mechancial erosion as illustrated in Figure 22. The APEX concept may prolong tube life by preventing the corrosive effects of the scale rather than shortening life due to erosion.

The presence of scale on the top half of the horizontal APEX 300 tube and its absence on the bottom half suggest saltation of the 100 mesh garnet at the $10 \mathrm{ft} / \mathrm{sec}$ velocities. The velocity apparently is not sufficient to prevent stratification. The $10 \mathrm{ft} / \mathrm{sec}$ velocity was based on visual observations made during Phase I of the program in which it was found that $10 \mathrm{ft} / \mathrm{sec}$ provided a uniform distribution. The $10 \mathrm{ft} / \mathrm{sec}$ velocity appears marginal for a 100 mesh garnet bed in a horizontal exchanger. These are, of course, obvious alternatives such as vertical orientation and the use of flow turbulators inside the tubes.

In the group 2 tests the brine from Well 6-2 was run through the baseline heat exchanger to heat the working fluid (clean water) which was in turn used to heat the facility water tubeside as the fouling 


\section{5, Data Interpretation (cont.)}

fluid in the APEX 200 and 300 units. The foul ing rate for the well 6-2 brine changed as shown in Figure 25. This variation in the well 6-2 fouling characteristics is consistent with observations made at East Mesa subsequent to the APEX testing. The variation in fouling was apparently caused by fluctuations in the $\mathrm{CO}_{2}$ content.

\subsubsection{Facility Cooling Water Test Results}

The facility cooling water was used to foul the APEX 200 and 300 tubes by first heating the clean working fluid water in the baseline heat exchanger using the brine from well 6-2 and then using the working fluid to heat the facility cooling water in APEX 200 and 300 . The facility cooling water contains $\mathrm{CaCO}_{3}$ which has retrograde solubility and which therefore scales on heating.

The initial tests with the facility cooling water indicated that the fouling was different than that caused by the brine. The scale appeared to be much more tenacious than that produced by the brine.

As shown in Figures 23 and 24 intermittent recirculation of the solids stops fouling, but does not completely remove the scale; continuous operation prevents fouling, but does not restore the tube to an unfouled condition once fouling has occurred.

There are two possible explanations. 1) Continuous recirculation of the solids material may prevent scaling by providing nucleation sites for deposition of the scale. 2) The toughness of the scale may be age dependent. If this is the case it apparently can be removed as fast as it forms, but cannot be removed if it sets a few hours. 


\section{5, Data Interpretation (cont.)}

Any influence of exchanger orientation on fouling, vertical Figure 24 or horizontal Figure 23, was completely masked by the predominant influence of duty cycle.

The testing with the cooling water as the fouling medium indicates that the more tenacious $\mathrm{CaCO}_{3}$ scale is not readily removed once it has formed and allowed to set a few hours. However, scale formation can be precluded by continuous solids recirculation.

These results were confirmed in the Group 3 testing as shown in Figure 26. In the Group 3 tests the basel ine heat exchanger was again used to heat the working fluid (water). APEX 200 was mounted horizontally and APEX 300, vertically. In Group 2 testing the two heat exchangers were operated sequentially. In the group 3 tests the lower velocity $(6-1 / 2 \mathrm{ft} / \mathrm{sec}$ vs $10 \mathrm{ft} / \mathrm{sec})$ permitted both APEX 200 and 300 to be operated simultaneously. As shown in the data plotted in Figure 27 APEX 200 was brought onstream 22 hours after the APEX 200 unit. $\mathrm{SiO}_{2}$ bed material which is lower in density than the garnet was used in the horizontal APEX 200 unit to avoid stratification. The solids were recirculated continuously in the horizontal unit and garnet bed material was recirculated intermittently in the vertical APEX 300 unit.

The data obtained with APEX 300 confirm the earlier data: intermittent bed recirculation stops fouling while the bed is being recirculated, but does not appreciably reduce the fouling that occurred while the solids were not being recirculated.

The results with continuous solids recirculation confirm earlier results. There is an initial reduction in the fouling factor similar to what was observed with the brine, and continuous solids recirculation prevents fouling. 


\section{5, Data Interpretation (cont.)}

Besides confirmation of earlier results the Group 3 tests provided the additional information that $6-1 / 2 \mathrm{ft} / \mathrm{sec}$ velocities were adequate in the veritical tube orientation with 100 mesh garnet bed material and in the horizontal tube orientation with 90 mesh $\mathrm{SiO}_{2}$.

\subsubsection{APEX Concept}

Figures 18 and 19 clearly indicate the fouling of heat exchanger tubes due to scale from brine flowing tubeside, and the effectiveness of APEX intermittent recirculation of solid bed material in removing scale and thus negating fouling. Figure 26 shows the fouling of heat exchanger tubes due to a $\mathrm{CaCO}_{3}$ scale from facility cooling water flowing tubeside, and the effectiveness of APEX continuous recirculation of solids bed material in preventing scale formation (fouling).

The test data are presented in Figures 28 and 29 as fouling rate data instead of fouling resistance data as was done previously. This was done to permit comparison of the results obtained with no solids recirculation and with various operating conditions (duty cycle, velocity, bed material and bed weight percent).

Application of the fouling rates other than is made in this discussion should be done with caution. The foul ing rates represent the data at the conditions under which the tests were run. Extrapolation to longer times, different wells, or even the same wells at different times could be in error. There are two reasons for this caveat. First fouling rate cannot be expected to be linear with time. Thus, the fouling rate can depend on length of test. All of the data shown in Figures 28 and 29 were based on tests of different duration and all were relatively short in duration compared to heat exchanger operating times. Secondly water chemistry 


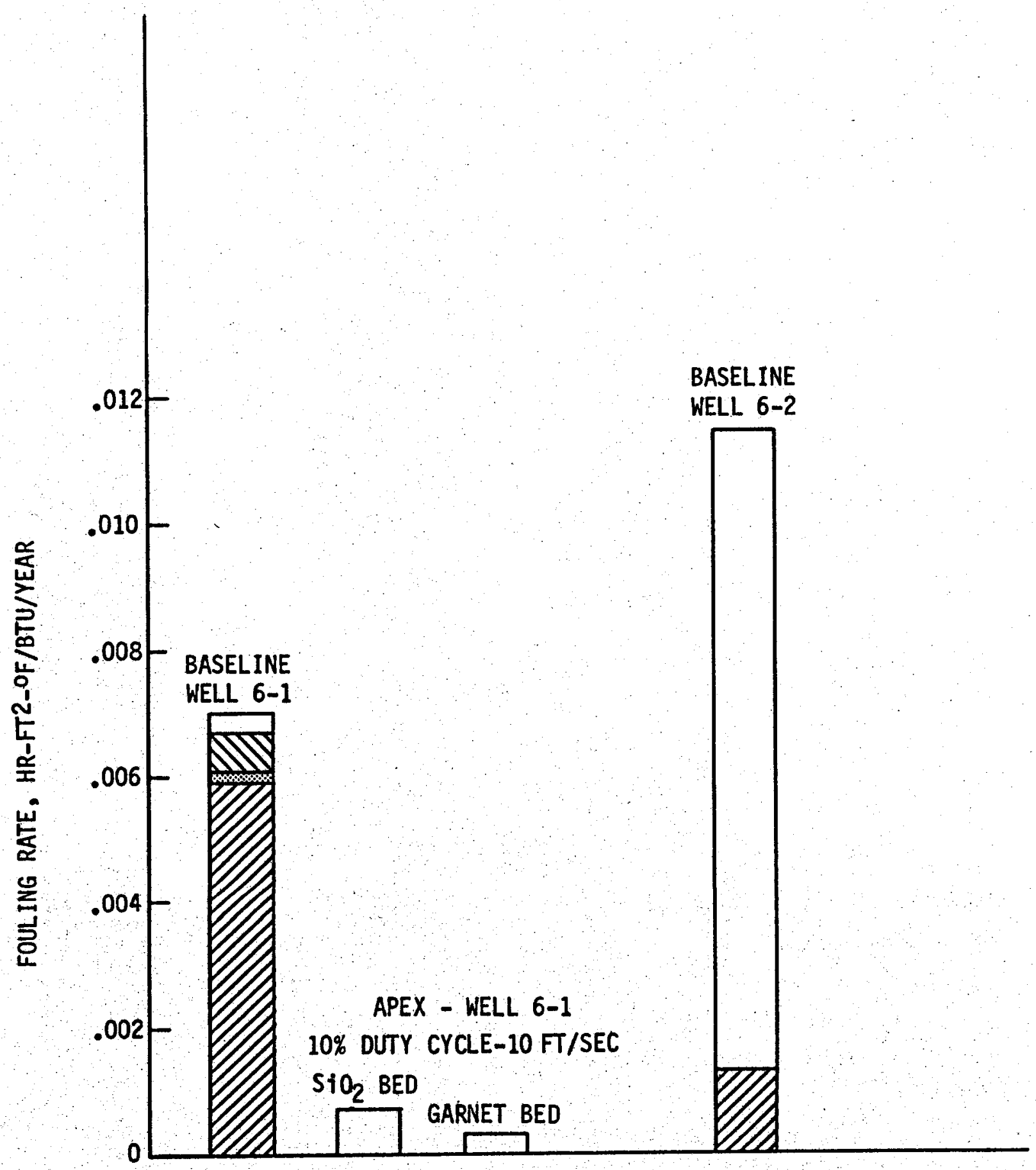

Figure 28. Fouling Rates for East MESA Brimes Unflashed 


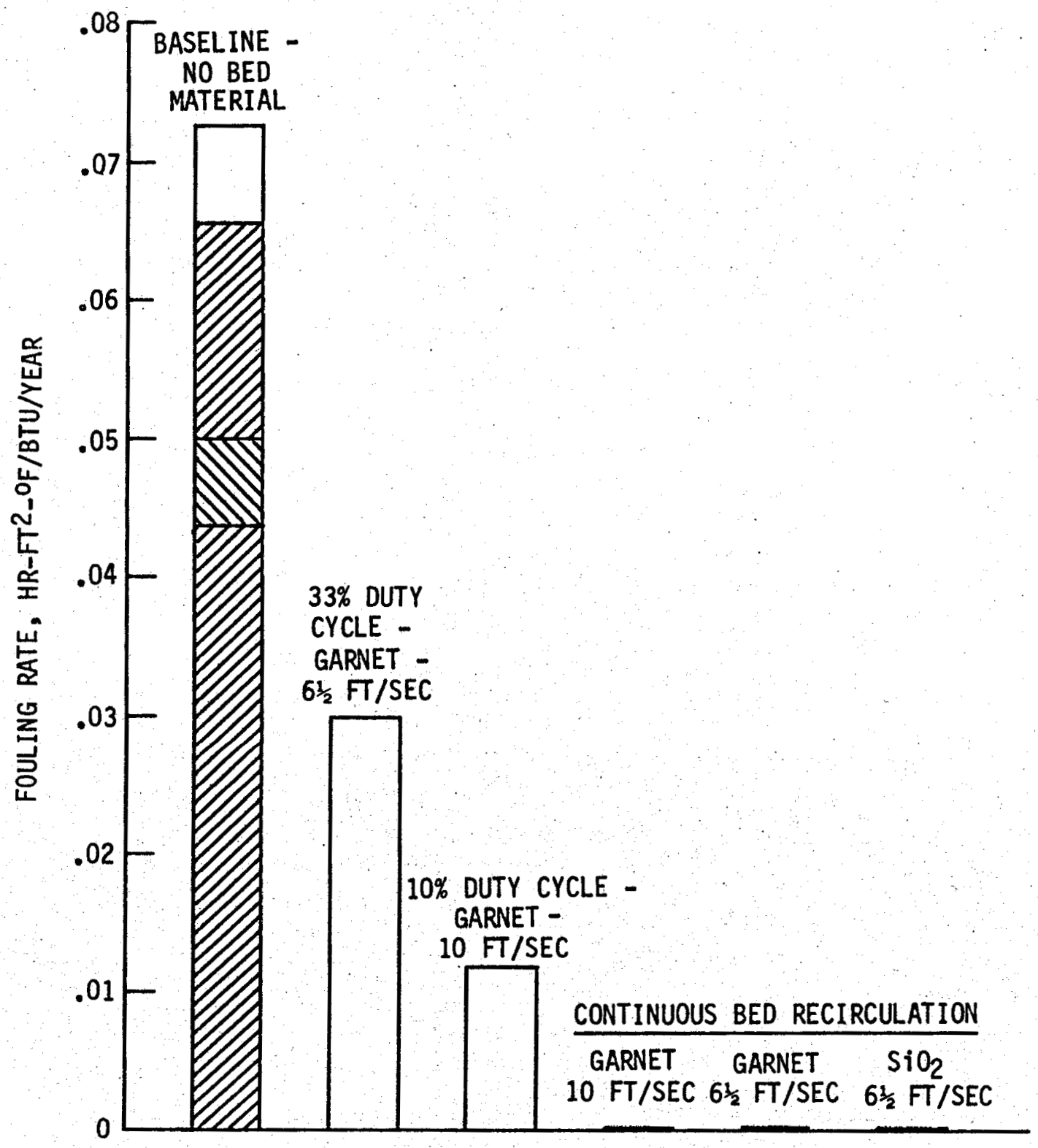

Figure 29. Fouling Rates for East MESA Cooling Water 


\section{5, Data Interpretation (cont.)}

can affect the fouling rate. The brine chemistry changes with $\mathrm{CO}_{2}$ content, and the East Mesa facility water was treated periodicaliy.

It is obvious from the fouling rates that were obtained with the brine from wells $6-1$ and $6-2$ and with the facility cooling water that heat exchangers using these fluids would have to be overdesigned and would require frequent shutdown for scale removal. This was demonstrated by the frequent chemical cleaning required for surfaces of the APEX equipment in contact with the facility cooling water (coolant heat exchanger). The fouling rates for the brine is an order of magnitude less with intermittent bed recirculation as shown in Figure 28 . The garnet material is better than the $\mathrm{SiO}_{2}$.

Intermittent bed recirculation significantly reduced the cooling water fouling rate as shown in Figure 29 , but did not achieve enought reduction to be practical. Higher velocity significantly reduced the fouling rate. However, continuous bed recirculation independent of velcoity $\left(6-1 / 2\right.$ to $10 \mathrm{ft} / \mathrm{sec}$ ) and bed material (garnet and $\mathrm{SiO}_{2}$ ) reduced the fouling rate to zero.

As shown in Figures 28 and 29 the APEX concept was demonstrated to prevent fouling of heat exchanger tubes operating with geothermal brine containing 22,000 PPM* total dissolved solids and facility cooling water containing $\mathrm{CaCO}_{3}$.

\#Verbat communication of well condition at time of testing. 
4.5, Data Interpretation (cont.)

\subsubsection{Economic Implications}

An analysis of the economic practicality of the APEX concept was performed as part of the Phase I final report, Ref. 1. The parameter having the greatest impact on the results of this analysis was the assumed fouling factor. The analysis was based on the assumption of a .003 fouling factor for the conventional exchanger, .0025 tubeside and .0005 shellside. A total fouling factor of .0005 was assumed for the APEX exchanger, all of which was assumed to occur on the shellside. The Phase II results verified the validity of the zero tubeside fouling factor selection for the APEX exchanger. The .0025 fouling factor chosen for the tubeside of the conventional unit was based on an assumed shutdown for cleaning every 6,000 to $7,000 \mathrm{hrs}$ of operation. This then would translate to a yearly fouling rate of about $.0035 \mathrm{hr}-{ }^{\circ} \mathrm{F}-\mathrm{ft}^{2} / \mathrm{BTU}$. Referring to Figure 28 it can be seen that the projected fouling rate of well $6-1$ is about double this value assuming a straight line fouling rate. Therefore, the Phase 1 fouling factor assumptions for the conventional exchanger also appear reasonable with the probable erorr tending toward conservatism, i.e. prediction of a smaller savings with APEX than will actually be realized.

No adverse experiences which would prevent concept application in a full scale power plant were encountered in Phase II; therefore, the verification of the Phase $I$ assumed fouling factors confirms the validity of the Phase I analysis as a minimum for potential savings.

The potential for operation of the concept on a duty cycle basis, while appearing promising, was not established for all operating

Ref. 1. Laboratory Investigation of an Advanced Geothermal Primary Heat Exchanger 9-24-76, SAN/1125-08. 


\section{5, Data Interpretation (cont.)}

conditions. This capability will probably be dependent on the brine characteristics in each discrete field and/or well. If duty cycle operation does prove feasible, a significant savings over that projected in the Phase I analysis will be possible, both in the areas of reduced operating costs and reduced exchanger surface due to increased MTD. The higher MTD will be realized because continuous recirculation of a portion of the brine flow will not be required.

Summarizing the results of the economic analysis, a savings of $\$ 300,000$ per year, or $1.34 \mathrm{mills} / \mathrm{kwh}$ was predicted if the APEX concept were employed rather than a conventional exchanger in a $30 \mathrm{MW}$ unflashed binary system power plant. The Phase II results indicate this figure is a minimum savings to be anticipated with a potential for significantly greater savings.

The potential savings in operating costs accruing from duty cycle operation include reduced pumping costs and reduced maintenance on the solids separation and recirculation system. These savings, assuming a 10 percent duty cycle, amount to $\$ 23,000$ per year, or an $8 \%$ increase over the $\$ 300,000$ savings predicted in the Phase $I$ analysis.

The larger MTD during the off period of the duty cycle can produce an additional savings. The exchanger cost can be reduced by $\$ 50,000$ which, when converted to an annual basis, amounts to an additional $\$ 9,000$ per year savings. To capitalize on this reduced exchanger surface savings, it would be necessary to schedule the on cycle of the APEX concept during periods of reduced plant power output since the lower MTD still exists while the bed material is recirculating. 
APPENDIX A

CHEMICAL ANALYSIS OF EAST MESA GEOTHERMAL

WELL 6-1 AND 6-2 BRINES*

*Reference: Lawrence Berkeley Laboratory Analysis 


\section{Mesa 6-1 \\ Wellhead Unflashed \\ 6-9-76 0930}

Chloride $\left(\mathrm{Cl}^{-}\right)$

Sulfide $\left(s^{=}\right)$

Conductivity (at $25^{\circ} \mathrm{C}$ )

Silica $\left(\mathrm{SiO}_{2}\right)$

pH

Total Dissolved Sol ids (TDS)

Titanium (Ti)

Iron (Fe)

Lithium (Li)

Potassium (K)

Copper (CU)

Magnesium (Mg)

Molybdenum (Mo)

Zinc ( $Z n)$

Manganese (Mn)

Nickel (Ni)

Barium (Ba)

Bicarbonates $\left(\mathrm{HCO}_{3}^{-}\right)$

Carbonates $\left(\mathrm{CO}_{3}\right)$

Sulfate $\left(\mathrm{SO}_{4}\right)$

Fluoride ( $F$ )

Nitrate $\left(\mathrm{NO}_{3}^{-}\right)$

Phosphate $\left(\mathrm{PO}_{4}\right)$ Total

Cadmium (Cd)

Ammonia $\left(\mathrm{NH}_{4}\right)$

Beryllium (Be)

Cesium (Ce)
$15,850 \mathrm{mg} / 1$

$3.0 \mathrm{mg} / 1$

40,000 umhos

$320 \mathrm{mg} / 1$

5.45

$26,300 \mathrm{mg} / 1$

$<0.10 \mathrm{mg} / 1$

$8.8 \mathrm{mg} / 1$

$40.0 \mathrm{mg} / 1$

$1,050 \mathrm{mg} / 1$

$<0.10 \mathrm{mg} / 1$

$17.2 \mathrm{mg} / 1$

$<0.005 \mathrm{mg} / 1$

$0.07 \mathrm{mg} / 1$

$0.95 \mathrm{mg} / 1$

$0.10 \mathrm{mg} / 1$

$14 \mathrm{mg} / 1$

$202 \mathrm{mg} / \mathrm{T}$

$0.0 \mathrm{mg} / 1$

$42.8 \mathrm{mg} / 1$

$0.99 \mathrm{mg} / 1$

TRACE, less than $0.02 \mathrm{mg} / 1$

N.D., Less than $0.01 \mathrm{mg} / 1$

N.D., Less than $0.01 \mathrm{mg} / 1$

$40.75 \mathrm{mg} / 1$

N.D., Less than $0.02 \mathrm{mg} / 1$

$2.75 \mathrm{mg} / 1$

N.D. $=$ None Detected

$<=$ Less Than 


\section{Mesa 6-1 \\ Wellhead Unflashed (cont.) \\ 6-9-76 0930}

\begin{tabular}{|c|c|c|c|}
\hline Bismuth (Bi) & $3 \mathrm{mg} / 1$ & & \\
\hline Mercury $(\mathrm{Hg})$ & N.D., Tess & than & $01002 \mathrm{mg} / 1$ \\
\hline Arsenic (As) & $0.26 \mathrm{mg} / 1$ & & \\
\hline Selenium ( $\mathrm{Se}$ ) & N.D., Less & than & $0.1 \mathrm{mg} / 1$ \\
\hline Antimony (Sb) & $5.5 \mathrm{mg} / 1$ & & . \\
\hline Tantalum (Ta) & $0.14 \mathrm{mg} / 1$ & & \\
\hline Niobium (Nb) & $0.40 \mathrm{mg} / 1$ & & \\
\hline Sodium (Na) & $8,100 \mathrm{mg} / 1$ & & \\
\hline Calcium $(\mathrm{Ca})$ & $1,360 \mathrm{mg} / 1$ & & \\
\hline Strontium (Sr) & $320 \mathrm{mg} / 1$ & & \\
\hline Germanium (Ge) & N.D., Less & than & $0.1 \mathrm{mg} / \mathrm{l}$ \\
\hline Indium (In) & N.D:, Less & than & $0.1 \mathrm{mg} / 1$ \\
\hline Gold $(\mathrm{Au})$ & N.D., Less & than & $0.01 \mathrm{mg} / 1$ \\
\hline Palladium (Pd) & N.D., Less & than & $0.1 \mathrm{mg} / 1$ \\
\hline Platinum $(P t)$ & N.D., Less & than & $0.1 \mathrm{mg} / 1$ \\
\hline Cobalt (Co) & $0.06 \mathrm{mg} / 1$ & & \\
\hline Iridium (Ir) & N.D., Less & than & $0.1 \mathrm{mg} / 1$ \\
\hline Tungsten (W) & N.D., Less & than & $0.1 \mathrm{mg} / 1$ \\
\hline Aluminum $(A 1)$ & $0.04 \mathrm{mg} / \mathrm{l}$ & & \\
\hline Boron (B) & $9.75 \mathrm{mg} / 7$ & & \\
\hline Chromium (Cr) & N.D., Less & than & $0.7 \mathrm{mg} / 1$ \\
\hline
\end{tabular}




\section{Mesa 6-2 \\ Wellhead Unflashed \\ 6-3-76 1430}

Chloride $\left(\mathrm{Cl}^{-}\right)$

Sulfide $(s)$

Conductivity (at $25^{\circ} \mathrm{C}$ )

Silica $\left(\mathrm{SiO}_{2}\right)$

$\mathrm{pH}$

Total Dissolved Solids (TDS)

Titanium (Ti)

Iron ( $\mathrm{Fe}$ )

Lithium (Li)

Potassium (K)

Copper (Cu)

Magnesium (Mg)

Molybedenum (Mo)

Zinc (Zn)

Manganese (Mn)

Nickel (Ni)

Barium (Ba)

Bicarbonates $\left(\mathrm{HCO}_{3}^{-}\right)$

Carbonates $\left(\mathrm{CO}_{3}^{=}\right)$

Sulfate $\left(\mathrm{SO}_{4}\right)$

Fluoride (F)

Nitrate $\left(\mathrm{NO}_{3}^{-}\right)$

Phosphate $\left(\mathrm{PO}_{4}\right)$ Total

Cadmium (Cd)

Ammonia $\left(\mathrm{NH}_{4}\right)$

Beryllium (Be)

Cesium (Ce)

Bismuth (Bi)
$2,142 \mathrm{mg} / 1$

$1.5 \mathrm{mg} / 1$

6,000 umhos

$269 \mathrm{mg} / 1$

6.12

$5,000 \mathrm{mg} / 1$

$<0.10 \mathrm{mg} / 1$

$<0.10 \mathrm{mg} / 1$

$4.0 \mathrm{mg} / 1$

$150 \mathrm{mg} / 1$

$<0.10 \mathrm{mg} / 1$

$0.24 \mathrm{mg} / 1$

$<0.005 \mathrm{mg} / 1$

$<0.01 \mathrm{mg} / 1$

$0.05 \mathrm{mg} / 1$

$<0.10 \mathrm{mg} / 1$

$0.25 \mathrm{mg} / 1$

$560 \mathrm{mg} / 1$

0.0

$156 \mathrm{mg} / 1$

$1.23 \mathrm{mg} / 1$

$0.1 \mathrm{mg} / 1$

Less than $0.2 \mathrm{mg} / 1$

N.D., Less than $0.01 \mathrm{mg} / 1$

$14.7 \mathrm{mg} / 1$

N.D., Less than $0.02 \mathrm{mg} / 1$

$0.38 \mathrm{mg} / 1$

N.D., Less than $0.005 \mathrm{mg} / 1$ 


\section{Mesa 6-2 \\ Wellhead Unflashed (cont.) \\ 6-3-76 1430}

Mercury $(\mathrm{Hg})$

Arsenic (As)

Selenium (Se)

Antimony (Sb)

Tantalum (Ta)

Niobium (Nb)

Sodium (Na)

Calcium (Ca)

Strontium (Sr)

Germanium (Ge)

Indium (In)

Gold (Au)

Palladium (Pd)

Platinum (Pt)

Cobait (Co)

Iridium (Ir)

Tungsten (W)

Aluminum (A1)

Boron (B)

Chromium (Cr)
N.D., Less than $0.002 \mathrm{mg} / 1$

$0.22 \mathrm{mg} / 1$

N.D., Less than $0.1 \mathrm{mg} / 1$

$0.90 \mathrm{mg} / 1$

$0.17 \mathrm{mg} / 1$

$0.40 \mathrm{mg} / 1$

$1,700 \mathrm{mg} / 1$

$16.4 \mathrm{mg} / 1$

$6.4 \mathrm{mg} / 1$

N.D., Less than $0.1 \mathrm{mg} / 1$

N.D., Less than $0.1 \mathrm{mg} / 1$

N.D., Less than $0.01 \mathrm{mg} / 1$

N.D., Less than $0.1 \mathrm{mg} / 1$

N.D., Less than $0.1 \mathrm{mg} / 1$

N.D., Less than $.01 \mathrm{mg} / 1$

N.D., Less than $0.1 \mathrm{mg} / 1$

N.D., Less than $0.1 \mathrm{mg} / 1$

$0.03 \mathrm{mg} / 1$

$7.45 \mathrm{mg} / 1$

N.D., Less than $0.01 \mathrm{mg} / \mathrm{l}$ 
Mesa 8-1

Well head Unflashed

6-22-76 0910

Chrloride $\left(\mathrm{Cl}^{-}\right)$

sulfide $\left(S^{=}\right)$

Conductivity (at $25^{\circ} \mathrm{C}$ )

Silica $\left(\mathrm{SiO}_{2}\right)$

$\mathrm{pH}$

Total Dissolved Solids (TDS)

Titanium (Ti)

Iron ( $\mathrm{Fe})$

Lithium (Li)

Potassium (K)

Copper (Cu)

Magnesium (Mg)

Molybdenum (Mo)

Zinc ( $Z n$ )

Manganese (Mn)

Nickel (Ni)

Barium (Ba)

Bicarbonate $\left(\mathrm{HCO}_{3}^{-}\right)$

Carbonates $\left(\mathrm{CO}_{3}=\right.$

Sulfate $\left(\mathrm{SO}_{4}^{2}\right)$

Fluoride $(F)$

Nitrate $\left(\mathrm{NO}_{3}^{-}\right)$

Phosphate $\left(\mathrm{PO}_{4}\right)$

Cadmium (Cd)

Ammonia $\left(\mathrm{NH}_{4}\right)$

Beryllium (Be)

Cesium (Ce)

Bismuth (Bi)

Mercury $(\mathrm{Hg})$
$500 \mathrm{mg} / 1$

$1.0 \mathrm{mg} / 1$

3,200 umhos

$389 \mathrm{mg} / 1$

6.27

$1,600 \mathrm{mg} / 1$

$<0.10 \mathrm{mg} / 1$

$<0.10 \mathrm{mg} / 1$

$1.1 \mathrm{mg} / 1$

$70 \mathrm{mg} / 1$

$<0.10 \mathrm{mg} / 1$

$<0.05 \mathrm{mg} / 1$

$<0.005 \mathrm{mg} / 1$

$<0.01 \mathrm{mg} / 1$

$<0.05 \mathrm{mg} / 1$

$<0.10 \mathrm{mg} / 1$

$0.15 \mathrm{mg} / 1$

$417 \mathrm{mg} / 1$

$0.0 \mathrm{mg} / 1$

$173 \mathrm{mg} / 1$

$1.60 \mathrm{mg} / \mathrm{l}$

$0.34 \mathrm{mg} / 7$

N.D., $<0.1 \mathrm{mg} / 1$

TRACE, $<0.01 \mathrm{mg} / 1$

$4.95 \mathrm{mg} /$

N.D., $<0.02 \mathrm{mg} / 1$

$0.14 \mathrm{mg} / 1$

N.D., $<0.005 \mathrm{mg} / 1$

$0.014 \mathrm{mg} / 1$ 


\section{Mesa 8-1 \\ Wel lhead Unflashed (cont.) \\ 6-22-76 0910}

Arsenic (As)

Selenium (Se)

Antimony (Sb)

Tantalum ( $\mathrm{Ta}$ )

Niobium (Nb)

Sodium (Na)

Calcium (Ca)

Strontium (Sr)

Germanium (Ge)

Indium (In)

Gold (Au)

Paladium (Pd)

Platinum ( $P t$ )

Cobalt (Co)

Iridium (Ir)

Tungsten (W)

Aluminum (AT)

Boron (B)

Chromium (Cr)
$0.053 \mathrm{mg} / 1$

$0.5 \mathrm{mg} / 1$

$1.2 \mathrm{mg} / 1$

$0.12 \mathrm{mg} / 1$

$0.40 \mathrm{mg} / 1$

$610 \mathrm{mg} / 1$

$8.5 \mathrm{mg} / 1$

$2.1 \mathrm{mg} / 1$

N.D., $<0.1 \mathrm{mg} / 1$

N.D., $<0.1 \mathrm{mg} / 1$

$0.024 \mathrm{mg} / 1$

N.D., $<0.1 \mathrm{mg} / 1$

N.D., $<0.1 \mathrm{mg} / 1$

N.D., $<0.01 \mathrm{mg} / 1$

N.D., $<0.1 \mathrm{mg} / 1$

N.D., $<0.1 \mathrm{mg} / 1$

$0.02 \mathrm{mg} / 1$

$1.60 \mathrm{mg} / 1$

N.D., $<0.01 \mathrm{mg} / 1$ 


\section{Mesa 31-1 \\ Wellhead Unflashed \\ 6-18-76 0830}

Choloride $\left(\mathrm{Cl}^{-}\right)$

Sulfide $\left(S^{=}\right)$

Conductivity (at $25^{\circ} \mathrm{C}$ )

silica $\left(\mathrm{SiO}_{2}\right)$

$\mathrm{pH}$

Total Dissolved Solids (TDS)

Titanium (Ti)

Iron (Fe)

Lithium (Li)

Potassium (K)

Copper (Cu)

Magnesium (Mg)

Molybdenum (Mo)

Zinc ( $\mathrm{Zn}$ )

Manganese (Mn)

Nickel (Ni)

Barium (Ba)

Bicarbonates $\left(\mathrm{HCO}_{3}^{-}\right)$

Carbonates $\left(\mathrm{CO}_{3}^{-}\right)$

Sulfate $\left(\mathrm{SO}_{4}^{-}\right)$

Fluoride (F)

Nitrate $\left(\mathrm{NO}_{3}^{-}\right)$

Phosphate $\left(\mathrm{PO}_{4}\right)$

Cadmium (Cd)

Ammonia $\left(\mathrm{NH}_{4}\right)$

Beryllium (Be)

Bismuth ( $\mathrm{Bi}$ )

Arsenic (As)
$510 \mathrm{mg} / 1$

$0.3 \mathrm{mg} / 1$

4,700 umhos

$274 \mathrm{mg} / 1$

6.27

$2,900 \mathrm{mg} / 1$

$<0.10 \mathrm{mg} / 1$

$<0.10 \mathrm{mg} / 1$

$0.60 \mathrm{mg} / 1$

$85 \mathrm{mg} / 1$

$<0.10 \mathrm{mg} / 1$

$<0.05 \mathrm{mg} / 1$

$<0.005 \mathrm{mg} / 1$

$<0.01 \mathrm{mg} / 1$

$<0.05 \mathrm{mg} / 1$

$<0.10 \mathrm{mg} / 1$

$0.15 \mathrm{mg} / \mathrm{l}$

$845 \mathrm{mg} / 1$

$0.0 \mathrm{mg} / 1$

$183 \mathrm{mg} / 1$

$1.42 \mathrm{mg} / 1$

$0.43 \mathrm{mg} / \mathrm{l}$

N.D., $<0.1 \mathrm{mg} / 1$

$0.02 \mathrm{mg} / 1$

$2.45 \mathrm{mg} / 1$

$<0.01 \mathrm{mg} / 1$

N.D., $<0.005 \mathrm{mg} / 1$

$0.025 \mathrm{mg} / 1$ 


\section{Mesa 31-1 \\ Wellhead Unflashed (cont.) \\ $6-18-76 \quad 0830$}

\begin{tabular}{|c|c|}
\hline Selenium (Se) & $1.8 \mathrm{mg} / 1$ \\
\hline Antimony (Sb) & $1.0 \mathrm{mg} / 1$ \\
\hline Tantalum (Ta) & $0.10 \mathrm{mg} / 1$ \\
\hline Niobium (Nb) & $0.40 \mathrm{mg} / \mathrm{T}$ \\
\hline Sodium $(\mathrm{Na})$ & $730 \mathrm{mg} / 1$ \\
\hline Calcium (Ca) & $8.9 \mathrm{mg} / 1$ \\
\hline Strontium (Sr) & $1.4 \mathrm{mg} / 1$ \\
\hline Germanium (Ge) & N.D., $<0.1 \mathrm{mg} / 1$ \\
\hline Indium (In) & N.D.,$<0.1 \mathrm{mg} / 1$ \\
\hline Gold $(A u)$ & $0.080 \mathrm{mg} / 1$ \\
\hline Paladium $(P d)$ & N.D., < <. $1 \mathrm{mg} / 1$ \\
\hline Cobalt (Co) & N.D., $<0.01 \mathrm{mg} / 1$ \\
\hline Iridium (Ir) & N.D. , <0.1 mg/T \\
\hline Tungsten $(W)$ & N.D.,$<0.1 \mathrm{mg} / 1$ \\
\hline Aluminum (A1) & $0.02 \mathrm{mg} / 1$ \\
\hline Boron (B) & $2.50 \mathrm{mg} / 1$ \\
\hline Chromium $(\mathrm{Cr})$ & $N . D_{,},<0.01 \mathrm{mg} / 1$ \\
\hline Cesium (Ce) & $0.20 \mathrm{mg} / 1$ \\
\hline Platinum $(\mathrm{Pt})$ & N.D., $<0.1 \mathrm{mg} / \mathrm{l}$ \\
\hline
\end{tabular}




\section{APPENDIX B}

\section{TABULATION OF REDUCED DATA FROM}

GROUP 1 TESTS 
This appendix shows a tabulation of the reduced data from the group 1 tests and describes the techniques, assumptions, and formulas used to arrive at a tubeside fouling resistance for each data time.

Table B-I and B-II summarize the reduced thermal data for APEX 100 and 300 , respectively. The first columns are the sample point data and time. Column three indicates the number of hours the experiment was on-stream on that particular day, and in the case of APEX-300, the time period the bed was recirculated and the average bed composition. The next column indicates the cumulative time on-stream for that data point.

The flowrates are shown in the next columns. The coolant flowrate and brine supply flowrates were calculated from the measured volumetric flowrate and converted to $\mathrm{lb} / \mathrm{hr}$. This conversion was made for the brine, assuming the same density that would be measured if the total dissolved solids were made up exclusively of $\mathrm{NaCl}$.

The brine recirculation flowrate was calculated from an energy balance around the sand injector. The brine inlet, exit, and recirculation temperatures were measured, as well as the brine supply flowrate. The recirculation flowrate is inversely proportioned to the temprature differences measured if the minor changes in specific heat with temperature are ignored.

$$
\text { Brine Recirculation }=\text { Brine Supply } \times \frac{T_{\text {brine }}{ }^{\text {in }}-T_{\text {brine }}{ }^{\text {mix. }}}{\text { brine }^{\text {mix }}-T_{\text {brine }}{ }^{\text {recirc. }}}
$$

The brine recirculation flowrate calculated is seen to vary from data point to data point over a range of roughly 400 to $800 \mathrm{lb} / \mathrm{hr}$. Since the operating conditions were essentially unchanged for each data point, it is unreasonable to expect such a wide variation in recirculation flowrates. The variation. is probably due to the relatively small temperature differences measured and the inability to measure these temperatures simultaneously. An average constant recirculation rate of $600 \mathrm{lb} / \mathrm{hr}$ was assumed in calculating the 
TABLE B-I

REDUCED DATA APEX 100

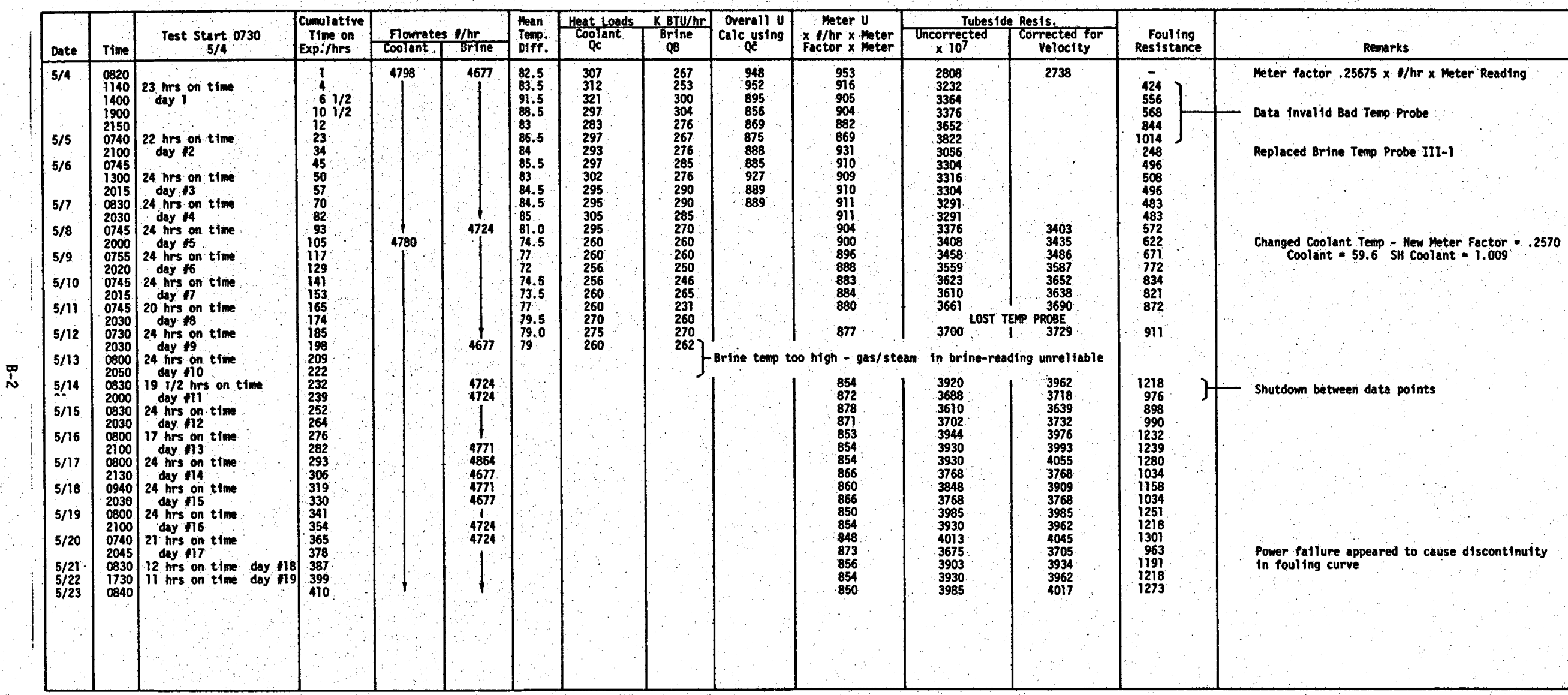


TABLE B-II

REDUCED DATA APEX 300

\begin{tabular}{|c|c|c|c|c|c|c|c|c|c|c|c|c|c|c|c|c|c|c|}
\hline \multirow[b]{2}{*}{ Date } & \multirow[b]{2}{*}{$T i m e$} & \multirow{2}{*}{$\begin{array}{l}\text { Experiment } \\
\text { Cycle } 2 \mathrm{hrs} / 24 \\
\text { nom }\end{array}$} & \multirow{2}{*}{ Stimul. } & \multirow{2}{*}{$\begin{array}{l}\text { net } \\
\text { Bed at } \\
\text { outa Trim }\end{array}$} & \multicolumn{2}{|c|}{ Flowrates-e/1b } & \multirow{2}{*}{$\left.\right|_{\text {Recire }} ^{\mathrm{Brne}}$} & \multirow{2}{*}{$\begin{array}{l}\text { romal } \\
\text { orine }\end{array}$} & \multirow{2}{*}{$\begin{array}{l}\text { mear } \\
\text { Temp. } \\
\text { oiff. }\end{array}$} & \multirow{2}{*}{\multicolumn{2}{|c|}{$\begin{array}{l}\text { Heat Load } \\
\text { Coolant }\end{array}$}} & \multirow{2}{*}{$\begin{array}{l}\text { Overell u } \\
\text { Using } \\
\text { coolant Loid }\end{array}$} & \multirow{2}{*}{$\begin{array}{c}\text { Overall } u \\
\text { Noter } x \\
\text { ofhr } \times .2568 \times 10^{-3} \times 1\end{array}$} & \multicolumn{2}{|c|}{$\begin{array}{l}\text { Tubes sde coof. } \\
\text { Corrected }\end{array}$} & \multirow{2}{*}{$\begin{array}{c}\text { Foulling } \\
\text { Resistance }\end{array}$} & \multirow[b]{2}{*}{ Remarks } & \multirow{2}{*}{$\begin{array}{c}\text { Foulling } \\
\text { Constant Recirc. }\end{array}$} \\
\hline & & & & & coolant & Suppiy & & & & & & & & Uncorrected & $\begin{array}{l}\text { velocity Brine } \\
\text { ver tor }\end{array}$ & & & \\
\hline $\begin{array}{l}5 / 4 \\
5 / 5 \\
5 / 6 \\
5 / 7 \\
5 / 8 \\
5 / 9 \\
5 / 10 \\
5 / 11 \\
5 / 12 \\
5 / 13 \\
5 / 14 \\
5 / 15 \\
5 / 16 \\
5 / 17\end{array}$ & 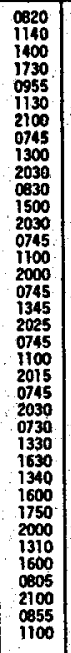 & 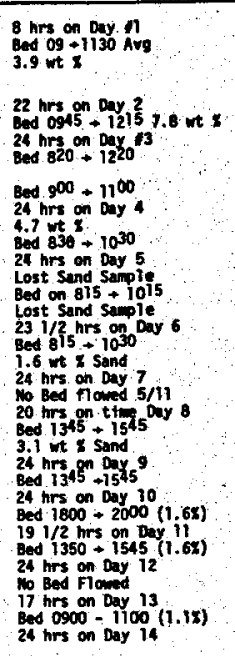 & 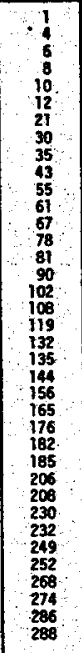 & 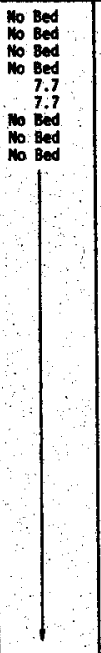 & 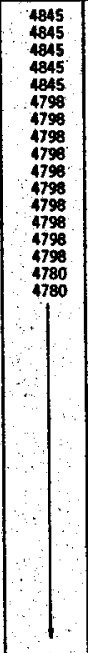 & $\begin{array}{r}4302 \\
4302 \\
4349 \\
4349 \\
4302 \\
4302 \\
4302 \\
4302 \\
1 \\
4349 \\
3449 \\
3449 \\
4349 \\
4302 \\
4349 \\
44 \\
4\end{array}$ & 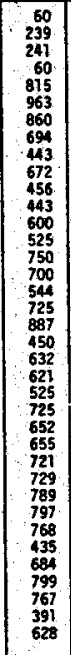 & 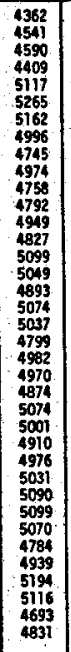 & 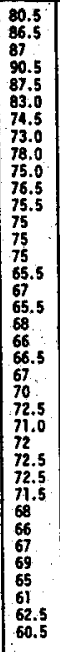 & 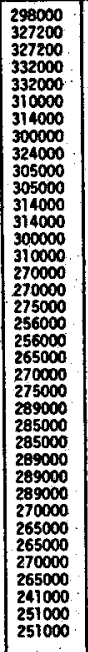 & 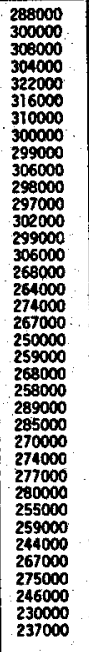 & $\begin{array}{c}943 \\
964 \\
954 \\
934 \\
966 \\
950 \\
1053 \\
1046 \\
1058 \\
1036 \\
1014\end{array}$ & $\begin{array}{l}993 \\
983 \\
.962 \\
943 \\
977 \\
967 \\
1067 \\
1041 \\
1060 \\
1053 \\
1041 \\
1061 \\
1059 \\
1046 \\
1059 \\
1054 \\
1039 \\
1056 \\
1050 \\
1037 \\
1053 \\
1049 \\
1042 \\
1036 \\
1025 \\
1020 \\
1041 \\
1025 \\
1047 \\
1042 \\
1050 \\
1025 \\
.1050 \\
1037 \\
1020 \\
1007 \\
1036\end{array}$ & 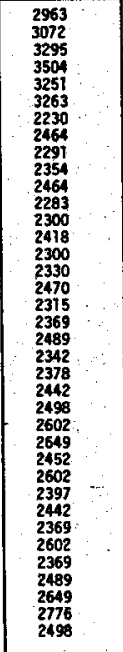 & 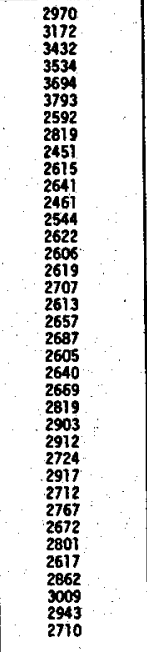 & 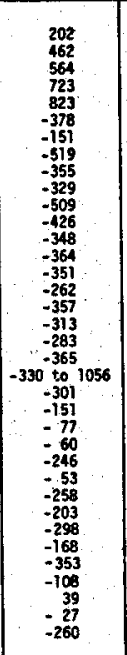 & 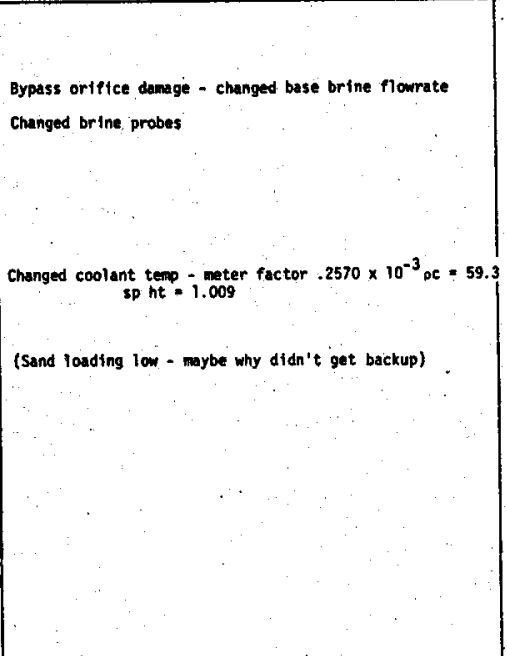 & 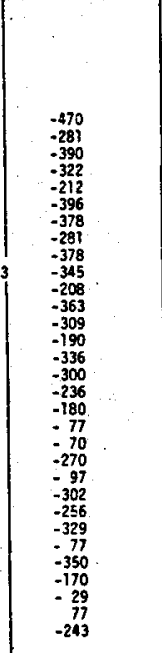 \\
\hline
\end{tabular}


TABLE B-II (cont.)

REDUCED DATA APEX 300

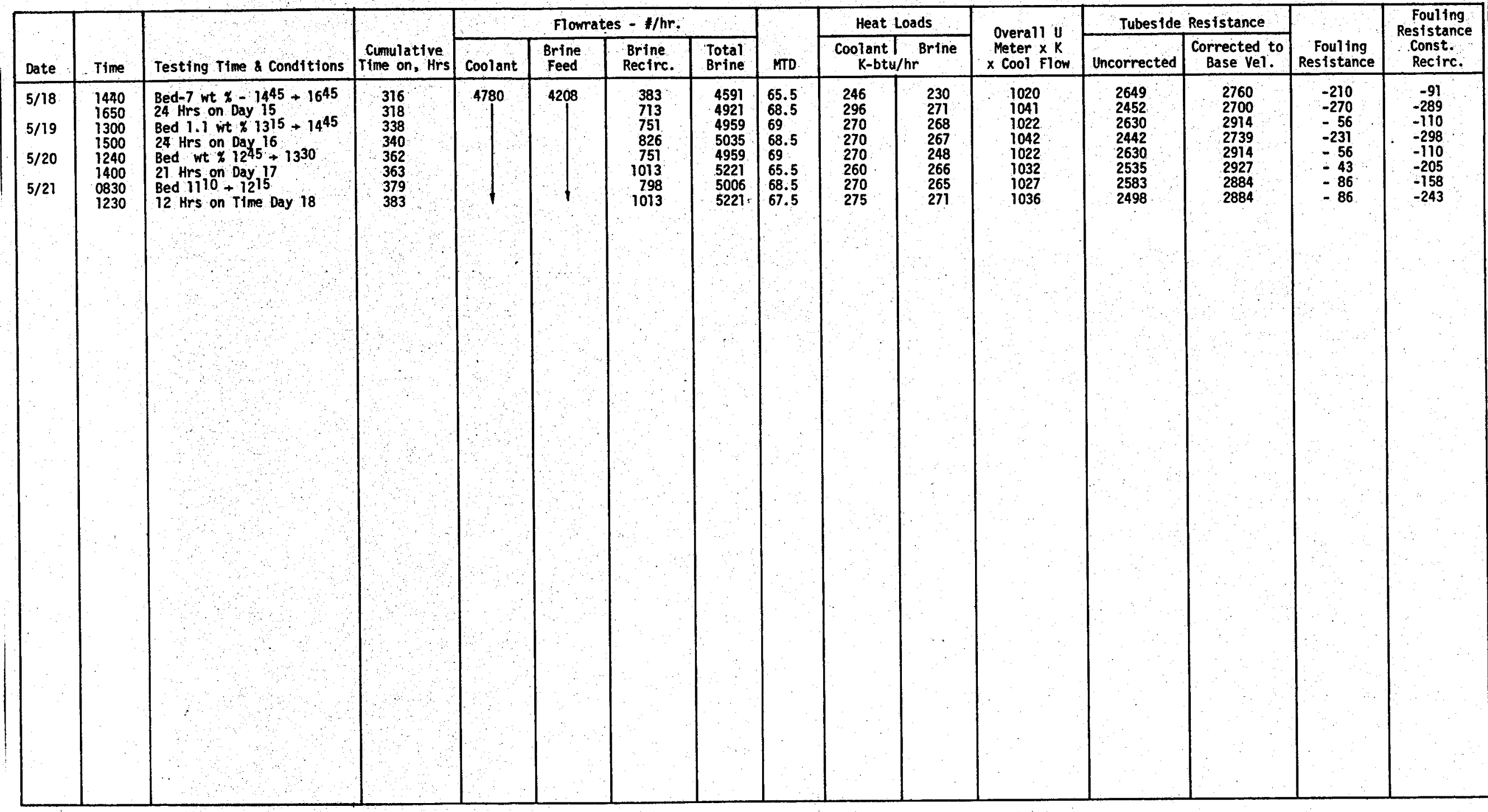


fouling resistances. This is believed to be more representative of the true operating conditions.

The next column is mean temperature difference. This value fluctuates somewhat, depending primarily on the well conditions. The only temperature controlled is the coolant inlet temperature, thus as the well gets cooler, the MTD decreases. The MTD was maintained in the upper 60's for the bulk of the testing.

The heat loads calculated for the coolant and brine circuits appear in the next two columns. The coolant heat load is used for all heat transfer coefficient calculations because the calculation is more straight forward with fewer unknowns and hence more reliable. The comparison of the two heat loads, which should be the same, does provide a cross check on data reliability, however. Any wide discrepancy between the two values would be a signal for questioning the data or the experiment operation. In comparing the two heat loads no major difference was measured and it will be observed that the coolant load is generaly only about a few percent greater. This may indicate that some of the coolant heat is being leaked to the atmosphere through the insulation and that the assumed density and specific heat of the brine were in error.

The next two columns show the actual overall heat transfer coefficient, first as determined by calculation from the individual temperature readings, and second as determined from the U-meter. The overall $U$ determined from the U-meter is calculated by multiplying by the meter factor and the coolant flowrate. The meter factor is the average specific heat of the coolant divided by the heat exchanger surface area in square feet.

The final columns are the resistance readings first of the tubeside uncorrected, then corrected for velocity and finally, the fouling resistances. The resistances were calculated as follows. The initial overall heat 
transfer coefficient, measured for each exchanger, was considered to represent a valid clean coefficient. A tubeside heat transfer coefficient was calculated using the formula

$$
\begin{aligned}
& h t=\frac{.023 \mathrm{GPCP}}{\left(\frac{D G}{\mu}\right)^{.02} \mathrm{Pr}} \times \frac{.062(I . D .)}{.075(0 . D .)} \\
& G=\text { mass velocity }-1 b / h r-f t^{2} \\
& C p=\text { specific heat }-B T U / 1 b^{\circ} \mathrm{F} \\
& \mu=\text { viscosity }-1 \mathrm{~b} / \mathrm{ft}-\mathrm{hr} \\
& D=\text { hydraulic diameter }-\mathrm{ft} \\
& \mathrm{Pr}=\text { Prandtl number }\left(\mathrm{CP}_{\mu} / \mathrm{K}\right) \\
& K=\text { thermal conductivity }-\mathrm{BTU} / \mathrm{hr}-\mathrm{ft}^{2}
\end{aligned}
$$

A tubewall resistance of $.00023 \mathrm{hr}-\mathrm{ft}^{2}-{ }^{\circ} \mathrm{F} / \mathrm{BTU}$ was calculated using the formula

$$
R_{t w}=\frac{O D}{2 K} \ln \frac{O D}{I D}
$$

From these data, the shellside heat transfer coefficient was determined for the measured flowrate, using the formula

$$
h s=\frac{1}{U_{\text {clean }}}-\frac{1}{n t(\text { calc })}-R_{t w}
$$

The purpose of determining hs is to permit the proper weighting of corrections for variations in shellside flowrate in interpreting the test data. In actuality, the coolant control valves were so effective that virtually no variation in coolant (shellside) flowwas observed during the testing period. 
Figure B-1 illustrates the calculated hs for both APEX-100 and APEX-300 as a function of flowrate. The curves were extended from the point value calculated using the formula hs $\sim w_{c}^{0.8}$. There is about a $10 \%$ difference in the calculated values for the two exchangers. This may be explained by differences in fabrication. The nature of the construction of the exchangers, i.e., a tube within a tube with wire wrapped around the inside tube and tacked to provide separation and flow direction permits construction tolerances to create variations in flow area and leakage past the flow directing spacers. These differences could easily result in a real difference of hs between the exchangers of this magnitude. It appears more likely after examining the fouling data, that the APEX-100 unit had some fouling built up on the tubeside at the start of testing which had been cleaned off of the APEX-300 unit during checkout testing of the bed recirculation system. The resolution of the discrepancy has no significance as far as the fouling test results are concerned.

The total tubeside resistance is calculated for each data point by subtracting the shellside resistance and the tubewall metal resistance from the overall resistance. The clean tubeside resistance from data point 1 is then corrected for the difference in tubeside velocity from the base data point by multiplying by the ratio of the flowrates to the 0.8 power. This corrected clean tubeside resistance determined from the first data point is then subtracted from the calculated total tubeside resistance and the remaining resistance is fouling. This resistance is made up of both tubeside and shellside fouling, however, it is assumed that the fouling is exclusively on the brine side because the shellside coolant is clean water, which is treated with hydrazine for deoxygenation. 


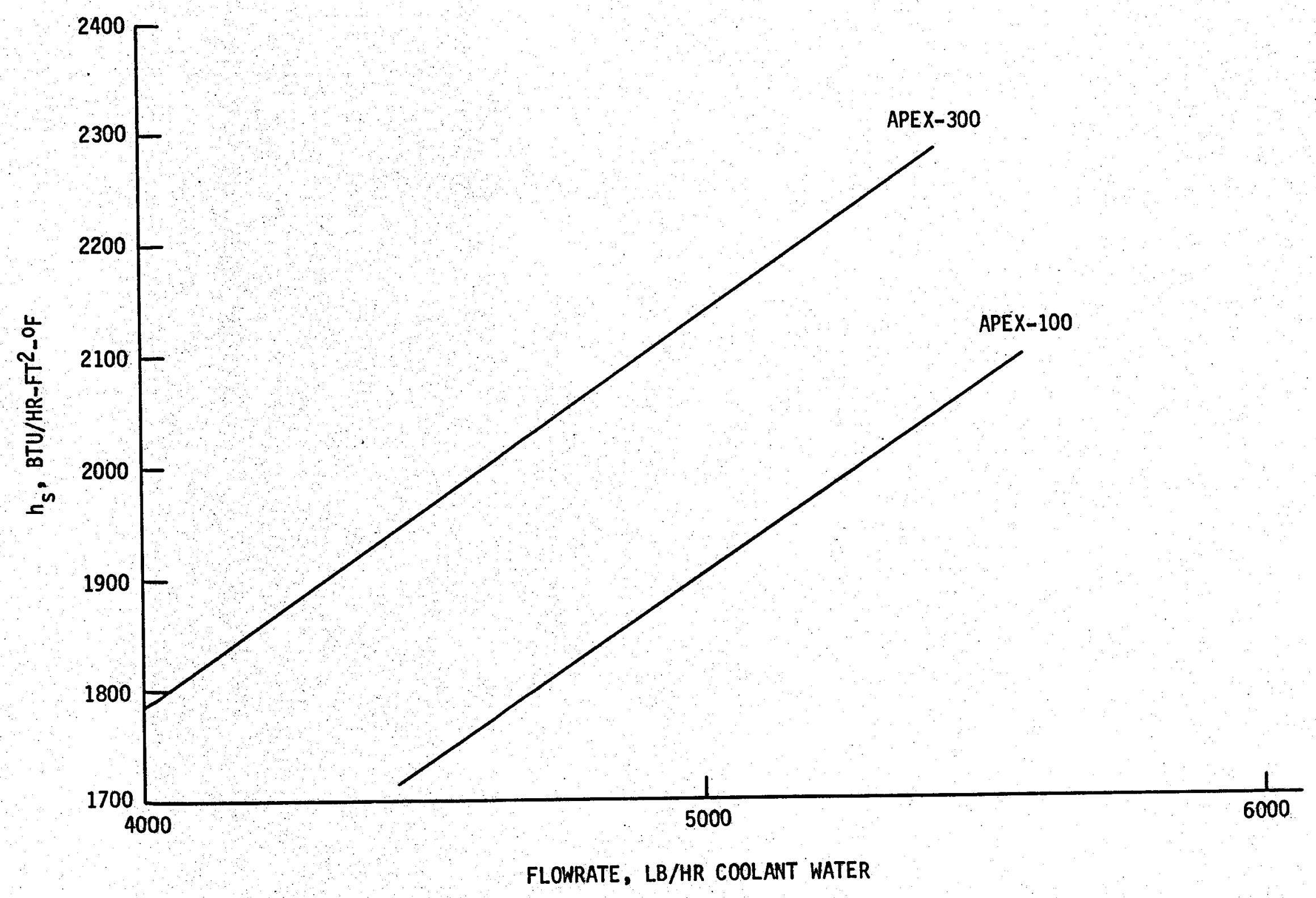

Figure B-1. Shellside Heat Transfer Coefficients for APEX-100 and APEX-300 